\title{
Study on The Thermal Properties of Concrete Containing Ground Granulated Blast Furnace Slag, Fly Ash and Steel Reinforcement
}

\author{
Bekir Erdem Bas \\ WVU, beb0026@mix.wvu.edu
}

Follow this and additional works at: https://researchrepository.wvu.edu/etd

Part of the Civil Engineering Commons

\author{
Recommended Citation \\ Bas, Bekir Erdem, "Study on The Thermal Properties of Concrete Containing Ground Granulated Blast \\ Furnace Slag, Fly Ash and Steel Reinforcement" (2020). Graduate Theses, Dissertations, and Problem \\ Reports. 7654. \\ https://researchrepository.wvu.edu/etd/7654
}

This Thesis is protected by copyright and/or related rights. It has been brought to you by the The Research Repository @ WVU with permission from the rights-holder(s). You are free to use this Thesis in any way that is permitted by the copyright and related rights legislation that applies to your use. For other uses you must obtain permission from the rights-holder(s) directly, unless additional rights are indicated by a Creative Commons license in the record and/ or on the work itself. This Thesis has been accepted for inclusion in WVU Graduate Theses, Dissertations, and Problem Reports collection by an authorized administrator of The Research Repository @ WVU. For more information, please contact researchrepository@mail.wvu.edu. 
Study on The Thermal Properties of Concrete Containing Ground Granulated Blast Furnace Slag, Fly Ash and Steel Reinforcement

Bekir Erdem Bas

Thesis Submitted

to the Benjamin M. Statler College of Engineering and Mineral Resources at West Virginia University

in partial fulfillment of the requirements for the degree of

Master of Science

in

Civil and Environmental Engineering

Roger H. L. Chen, Ph.D., Chair

Fei Dai, Ph.D.

Terence Musho, Ph.D.

Department of Civil and Environmental Engineering

Morgantown, West Virginia

2020

Keywords: Mass Concrete; Ground Granulated Blast Furnace Slag; Class F Fly Ash; Thermal Conductivity; Semi Adiabatic-Calorimetry 


\begin{abstract}
Study on The Thermal Properties of Concrete Containing Ground Granulated Blast Furnace

Slag, Fly Ash and Steel Reinforcement
\end{abstract}

\title{
Bekir Erdem Bas
}

In this study, the thermal and mechanical properties of two types of concrete were measured. The first type contained ground granulated blast furnace slag, and the second type contained Class $\mathrm{F}$ fly ash. The compressive and splitting tensile strength, static elastic modulus, thermal conductivity, adiabatic temperature rise, shrinkage, and compressive creep of the two concretes were measured. Then, the experimental shrinkage and compressive creep results were compared to ACI 209.2R08 using the material properties of each mix design. Additionally, two semi-adiabatic designs were made and compared with the adiabatic calorimetry measurements.

Also, in this study, the thermal conductivity of concrete cylinders embedded with $4 \%$ and $8 \%$ steel reinforcement was measured. The thermal conductivity of concrete is an essential parameter in predicting the temperature distribution of large structures such as pier stems, and footers. Typically, these structures contain a significant amount of steel reinforcement. Therefore, to accurately predict the temperature gradients, the effect of the steel rebar must be considered. Larger reinforcement ratios were expected to increase the overall heat loss because steel has a higher thermal conductivity than concrete. An overall effective thermal conductivity is proposed to account for the steel reinforcement. The effective thermal conductivity was shown to increase with the reinforcement ratio. Finite-element analysis (FEA) was conducted to model the experimental thermal conductivity tests. Since the production of the experimental specimens is tedious, FEA was used to simulate specimens with different reinforcement ratios. Based on the FEA results, an equation was proposed to estimate the effective thermal conductivity with different reinforcement ratios. 


\section{ACKNOWLEDGMENTS}

I want to express my deepest gratitude to my esteemed advisor Dr. Roger Chen for his unwavering guidance and support by his substantial knowledge and experience during my graduate education, to rest of my thesis committee: Dr. Dai and Dr. Musho, for their willingness to show interest and give advice, to the Republic of Turkey Ministry of Agriculture and Forestry General Directorate of State Hydraulic Works (DSI) for my scholarship, to the West Virginia Department of Transportation (WVDOT) Division of Highways and FHWA for the research project WVDOH RP\#312, to my friends: Seyednavid Mardmomen, Guadalupe Leon, Nawaf Alsulami, and Luke Bucklen for their unswerving help and support by their knowledge and experience, to my family for standing beside me by their spiritual and selfless support and understanding, and to my fiancée: Senay for her inspiration and encouragement whenever I despair. 


\section{TABLE OF CONTENTS}

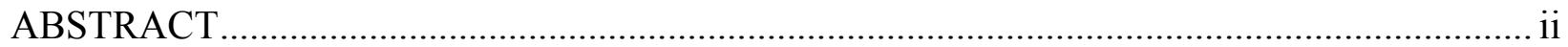

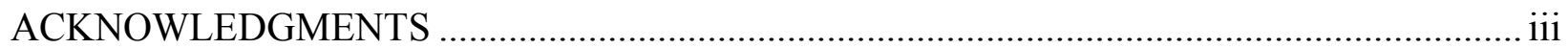

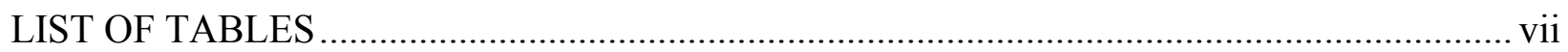

LIST OF FIGURES ….......................................................................................... vii

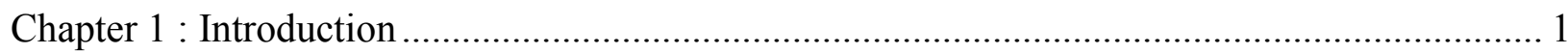

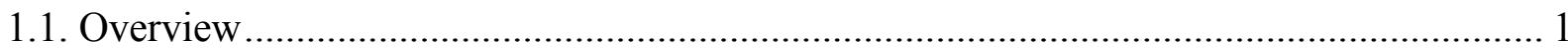

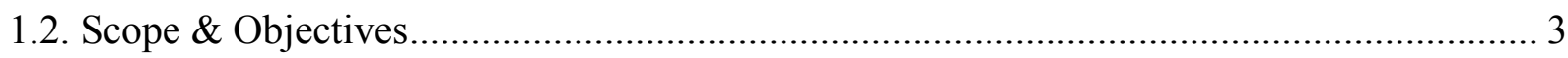

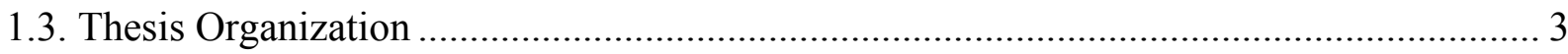

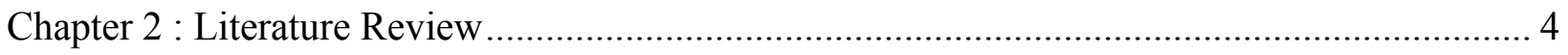

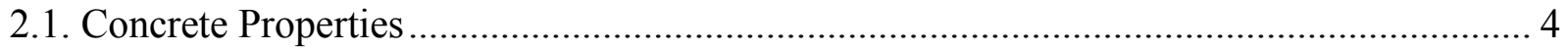

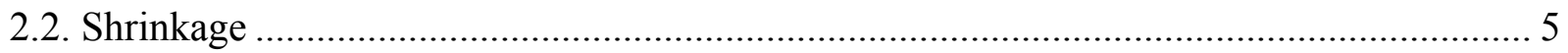

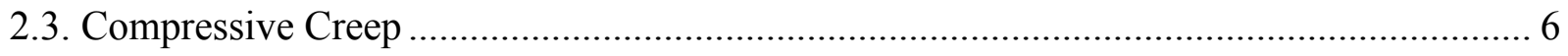

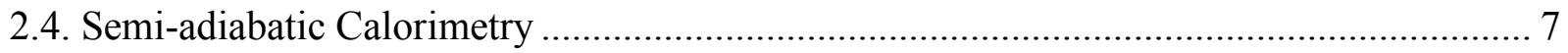

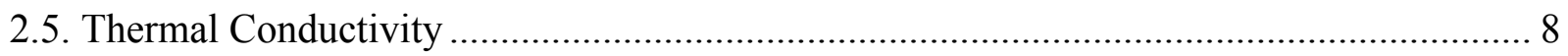

Chapter 3 : Properties of Concrete Used in the Study ......................................................... 10

Chapter 4 : Shrinkage and Compressive Creep Properties ................................................ 17

4.1. Experimental Procedure ................................................................................... 17

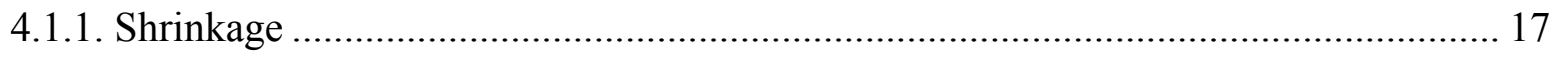




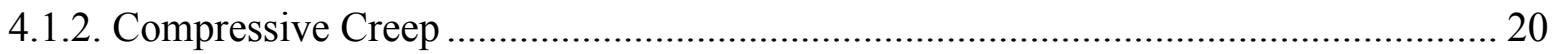

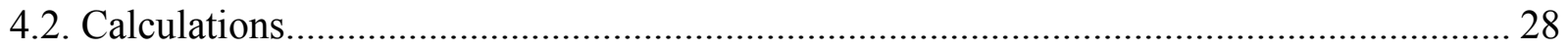

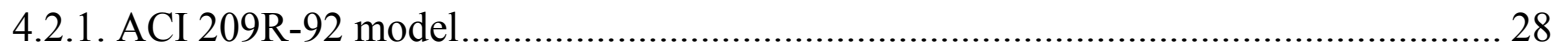

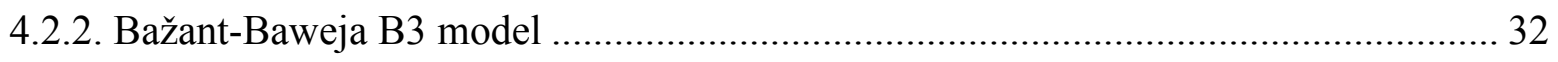

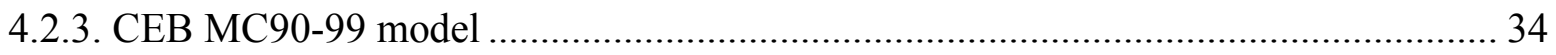

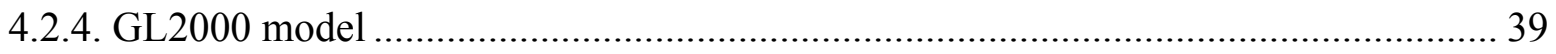

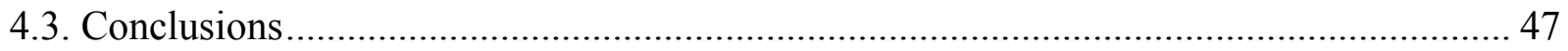

Chapter 5 : Measurement of Adiabatic Temperature Rise.......................................................... 48

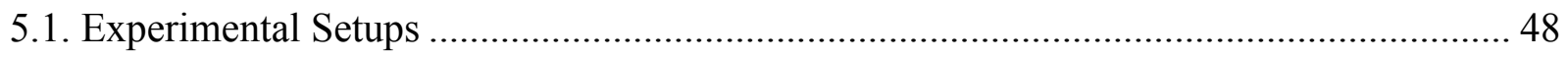

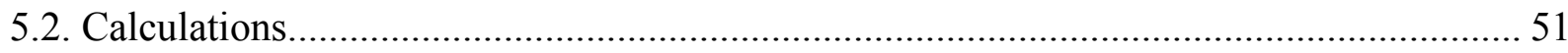

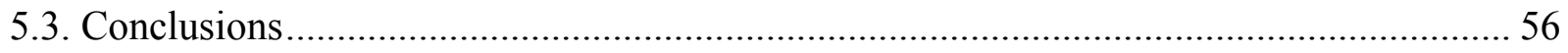

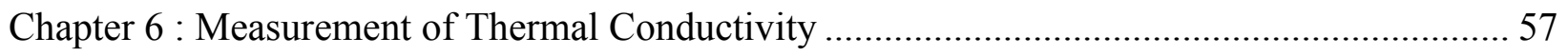

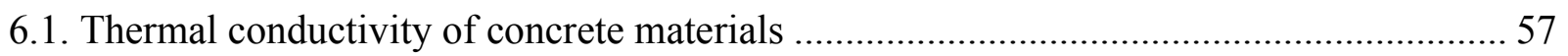

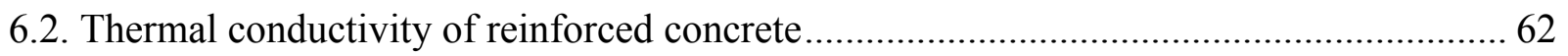

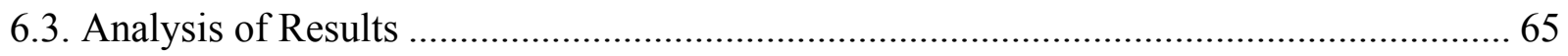

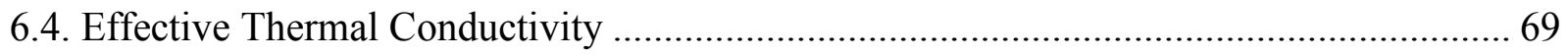

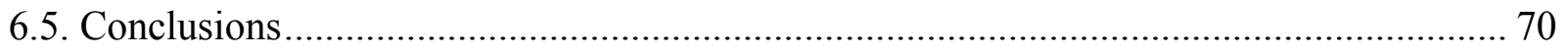

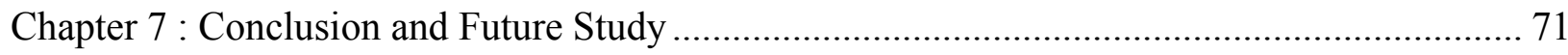

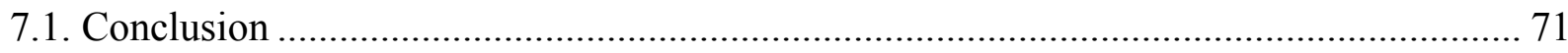

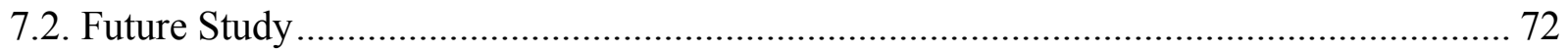


REFERENCES

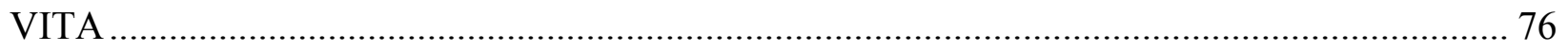




\section{LIST OF TABLES}

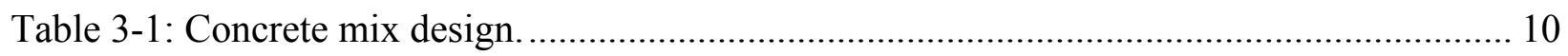

Table 3-2: Measured properties of concrete mixes.......................................................... 11

Table 3-3: Comparison of 28 days compressive and splitting tensile strength........................ 14

Table 4-1: Parameter ranges of each model (ACI Committee 209 2008). ............................. 27

Table 4-2: Input values used in the calculation process of 50\% slag 1 and $30 \%$ fly ash 1 shrinkage

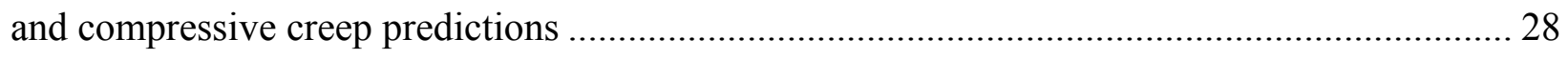

Table 4-3: The OPC mix design properties and input parameters......................................... 44

Table 5-1: Comparison of average $\lambda$ 's calculated with literature recommendation................... 56

Table 5-2: The heat loss characteristic ranges and effecting values taken into consideration of both

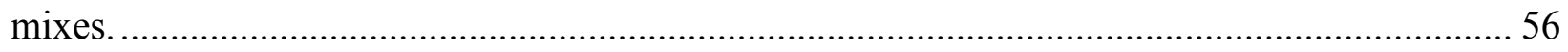

Table 6-1: Density and specific heat of $50 \%$ slag 1 and $30 \%$ fly ash 2 cylinders.................... 63

Table 6-2: Thermal conductivities of 50\% slag 1 and 30\% fly ash 2 cylinders....................... 63

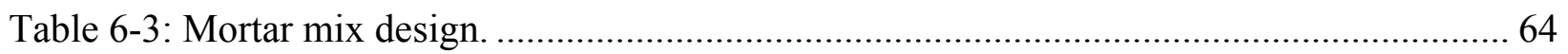

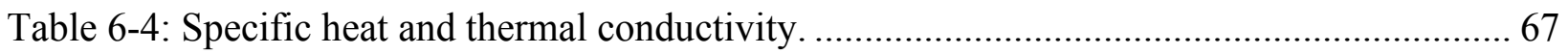




\section{LIST OF FIGURES}

Figure 3-1: Comparison of 50\% slag 4-in (10.2-cm diameter) by 8-in (20.3-cm height) cylinders

compressive strength results. 12

Figure 3-2: Comparison of 30\% fly ash 4-in (10.2-cm diameter) by 8-in (20.3-cm height) cylinders compressive strength results. 12

Figure 3-3 Comparison 50\% slag 4-in (10.2-cm diameter) by 8-in (20.3-cm height) cylinders splitting tensile results. 13

Figure 3-4: Comparison of 30\% fly ash 4-in (10.2-cm diameter) by 8-in (20.3-cm height) cylinders splitting tensile results. 13

Figure 3-5: The static elastic modulus loading frame and the setup..... 15

Figure 3-6: Static elastic modulus of 50\% slag 1 mix using 6-in (15.2-cm diameter) by 12-in (30.5cm height) cylinders 16

Figure 3-7: Static elastic modulus of 30\% fly ash 2 mix using 6-in (15.2-cm diameter) by 12-in (30.5-cm height) cylinders. 16

Figure 4-1: Shrinkage apparatus. The leftmost figure demonstrates the Invar calibration bar..... 18

Figure 4-2: Shrinkage test results of $50 \%$ slag 1. 19

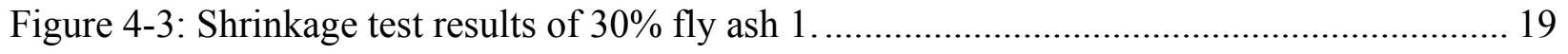

Figure 4-4: Ambient temperature recordings of two mix designs. ......................................... 20

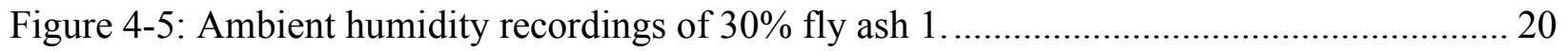

Figure 4-6: The loading set-up for the compressive creep test. ............................................ 21

Figure 4-7: The shrinkage test set-up of the sealed specimen. ............................................. 22

Figure 4-8: Compressive creep test result of 50\% slag 1 without sealed shrinkage deducted..... 23

Figure 4-9: Compressive creep test result of 30\% fly ash 1 without sealed shrinkage deducted. 23 
Figure 4-10: Comparison of 50\% slag 1 shrinkage results of 3 -in $(7.62-\mathrm{cm})$ by 3 -in $(7.62-\mathrm{cm})$ by 11.25-in $(28.58-\mathrm{cm})$ fully-wrapped prism and 6-in $(15.2-\mathrm{cm})$ by 12-in $(30.5-\mathrm{cm})$ cylinder........ 24

Figure 4-11: Comparison of 30\% fly ash 1 shrinkage results of 3 -in $(7.62-\mathrm{cm})$ by 3 -in $(7.62-\mathrm{cm})$ by 11.25 -in $(28.58-\mathrm{cm})$ fully-wrapped prism and 6-in $(15.24-\mathrm{cm})$ by 12-in $(30.5-\mathrm{cm})$ cylinder. 24 Figure 4-12: Compressive creep test result of 50\% slag 1 with sealed shrinkage deducted. ....... 25 Figure 4-13: Compressive creep test result of 30\% fly ash 1 with sealed shrinkage deducted. ... 25

Figure 4-14: The compressive creep loading over time of 50\% slag 1.................................... 26

Figure 4-15: The compressive creep loading over time of $30 \%$ fly ash 1 .................................... 26

Figure 4-16: Authorized reprint of shrinkage strain predictions of numeric examples from ACI 209 (ACI Committee 209 2008). 41

Figure 4-17: Authorized reprint of compliance predictions of numeric examples from ACI 209 (ACI Committee 209 2008). 42

Figure 4-18: Shrinkage strain predictions of numeric examples of ACI 209 document (ACI Committee 209 2008) were built in the Excel. 42

Figure 4-19: Compliance predictions of numeric examples of ACI 209 document (ACI Committee 209 2008) were built in the Excel. 43

Figure 4-20: Comparison of the OPC shrinkage test results and predictions.............................. 44

Figure 4-21: Comparison of the OPC compressive creep test results and predictions................. 44 Figure 4-22: Comparison of the shrinkage test results of 50\% slag 1, 30\% fly ash 1 and the OPC mixes. 45

Figure 4-23: Comparison of 50\% slag 1 shrinkage test results and predictions. 45

Figure 4-24: Comparison of 50\% slag 1 compressive creep test result and predictions. .............. 46

Figure 4-25: Comparison of 30\% fly ash 1 shrinkage test results and predictions. 46 
Figure 4-26: Comparison of 30\% fly ash 1 compressive creep test result and predictions. 47

Figure 5-1: Omega RDXL4SD 4-channel datalogger thermometer. 49

Figure 5-2: The first design of the semi-adiabatic device. 49

Figure 5-3: The second semi-adiabatic device with the lid opened in the first two pictures and one side opened in the right picture. 50

Figure 5-4: Insulated mold for 20-in (50.8-cm) cube specimen. 51

Figure 5-5: Temperature-time history of 10-in $(25.4-\mathrm{cm})$ cylinder specimen cast from 50\% slag 1.

Figure 5-6: Temperature-time history of 20-in (50.8-cm) cube specimen cast from $30 \%$ fly ash 2.

Figure 5-7: Comparison of the semi-adiabatic device and ATR calorimetry of 50\% slag $1 \ldots \ldots . . .55$

Figure 5-8: Comparison of the semi-adiabatic device and ATR calorimetry of 30\% fly ash 2... 56

Figure 6-1: 50\% slag 1 cylinder 1 temperature decay of center location and water temperature. 59

Figure 6-2: 50\% slag 1 cylinder 2 temperature decay of center location and water temperature. 59

Figure 6-3: Comparison of the temperature differences between two 50\% slag 1 cylinders. ...... 60

Figure 6-4: 30\% fly ash 2 cylinder 1 temperature decay of center location and ambient water. . 60

Figure 6-5: 30\% fly ash 2 cylinder 2 temperature decay of center location and ambient water. . 61

Figure 6-6: Comparison of the temperature differences between two $30 \%$ fly ash 2 cylinders... 61

Figure 6-7: Specimens layout of (a) 4.24\% reinforcement ratio (mortar +6 steel rebars) (b) 7.78\%

reinforcement ratio (mortar +11 steel rebars) (dimensions are in inch). 63

Figure 6-8: $4.24 \%$ reinforcement ratio (mortar +6 steel rebars) and $7.78 \%$ reinforcement ratio

(mortar +11 steel rebars) 64

Figure 6-9: Location of thermocouples (dimensions are in inch). 65 
Figure 6-10: Temperature distribution at $10 \mathrm{~min}$ for (a) mortar (b) $4.24 \%$ reinforcement ratio (mortar +6 steel rebars) (c) 7.78\% reinforcement ratio (mortar +11 steel rebars) (temperatures are in $\left.{ }^{\circ} \mathrm{F}\right)$.

Figure 6-11: Temperature time history comparisons of experiment and FEA at different locations: (a) mortar (b) 4.24\% reinforcement ratio (mortar +6 steel rebars) (c) 7.78\% reinforcement ratio

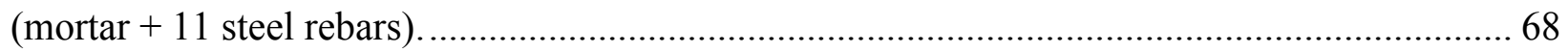
Figure 6-12: (a) Natural logarithm of temperature difference vs. time, (b) normalized effective thermal conductivity vs. volumetric reinforcement ratio. 70 


\section{Chapter 1 : Introduction}

\subsection{Overview}

Every passing year, manufacturers and consumers start to require higher quality concrete due to durability and performance demands. This trend sometimes prompts an increase in the strength of the concrete produced. To enhance the strength of the concrete, companies began adding more cement in the mix designs. However, the additional cement and higher fineness of cement lead to further heat accumulation in the concrete members, due to the hydration reaction. Lin (2015) stated that the increase of heat generation is generally not negligible in concrete members with large dimensions, and in substantial concrete members, so-called mass concrete structures, the buildup of heat prompts problems such as thermal cracking. The definition of mass concrete per the American Concrete Institute (ACI) is "any volume of concrete with dimensions large enough to require that measures be taken to cope with generation of heat from hydration of the cement and attendant volume change to minimize cracking" (ACI Committee 2000; 2016; ACI Committee 207 2005).

Thermal cracking generally develops because the temperature difference between the inside and surface of the concrete is immensely high. Rising heat causes the interior of the concrete to enlarge, but due to heat loss, the exterior of the concrete contracts, thus resulting in extreme tensile forces on the surface, especially for early age concretes. The need to decrease this temperature difference compels manufacturers and designers to come up with a variety of solutions such as arranging internal cooling pipes, using pre-cooled materials, or lowering the heat of hydration with supplementary cementitious materials (SCM). 
The most common SCMs are ground granulated blast furnace slag (GGBFS) and fly ash. Kosmatka et al. (2016) defined GGBFS as "a nonmetallic hydraulic cement consisting essentially of silicates and aluminosilicates of calcium developed in a molten condition simultaneously with iron in a blast furnace." They also defined fly ash "a byproduct of the combustion of pulverized coal in electric power generating plants" (2016). They are common because of their availability and ability to reduce the total heat of hydration. Determining the thermal properties of concrete containing slag or fly ash is significant for mass concrete structures such as arch dams due to their cost efficiency and thermal cracking preventing characteristics.

Part of the objectives of this study comprises of casting and testing concretes containing slag and fly ash. The experimental shrinkage and compressive creep were compared to ACI-209 (ACI Committee 2008). The adiabatic temperature rise (ATR) was back-calculated from a semiadiabatic test. Also, material properties such as compressive and tensile strength, static modulus of elasticity, and thermal conductivity were tested.

The thermal analysis is a vital task needed to define the thermal stresses and cracking potential of large reinforced concrete structures. One of the most critical parameters, in the thermal analysis, is the thermal conductivity of the materials. They should be defined precisely to predict the correct temperature distribution within the structure. Often, the steel reinforcement inside concrete is neglected, in the thermal analysis of a reinforced concrete structure, because of its layout complexity. However, the steel rebars can significantly affect the overall thermal conductivity and, therefore, the temperature and stress distribution. 


\subsection{Scope \& Objectives}

The scope and objectives of this thesis were investigating the comparability of the shrinkage and compressive creep prediction methods containing slag or fly ash. Afterward, designing an efficient semi-adiabatic calorimetry to estimate the adiabatic temperature rise of those mix designs. Then, proposing an equation to estimate the effective thermal conductivity in concrete with different reinforcement ratios.

\subsection{Thesis Organization}

The organization of this thesis consists of,

- Chapter 1 gives an overview and introduction.

- Chapter 2 gives a short review of studies about shrinkage, compressive creep, semiadiabatic calorimetry, and thermal conductivity.

- Chapter 3 shows the tested properties of the investigated concrete mix designs, such as the static modulus of elasticity, compressive, and splitting tensile strengths.

- Chapter 4 explains the experimental setups of shrinkage and compressive creep and their results; afterward, it compares with empirical predictions.

- Chapter 5 explains designs for the semi-adiabatic calorimetry and compare their backcalculated results with actual adiabatic temperature rise test results.

- Chapter 6 illustrates the test procedures for the thermal conductivity of both plain and reinforced concretes and the comparison with a finite element analysis (FEA) predictions. Afterward, an equation to estimate the effective thermal conductivity of reinforced concretes is proposed.

- Chapter 7 presents conclusions and recommendations. 


\section{Chapter 2 : Literature Review}

\subsection{Concrete Properties}

ASTM C39/C39M (ASTM Committee C09 2018) describes the testing of compressive strength property. The limitations of the test set-up, specimen properties, testing technique, and calculation stages were described.

ASTM C496/C496M (ASTM C09 Committee 2011) describes the testing of splitting tensile strength property. The limitations of the test set-up, specimen properties, testing technique, and calculation stages were described.

ASTM C469/C469M (ASTM C09 Committee 2010) describes the testing method of static modulus of elasticity and Poisson's ratio properties. The limitations of the test set-up, specimen properties, testing technique, and calculation stages were described.

LaBarca et al. (2007) stated that $30 \%$ and $50 \%$ slag replacement does not have any performance reduction in compressive and tensile strength after 14 days. American Coal Ash Association (2003) stated that fly ash replacement to some levels increases slump, the strength and durability of hydrated concrete. It also decreases water requirement in the mix design and hydration heat.

There are some studies about mass concrete and arc dam properties. Engineer Manual 1110-2-2201 (U.S. Army Corps of Engineers 1994) describes the temperature control of the mass concrete structures such as arch dams due to the generation of the heat of hydration. Subsequently, various design solutions are proposed to address this issue. 


\subsection{Shrinkage}

There are many tests and empirical models developed to measure and predict the shrinkage of concrete. ASTM C157-17 (Committee C09 2017) describes the testing of shrinkage properties. The limitations of the test set-up, specimen properties, testing technique, and calculation stages were described. The shrinkage prediction method developed by the ACI committee (ACI Committee 2008) has a limitation indicated by high and low predictions for early and late desiccation.

The estimated shrinkage properties by Bažant and Baweja (2000) are limited to ordinary Portland cement (OPC) and are limited by the water to cementitious ratio ( 0.35 to 0.85$)$, the aggregate to cementitious material ratio (2.5 to 13.5), 28-days compressive strength of cylinder [17 MPa (2465.6 psi) to $69 \mathrm{MPa}(10008 \mathrm{psi})]$, cementitious content $\left[160 \mathrm{~kg} / \mathrm{m}^{3}\left(269.7 \mathrm{lb} . / \mathrm{yd}^{3}\right)\right.$ to $\left.720 \mathrm{~kg} / \mathrm{m}^{3}\left(1214 \mathrm{lb} . / \mathrm{yd}^{3}\right)\right]$. Its calculation was very responsive to the water amount and permitted for extrapolation from early test data through early test data and early humidity deficit.

CEB MC90-99 (Gardner and Lockman 2001) model does not need input concerning the curing time or curing condition. GL2000 (Gardner and Lockman 2001) used the specified 28-day strength, loading strength, specimen size, relative humidity for concrete with a mean compressive strength lower than $82 \mathrm{MPa}$ (11893 psi), and no self-desiccation assumed.

He (2013) stated that AASHTO LRFD (2010) model is better than ACI 209R-90 (92), ACI 209R-Modified by Huo (2001), CEB-FIP 90 (1990) and the B3 (1995) models to predict the shrinkage of slag or fly ash replaced concrete. Kar (2010) stated that ACI 209R-Modified by Huo (2001) and ACI 209R-90 (92) models overestimate the shrinkage of slag or fly ash replaced concrete at a low water-cementitious material ratio by weight $(\mathrm{w} / \mathrm{cem})$ and underestimate it at 
high w/cem. Kar (2010) stated that the B3 (1995) and the CEB MC 90-99 (2008) models underestimate the shrinkage of slag or fly ash replaced concrete, but the GL 2000 (Gardner and Lockman 2001) model estimated the shrinkage of slag or fly ash replaced concrete closer than the other models.

\subsection{Compressive Creep}

There are many tests and empirical models developed to measure and predict the compressive creep of concrete, such as the ACI committee (ACI Committee 2008) defined primary creep as a sealed concrete, experiencing stable continuous load and having time-dependent growth in its strain. The pros of the model include ease of use, and it is straightforward to adjust to fit short-term test-data. However, the disadvantages of the model are that it does not have enough precision, especially when using different member sizes and being empirical. Elastic modulus calculation might have problems because it evaluated creep coefficient, not creep compliances.

ASTM C512/C512M-15 (C09 Committee 2015) described the testing of compressive creep. It proposes the limitations of the test set-up and specimen properties as well as testing technique and calculation stages.

Bažant and Baweja (2000) described a creep depiction in the concrete designing model (B3); however, it contains disadvantages from concrete design effect and design strength on the parameters while providing a way of compensation through revising some parameters based on short-time creep tests, and this parameter revising was significant for pozzolanic components. CEB MC90-99 and GL2000 (Gardner and Lockman 2001) described their models requiring the parameters such as curing and loading time, 28 days average compressive strength, relative humidity, volume/surface, and the type of the cement. He (2013) stated that AASHTO LRFD 
(2010) model is better than ACI 209R-90 (92),ACI 209R-Modified by Huo (2001), CEB-FIP 90

(1990) and the B3 (1995) models to predict the creep of slag or fly ash replaced concretes.

\subsection{Semi-adiabatic Calorimetry}

Predicting and testing the adiabatic temperature rise of the mix design is important for the mass concrete structures. Having and maintaining a proper adiabatic calorimetry at construction sites is not always feasible. However, semi-adiabatic calorimetry does not require any heating and does not consume electricity. It is much more economical and relatively easy to construct and maintain semi-adiabatic calorimetry. There are many studies that design a semi-adiabatic calorimetry. Morabito (Morabito 1998) expressed problems about the estimation of the adiabatic curve from semi-adiabatic calorimetry because of temperature variations and reaction rates affecting each other.

TC 119-TCE (1997) described a semi-adiabatic calorimeter consisting of a commercial vacuum bottle, insulating foam rubber, and a protecting exterior shell, respectively. Furthermore, it stated that the semi-adiabatic calorimeter's ultimate heat loss should be smaller than $100 \mathrm{~J} / \mathrm{h} / \mathrm{K}$ $(0.05 \mathrm{BTU} / \mathrm{h} / \mathrm{F})$.

Bai and Wild (Bai and Wild 2002) used semi-adiabatic calorimetry to study fly ash, and metakaolin added mortar. They found that fly ash is more effective than metakaolin to reduce the adiabatic temperature rise.

Poole et al. (L. Poole et al. 2007) examined cementitious substances' hydration with semiadiabatic calorimetry by casting twenty different concrete mixes. They studied numerous mix properties such as type and content of cementitious materials, w/cem ratio, coarse aggregate type, 
and placing temperature. They found that fly ash replacement, using low specific heat aggregate and low heat cement, and lowering cement dosage necessary to reduce ATR.

Ng et al. (P. L. Ng 2008) developed a mathematical model to compensate heat loss in semiadiabatic calorimetry by testing ten in-lab and two ready mixed batches to validate the proposed model and to lower the minimum limits of concrete size and insulation perfection. The method attained to stay below of error occurrence $\pm 1.3{ }^{\circ} \mathrm{C}\left( \pm 2.34{ }^{\circ} \mathrm{F}\right)$. They found that 4-point measurement is better than two and 1-point measuring. They recommended that the heat loss characteristic $(\lambda)$ of the setup ought to be under $2.18 \times 10^{-6} S^{-1}$.

\subsection{Thermal Conductivity}

Many researchers (K.-H. Kim et al. 2003; Davraz, Koru, and Akdağ 2015) have studied the effect of different mix properties (water-cement ratio, aggregate volume fraction, moisture conditions) on the thermal conductivity of concrete. There are few studies available that studied the effect of different types of inclusions (steel reinforcement, fiber) on the overall thermal conductivity of a composite. Fraternali et al. (Fraternali et al. 2011) investigated the thermal conductivity of recycled PET fiber reinforced concrete (RPETFRC), making use of PET filaments with a variety of mechanical properties and profiles and contrasting $1 \%$ volumetric fiber inclusion to unreinforced concrete monitored enhancements in thermal resistance. Kanbur et al. (Kanbur et al. 2013) studied the thermal conductivity of concrete and reinforced concrete experimentally and numerically using two types of reinforcements with a diameter of 10-mm (0.39-in) and 12-mm (0.47-in) in three different cross-sectional geometries and acquired the thermal conductivities of these cases exemplifying the remarkable effect of rebars. Agrawal and Satapathy (Agrawal and Satapathy 2015) developed a mathematical model for evaluating the thermal conductivity of polymer composites with hybrid fillers experimentally and theoretically using two types of each 
matrix materials, conductive fillers, and insulative fillers and found their model prognosticated the measurements closely.

Noh et al. (Noh et al. 2018) studied the effective thermal conductivity of reinforced concrete containing multiple layers of reinforcements; they developed a mathematical model to calculate the effective thermal conductivity of reinforced concrete, which was validated using a finite-volume method. The effective thermal conductivity $\left(\mathrm{k}_{\mathrm{ef}}\right)$ reduced when rebar quantity increased, which was perpendicularly placed to the heat flow; however, $\mathrm{k}_{\mathrm{ef}}$ was increased when rebar quantity increased, which was in parallel placing while both types of placings having steel volume ratios fixed.

Kim et al. (Kim, Jeon, \& Lee, 2012) studied the thermal conductivity of lightweight aggregate concrete with a high volume of entrained air using a heat flow meter. They found that using lightweight aggregates reduced thermal conductivity, and it kept being reduced by airentraining agent inclusion. Furthermore, porosity showed inverse proportionality with thermal conductivity.

Yun et al. (Yun et al. 2013) evaluated the thermal conductivity of lightweight concrete materials with various lightweight aggregate and glass bubbles using linear and plane heat source methods. They found that glass bubbles were less effective than lightweight aggregates in terms of reducing thermal conductivity.

In this study, the CRD-C 36-73 method (US Army Corps of Engineers 1973) was used to measure the thermal conductivity of mortar samples with and without steel reinforcement. Then, the experimental results were compared to numerical calculations using ABAQUS finite element analysis (FEA) software. Finally, the FEA software was used to simulate reinforced concrete with 
various volumetric reinforcement ratios, and an empirical equation was developed to calculate the effective thermal conductivity. 


\section{Chapter 3 : Properties of Concrete Used in the Study}

Two sets of experiments were performed. These concrete mix designs contain ground granulated blast furnace slag (GGBFS) grade 100, and Class F fly ash. ASTM C989 (AASHTO M 302-19) stated that GGBFS Grade 100 has a moderate activity index. ASTM C618 (2019) stated that Class F fly ash has pozzolanic properties. The mix design is shown in Table 3-1. The Portland cement used in the mixes is Type I/II. The coarse aggregate used is crushed no. 57 limestone aggregate and the fine aggregate is river sand. The absorption rate of coarse aggregate and fine aggregate are $0.5 \%$ and $1.4 \%$. To be consistent, the coarse aggregate and sand were dried in an industrial oven for about 24 hours at approximately $221^{\circ} \mathrm{F}\left(105^{\circ} \mathrm{C}\right)$.

Table 3-1: Concrete mix design.

\begin{tabular}{|c|c|c|c|c|}
\hline \multirow{2}{*}{ Materials } & \multicolumn{2}{|c|}{$50 \%$ slag } & \multicolumn{2}{|c|}{$30 \%$ fly ash } \\
\hline & $\left(\mathbf{l b} . / \mathbf{y d} \mathbf{d}^{3}\right)$ & $\left(\mathrm{kg} / \mathrm{m}^{3}\right)$ & $\left(\mathbf{l b} . / \mathbf{y d} \mathbf{d}^{3}\right)$ & $\left(\mathrm{kg} / \mathrm{m}^{3}\right)$ \\
\hline Cement & 254 & 150.7 & 340 & 201.7 \\
\hline Slag & 254 & 150.7 & & \\
\hline Fly ash & \multicolumn{2}{|c|}{-} & 168 & 99.7 \\
\hline Water & 233.7 & 138.6 & 233.5 & 138.5 \\
\hline Limestone aggregate & 1795 & 1064.9 & 1780 & 1056 \\
\hline Sand & 1364 & 809.2 & 1360 & 806.9 \\
\hline Water cementitious $(\mathrm{w} / \mathrm{cem})$ ratio & \multicolumn{2}{|c|}{0.46} & \multicolumn{2}{|c|}{0.459} \\
\hline
\end{tabular}

The required amounts of materials were measured based on the volume of each batch and mixed inside an electric concrete mixer. Thirty 4 -in (10.2-cm diameter) by 8 -in (20.3-cm height) cylinders were made for compressive and splitting tensile strength tests. Four 6-in (15.2-cm diameter) by 12 -in (30.5-cm height) cylinders were made for static elastic modulus, thermal conductivity, and compressive creep tests. Two of the 6-in by 12 -in $(15.2-\mathrm{cm}$ by $30.9-\mathrm{cm})$ cylinders were used for static elastic modulus test up to 28 days of curing then were drilled to be 
used for thermal conductivity testing. The other 6 -in by 12 -in $(15.2-\mathrm{cm}$ by $30.9-\mathrm{cm})$ cylinders both fully wrapped were used for compressive creep testing, and the other was placed in the same room for shrinkage compensation consideration. Six 3 -in by 3 -in by 11.25 -in $(7.62-\mathrm{cm}$ by $7.62-\mathrm{cm}$ by $28.58-\mathrm{cm}$ ) rectangle prisms were made for shrinkage tests. Two of the shrinkage prisms were fully wrapped using plastic sheet wrap. Four of the shrinkage prisms were used to measure the drying shrinkage. Two of the drying shrinkage specimens were half wrapped, and the other two were exposed to the ambient humidity and air temperature.

All the specimens were batched at the same time then unmold after 24 hours. The compressive and tensile cylinders were cured in lime water for 28 days at the curing temperature of $73{ }^{\circ} \mathrm{F}\left(23^{\circ} \mathrm{C}\right)$. The compressive creep and sealed (fully wrapped) cylinders for shrinkage were cured in lime water for seven days at the curing temperature of $73{ }^{\circ} \mathrm{F}\left(23^{\circ} \mathrm{C}\right)$. After mixing, the slump, air percentage, w/cem ratio of the fresh concrete were measured and are shown in Table $3-2$.

Table 3-2: Measured properties of concrete mixes.

\begin{tabular}{|c|c|c|c|c|c|}
\hline Date & Batch & Slump [in(cm)] & Air \% & Measured w/cem ratio & Target w/cem \\
\hline $04 / 01 / 2019$ & $50 \%$ slag 1 & $6.5(16.51)$ & 5.2 & 0.468 & 0.46 \\
\hline $04 / 01 / 2019$ & $50 \%$ slag 2 & $6(15.24)$ & 5 & 0.478 & 0.46 \\
\hline $06 / 25 / 2019$ & 30\% fly ash 1 & $6.5(16.51)$ & 6 & 0.466 & 0.459 \\
\hline $07 / 17 / 2019$ & $30 \%$ fly ash 2 & $6.5(16.51)$ & 4.75 & 0.508 & 0.459 \\
\hline
\end{tabular}

The w/cem ratio was measured using the microwave oven method (Mardmomen, Chen, and Leon 2019). The results of compressive strength are shown in Figure 3-1, and Figure 3-2 and the results of splitting tensile strength are shown in Figure 3-3 and Figure 3-4. Due to having a higher w/cem ratio in 50\% slag 2 and 30\% fly ash 2, both compressive and splitting tensile strength are shown lower results. The compressive and tensile strength of 28 days are compared in Table 3-3. 


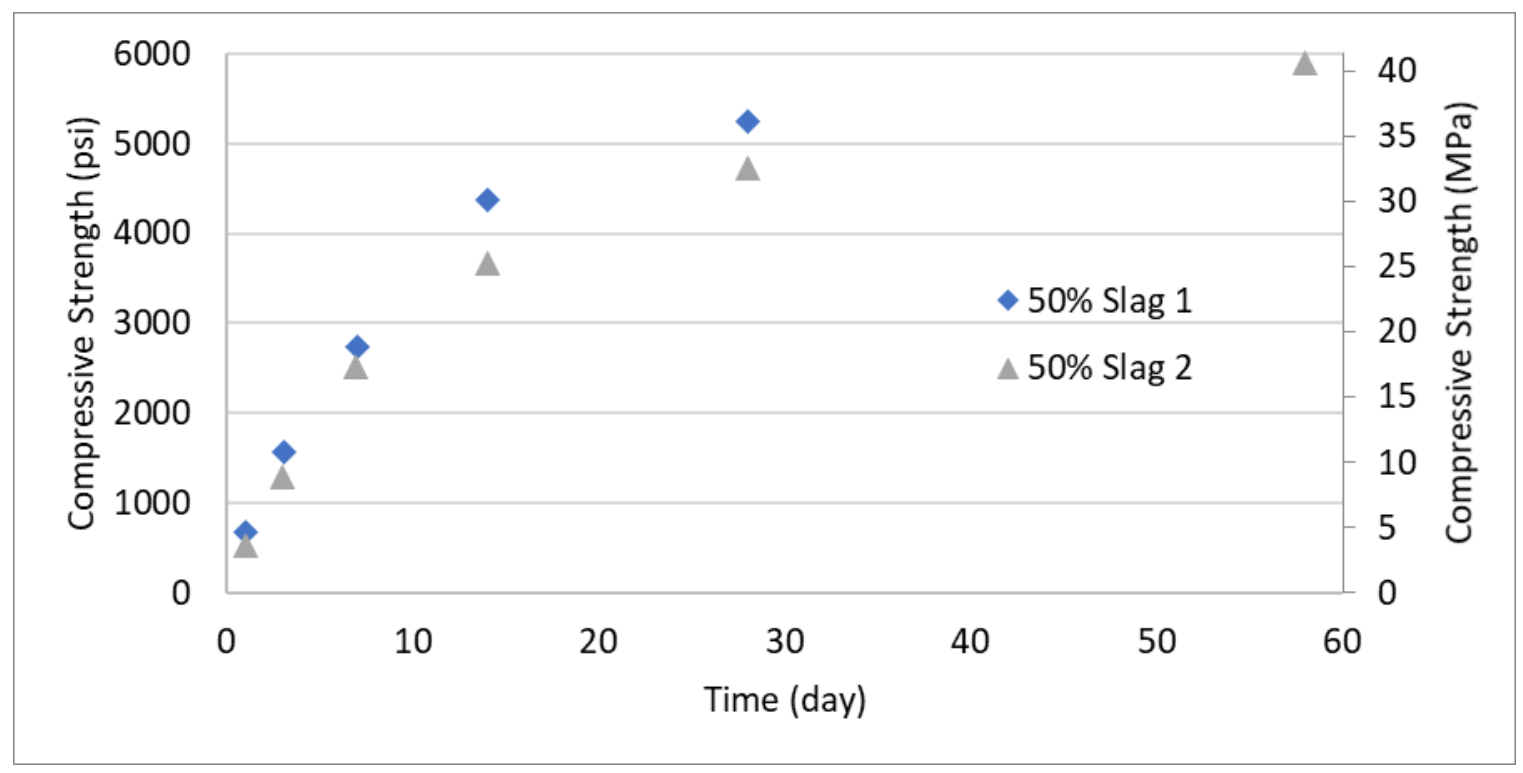

Figure 3-1: Comparison of 50\% slag 4-in (10.2-cm diameter) by 8-in (20.3-cm height) cylinders compressive strength results.

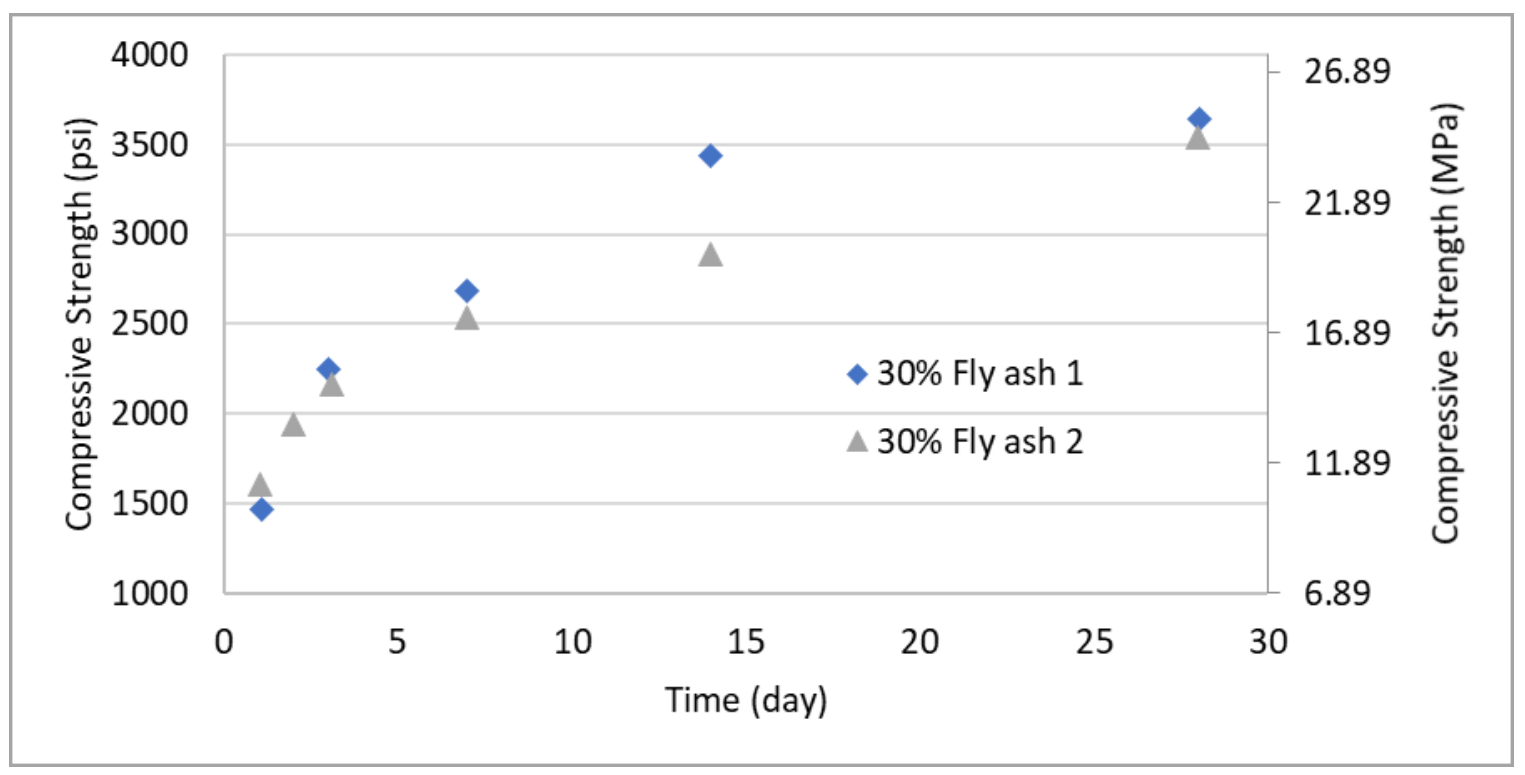

Figure 3-2: Comparison of 30\% fly ash 4-in (10.2-cm diameter) by 8-in (20.3-cm height) cylinders compressive strength results. 


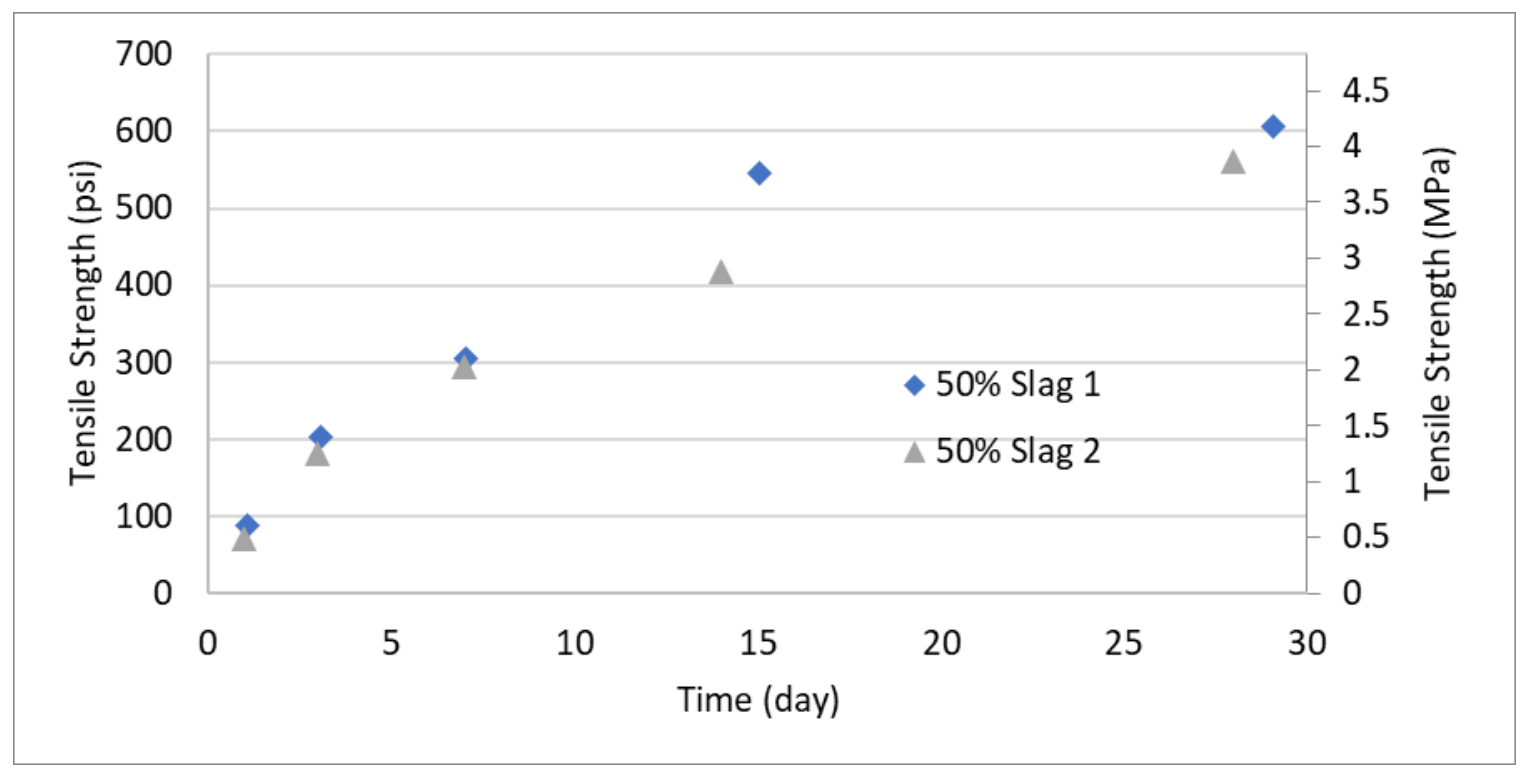

Figure 3-3 Comparison 50\% slag 4-in (10.2-cm diameter) by 8-in (20.3-cm height) cylinders splitting tensile results.

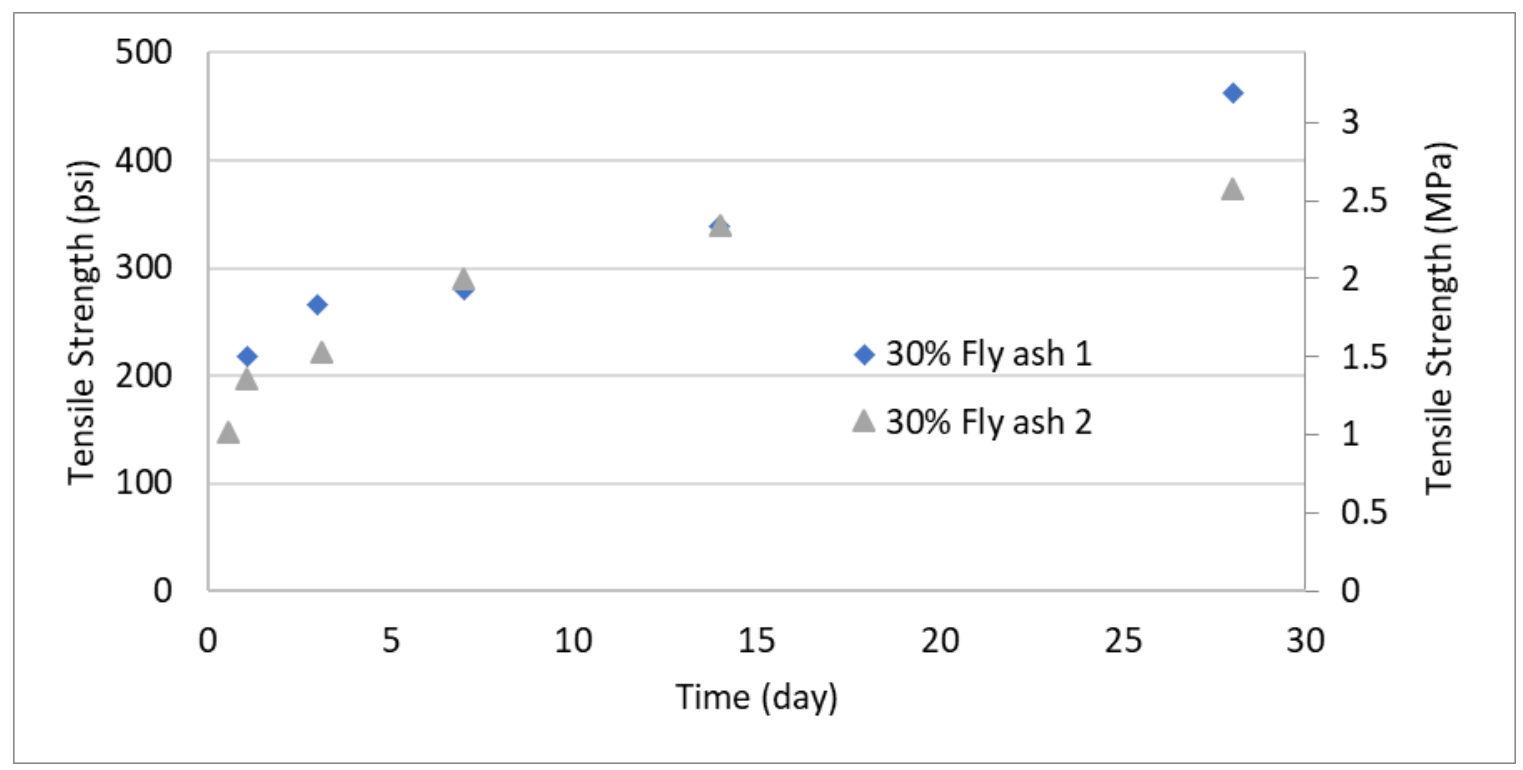

Figure 3-4: Comparison of 30\% fly ash 4-in (10.2-cm diameter) by 8-in (20.3-cm height) cylinders splitting tensile results. 
Table 3-3: Comparison of 28 days compressive and splitting tensile strength.

\begin{tabular}{|c|c|c|}
\hline Batch & $\begin{array}{c}\text { 28 days compressive strength, psi } \\
\text { (MPa) }\end{array}$ & $\begin{array}{c}\text { 28 days splitting tensile strength, psi } \\
\text { (MPa) }\end{array}$ \\
\hline 50\% slag 1 & $5252.1(36.212)$ & $606.6(4.182)$ \\
\hline $\mathbf{5 0 \%}$ slag 2 & $4734.9(32.646)$ & $560.5(3.865)$ \\
\hline 30\% fly ash 1 & $3644.6(25.129)$ & $462.7(3.190)$ \\
\hline 30\% fly ash 2 & $3541.2(24.416)$ & $373.5(2.575)$ \\
\hline
\end{tabular}

The static elastic modulus was measured at 1, 3, 7, 14, and 28 days using two 6-in (15.2$\mathrm{cm}$ diameter) by 12 -inch $(30.5$-cm height) cylinders. The cylinders were loaded up to $35 \%$ of the compressive strength. The loading frame and the setup that was used is shown in Figure 3-5. The dial gauge is used to measure the deflection in the axial direction with an accuracy of 0.0001 -in $(0.0025-\mathrm{mm})$. The average modulus from the two specimens are shown in Figure 3-6 and Figure 3-7. 


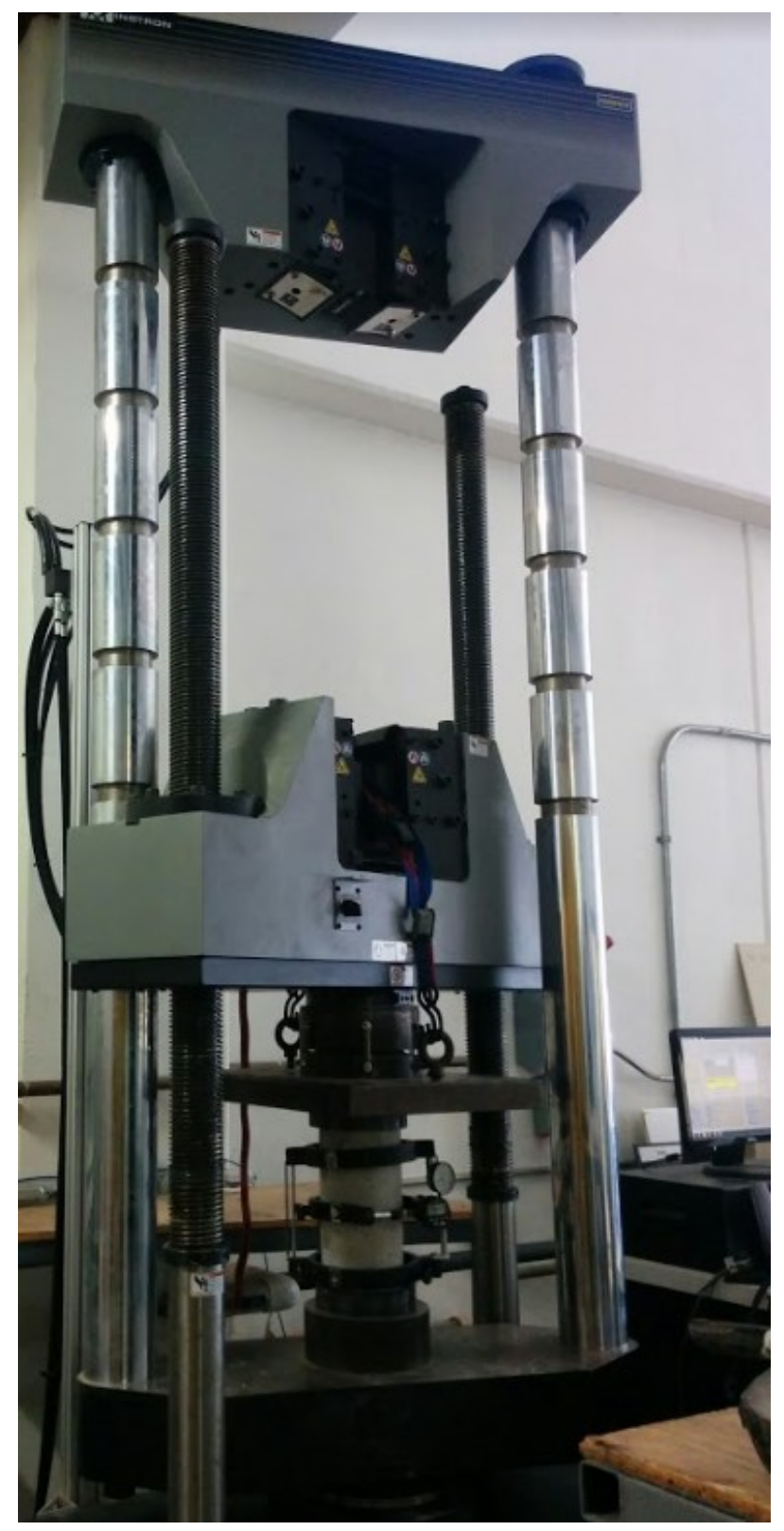

Figure 3-5: The static elastic modulus loading frame and the setup. 


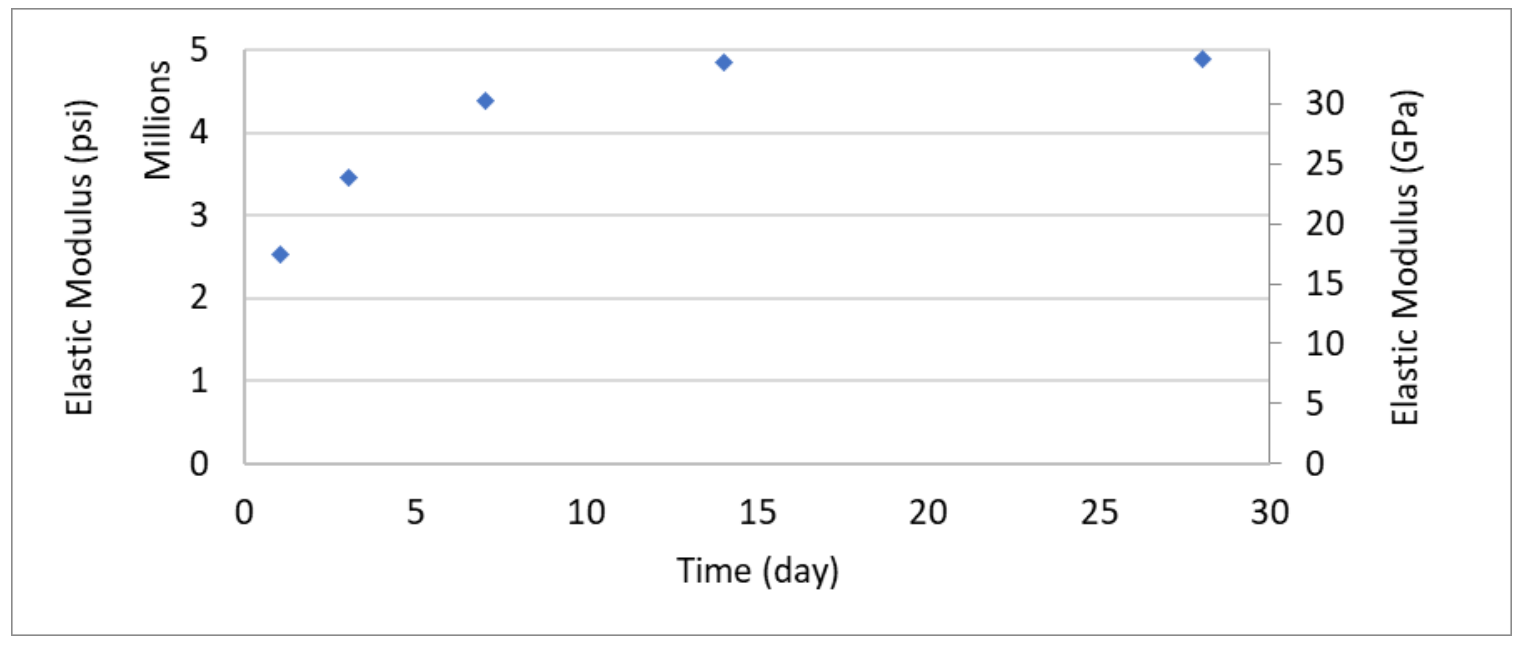

Figure 3-6: Static elastic modulus of 50\% slag $1 \mathrm{mix}$ using 6-in (15.2-cm diameter) by 12-in (30.5-cm height) cylinders.

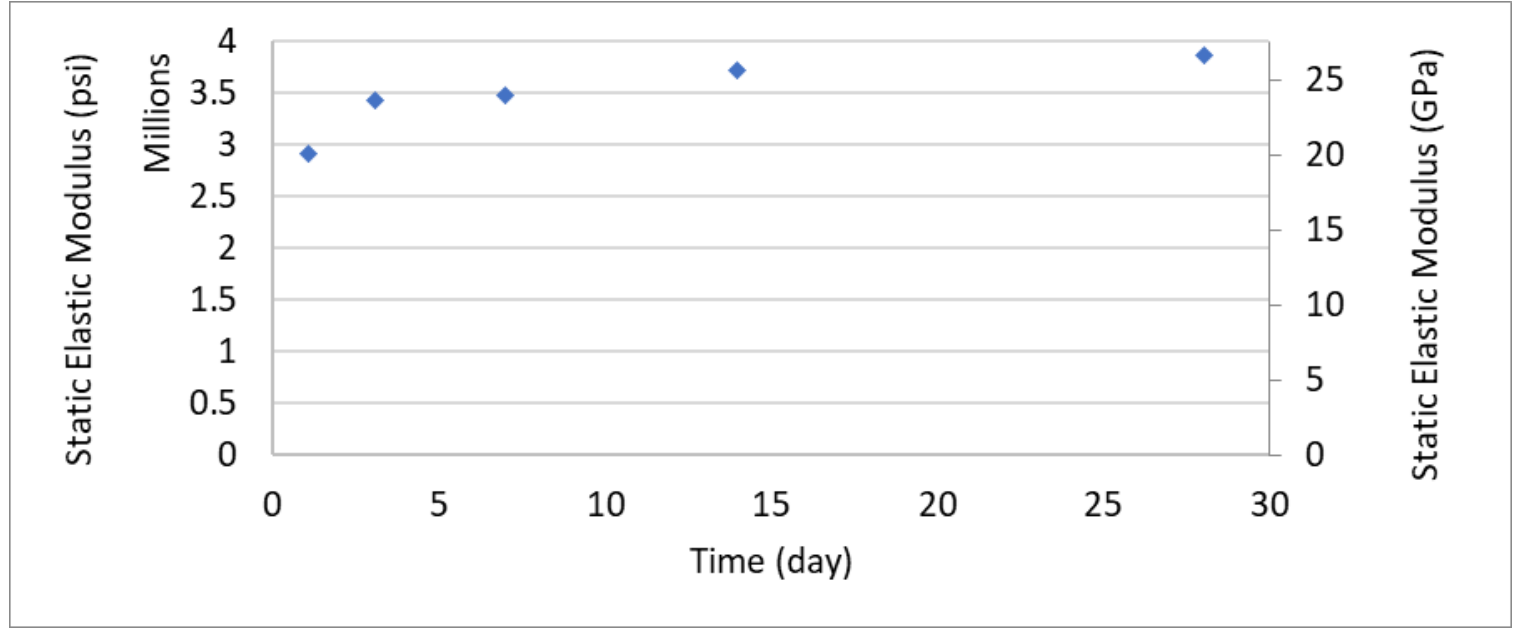

Figure 3-7: Static elastic modulus of 30\% fly ash 2 mix using 6-in (15.2-cm diameter) by 12in (30.5-cm height) cylinders. 


\section{Chapter 4 : Shrinkage and Compressive Creep Properties}

\subsection{Experimental Procedure}

\subsubsection{Shrinkage}

Six prisms with the dimension of $3 \times 3 \times 12$-in $(7.62 \times 7.62 \times 30.5$-in) were used in the shrinkage test based on ASTM C157 Method (Committee C09 2017). Figure 4-1 shows the shrinkage test setup. The length change is measured with an electronic gauge attached to the top of the setup. All the actions with the setup should be done very carefully because the device is susceptible. First, the Invar Bar placed on the apparatus to calibrate the digital indicator. The Invar Bar was made of a unique metal that has negligible temperature changes. The Invar Bar should be turned around $360^{\circ}$, and the digital gauge should be zeroed. The Invar Bar and the sample every time should be at the same point facing outwards before turned around placed on the apparatus. The calibration should be made twice before placing the first sample. When the first sample is placed, it should be turned around $360^{\circ}$ and the number appearing on the digital screen should be written down. Before placing the sample again, calibration with the Invar Bar should be repeated at least one time. In total, three numbers that have proximity to each other at least the sensitivity if the digital indicator - 0.0001-in $(0.0025-\mathrm{mm})$ - should be recorded for each specimen. Length change measurements should be recorded until 28 days. Starting with recording the time intervals every four hours. It might be prolonged, depending on the micro-strain changes. Three kinds of drying were done on the samples: full-wrapped (sealed shrinkage), half-wrapped, and no-wrapped (drying shrinkage). 

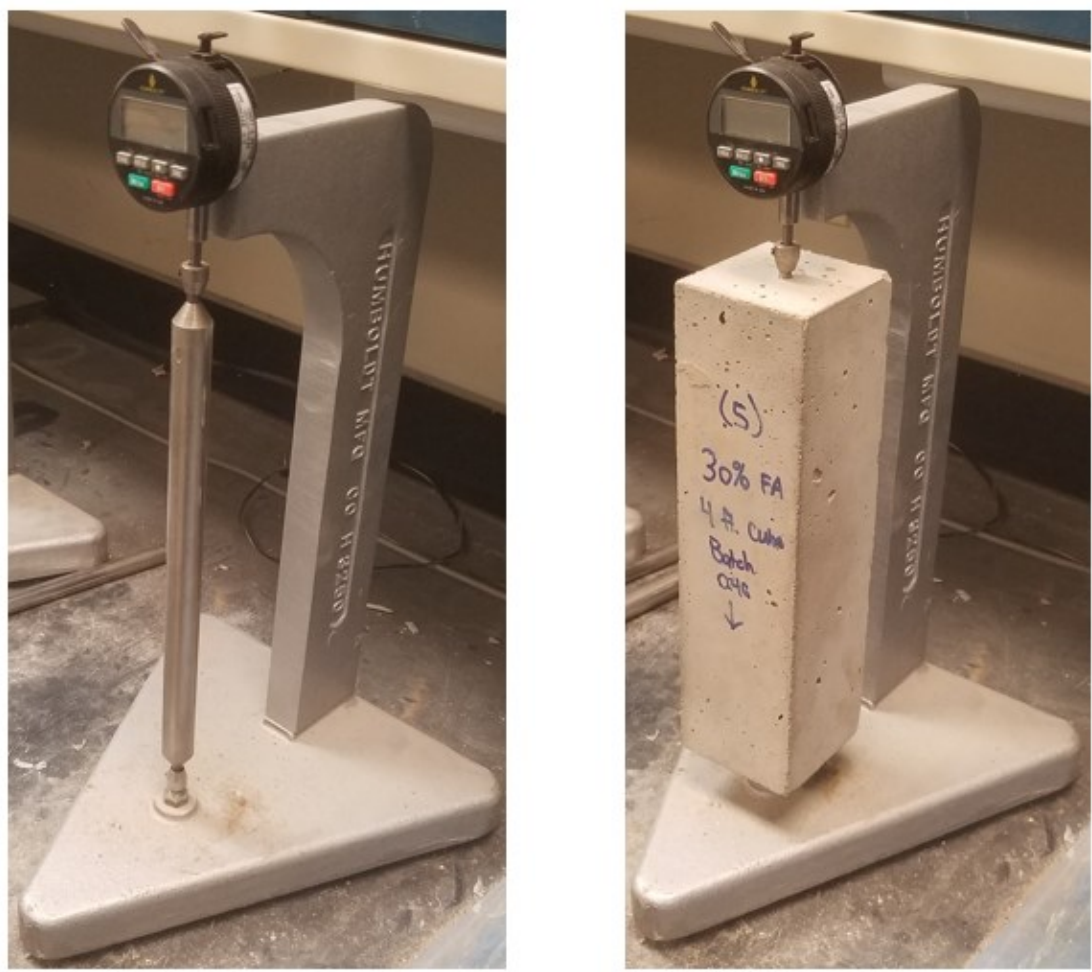

Figure 4-1: Shrinkage apparatus. The leftmost figure demonstrates the Invar calibration bar.

Drying shrinkage (micro-strain) test results of the two different mix designs and ambient temperature-humidity recordings of $30 \%$ fly ash 1 were shown in Figure 4-2, Figure 4-3, Figure 4-4, and Figure 4-5, respectively. Ambient humidity recording for 50\% slag was not performed and assumed as $40 \%$ in the prediction model input. 


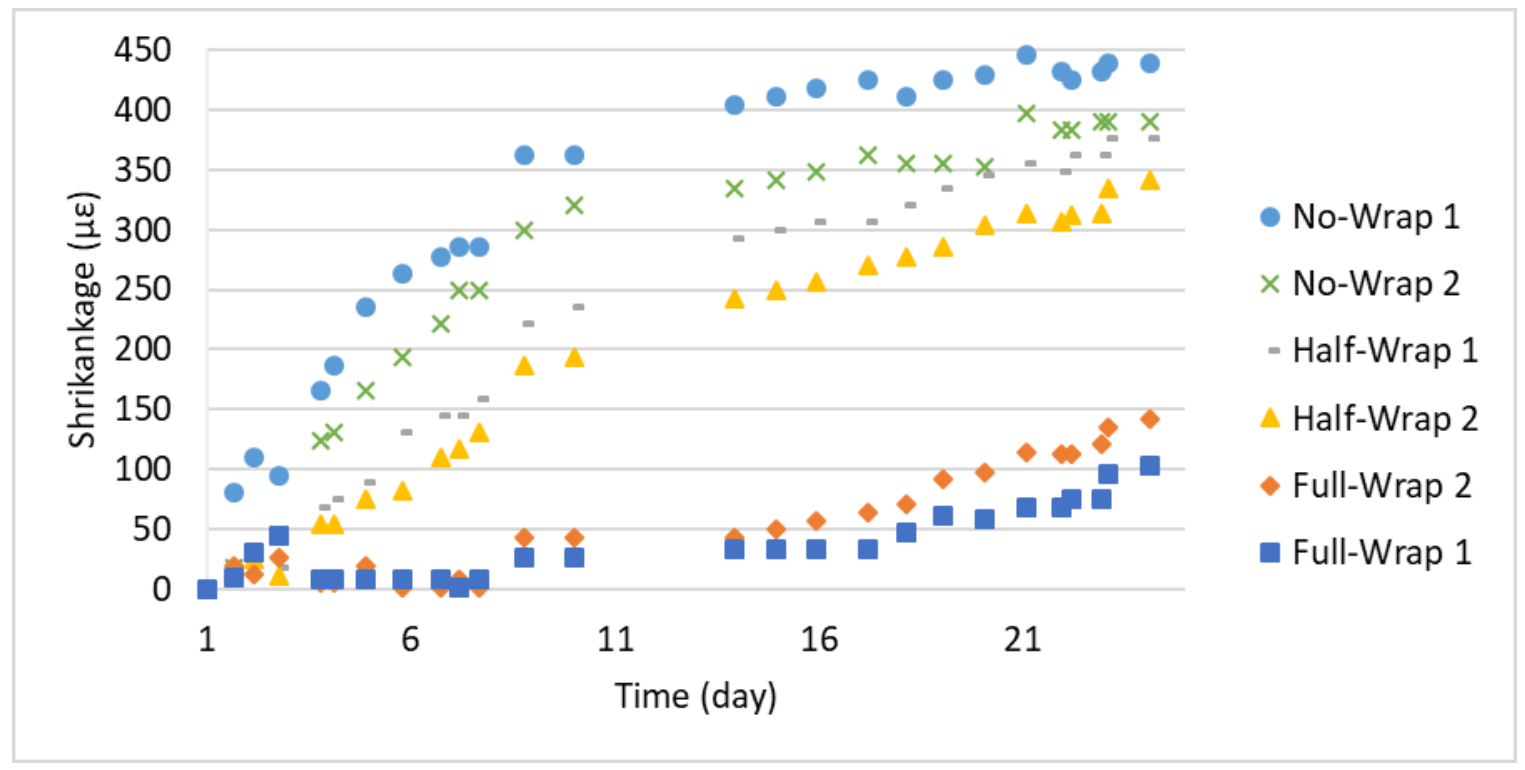

Figure 4-2: Shrinkage test results of $50 \%$ slag 1.

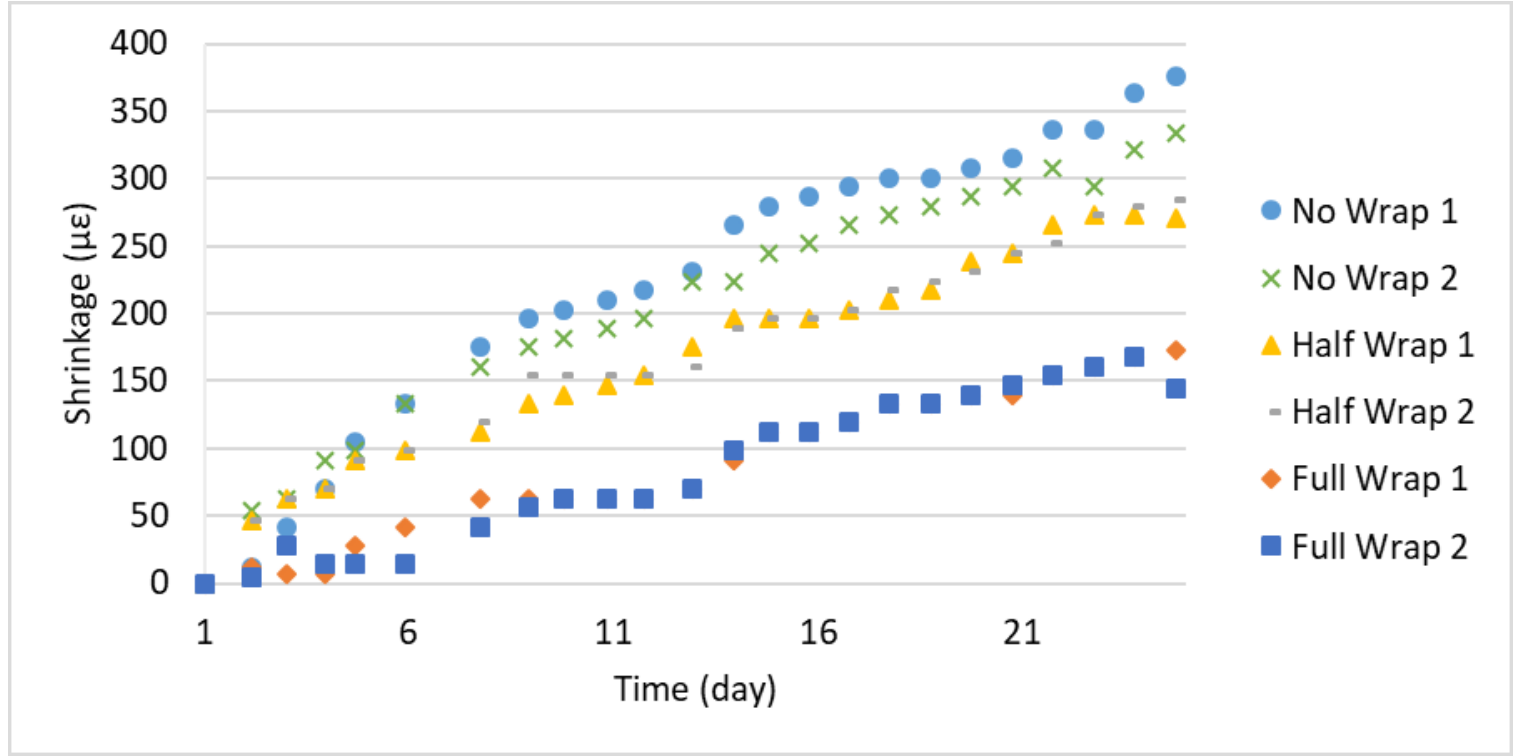

Figure 4-3: Shrinkage test results of $30 \%$ fly ash 1. 


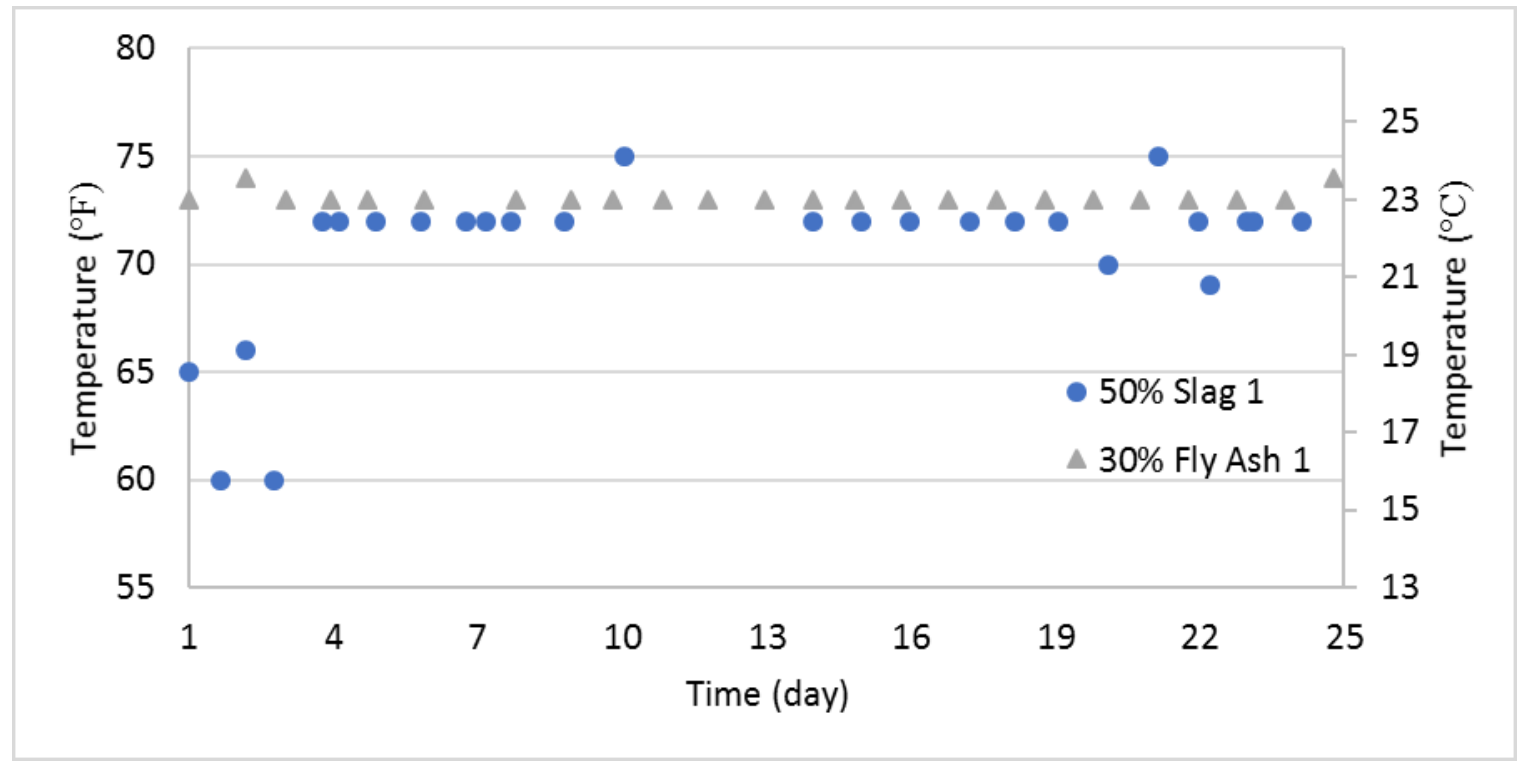

Figure 4-4: Ambient temperature recordings of two mix designs.

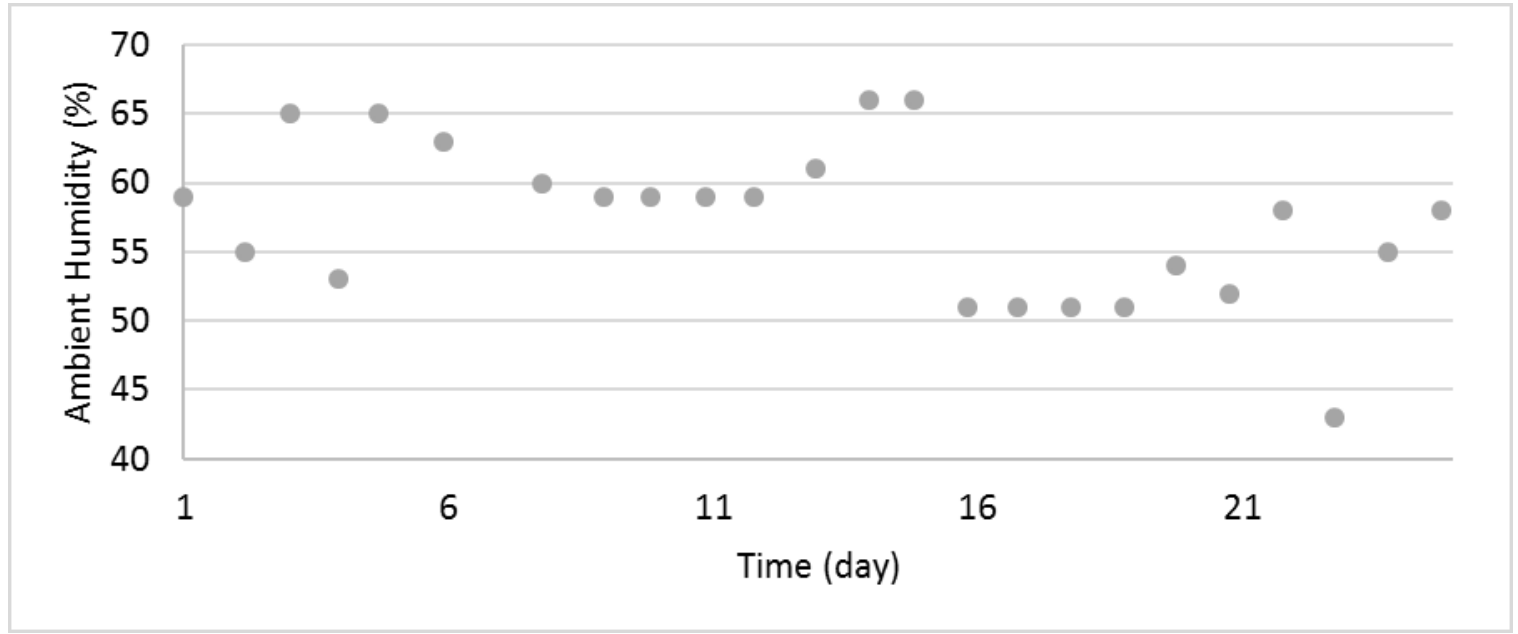

Figure 4-5: Ambient humidity recordings of $30 \%$ fly ash 1.

\subsubsection{Compressive Creep}

A 6-in (15.2-cm diameter) and 12-in (30.5-cm height) cylinder was used in the compressive creep test based on ASTM C512 Method (C09 Committee 2015). It specifies that, regardless of any dimension alteration of the specimen, a loading set-up should be able to utilize and sustain the requisite load on the specimen. The loaded specimen was held with steel header plates and a spring 
as a load-preserving component to damp the response of the loaded set-up. A jack utilized the preliminary compression. The spring-loaded set-up is shown in Figure 4-6. A load cell was implanted in the set-up to measure the utilized load. An affixed device was employed to measure the specimen's longitudinal strain.

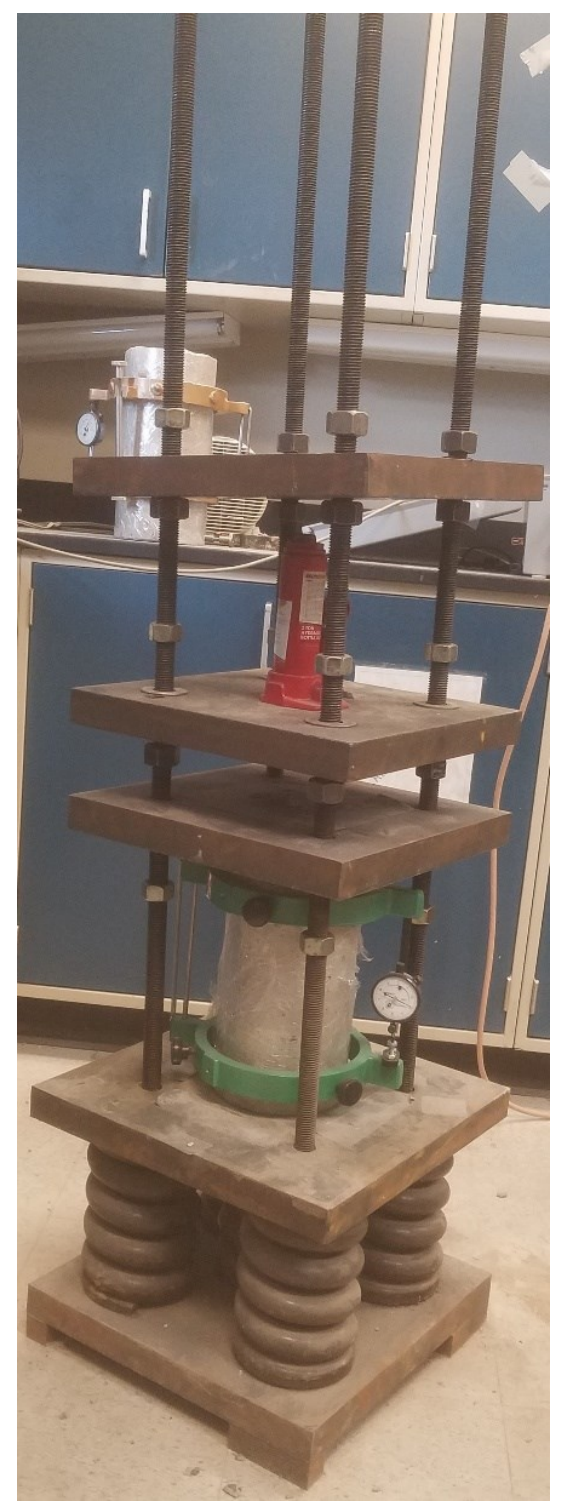

Figure 4-6: The loading set-up for the compressive creep test.

Shrinkage of a sealed (fully wrapped) cylinder was also measured to calculate the actual compressive creep because the results from the compressive loading setup include the shrinkage 
of the sealed specimen as well as the compressive creep. Both specimens were wrapped with plastic sheets to ensure there was very limited drying shrinkage. The shrinkage of the sealed specimen was tested based on the ASTM C157 Method (Committee C09 2017). The shrinkage test set-up of the sealed specimen was shown in Figure 4-7.

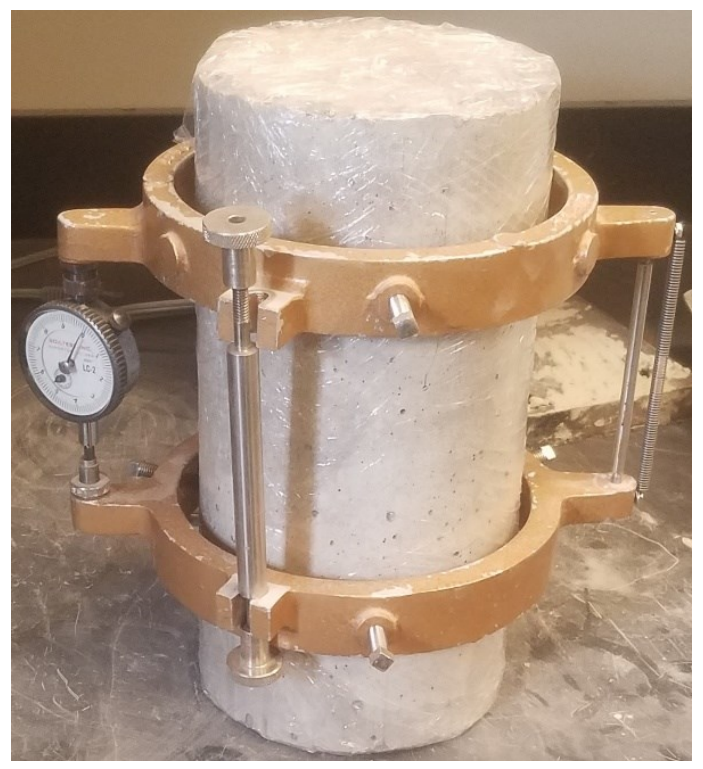

Figure 4-7: The shrinkage test set-up of the sealed specimen.

The compressive creep test results without deducting the shrinkage of the sealed specimen, and the compressive creep with the shrinkage of the sealed specimen deducted test are shown in Figure 4-8, Figure 4-9, Figure 4-12, and Figure 4-13, respectively. The compressive creep loading over time of two tests are shown in Figure 4-14 and Figure 4-15. Comparison of 50\% slag 1 shrinkage results of 3 -in $(7.62-\mathrm{cm})$ by 3 -in $(7.62-\mathrm{cm})$ by 11.25 -in $(28.58-\mathrm{cm})$ fully-wrapped prism and 6-in $(15.2-\mathrm{cm})$ by $12-$ in $(30.5-\mathrm{cm})$ cylinder is shown in Figure 4-10, and the difference between them was around 25 micro-strains around 58 days. Comparison of $30 \%$ fly ash 1 shrinkage results of 3-in $(7.62-\mathrm{cm})$ by 3 -in $(7.62-\mathrm{cm})$ by 11.25 -in $(28.58-\mathrm{cm})$ fully-wrapped prism and 6-in $(15.2-$ $\mathrm{cm})$ by 12-in $(30.5-\mathrm{cm})$ cylinder is shown in Figure 4-11 and difference between them was around 95 micro-strains around 23 days. 


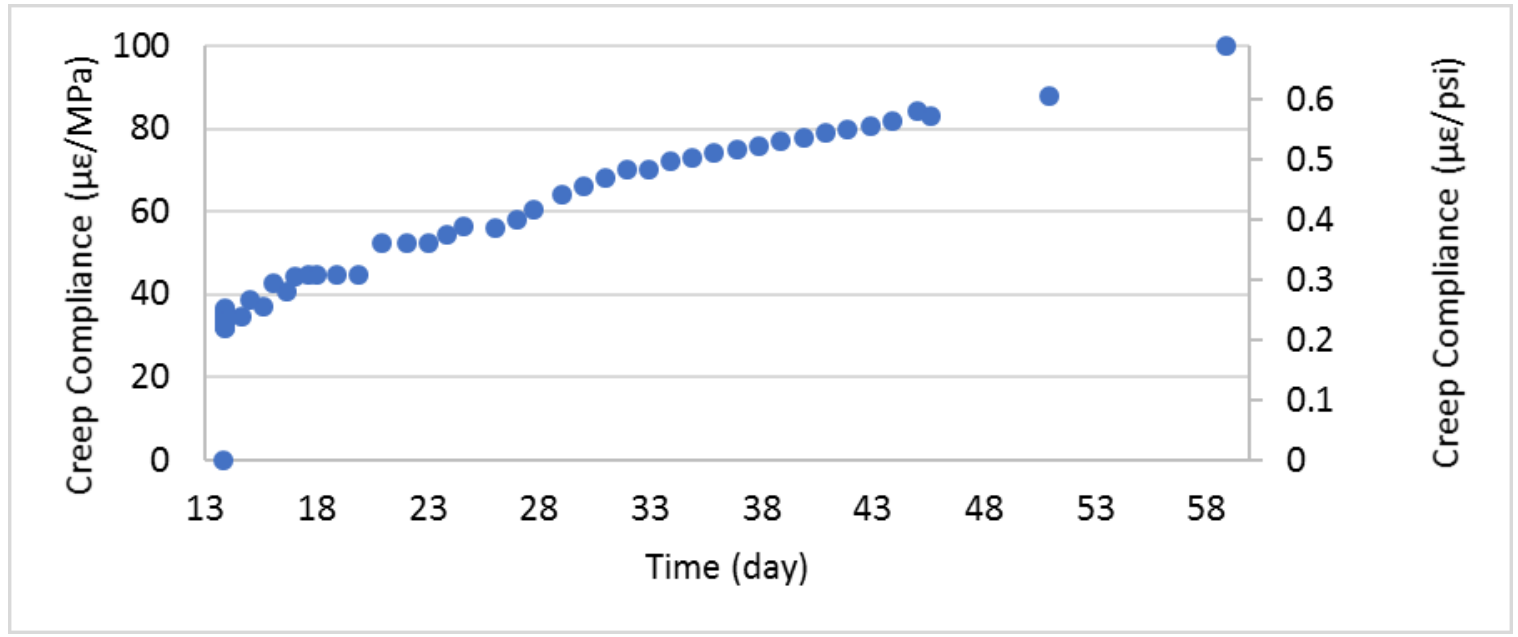

Figure 4-8: Compressive creep test result of $50 \%$ slag 1 without sealed shrinkage deducted.

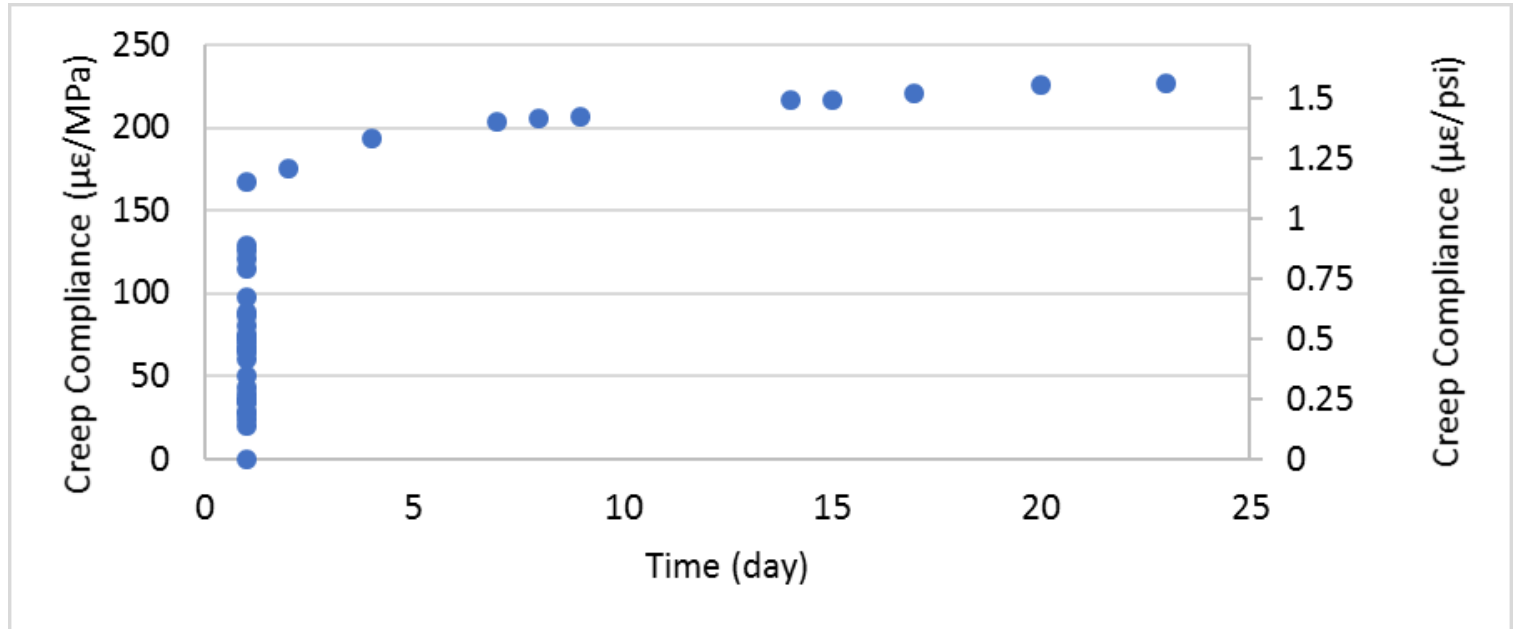

Figure 4-9: Compressive creep test result of $30 \%$ fly ash 1 without sealed shrinkage deducted. 


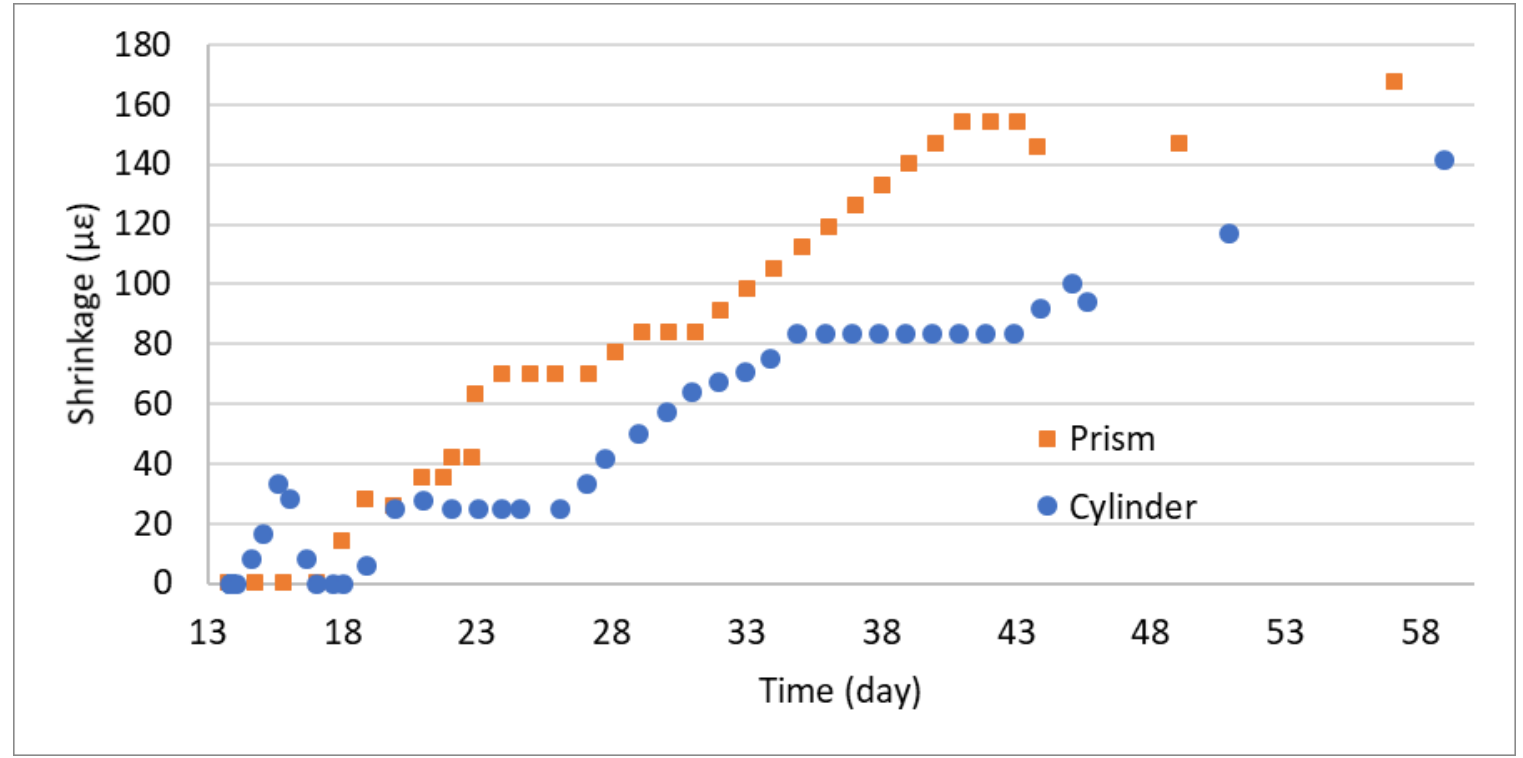

Figure 4-10: Comparison of 50\% slag 1 shrinkage results of 3 -in $(7.62-\mathrm{cm})$ by 3 -in $(7.62$ cm) by 11.25 -in $(28.58-\mathrm{cm})$ fully-wrapped prism and 6 -in $(15.2-\mathrm{cm})$ by 12 -in $(30.5-\mathrm{cm})$ cylinder.

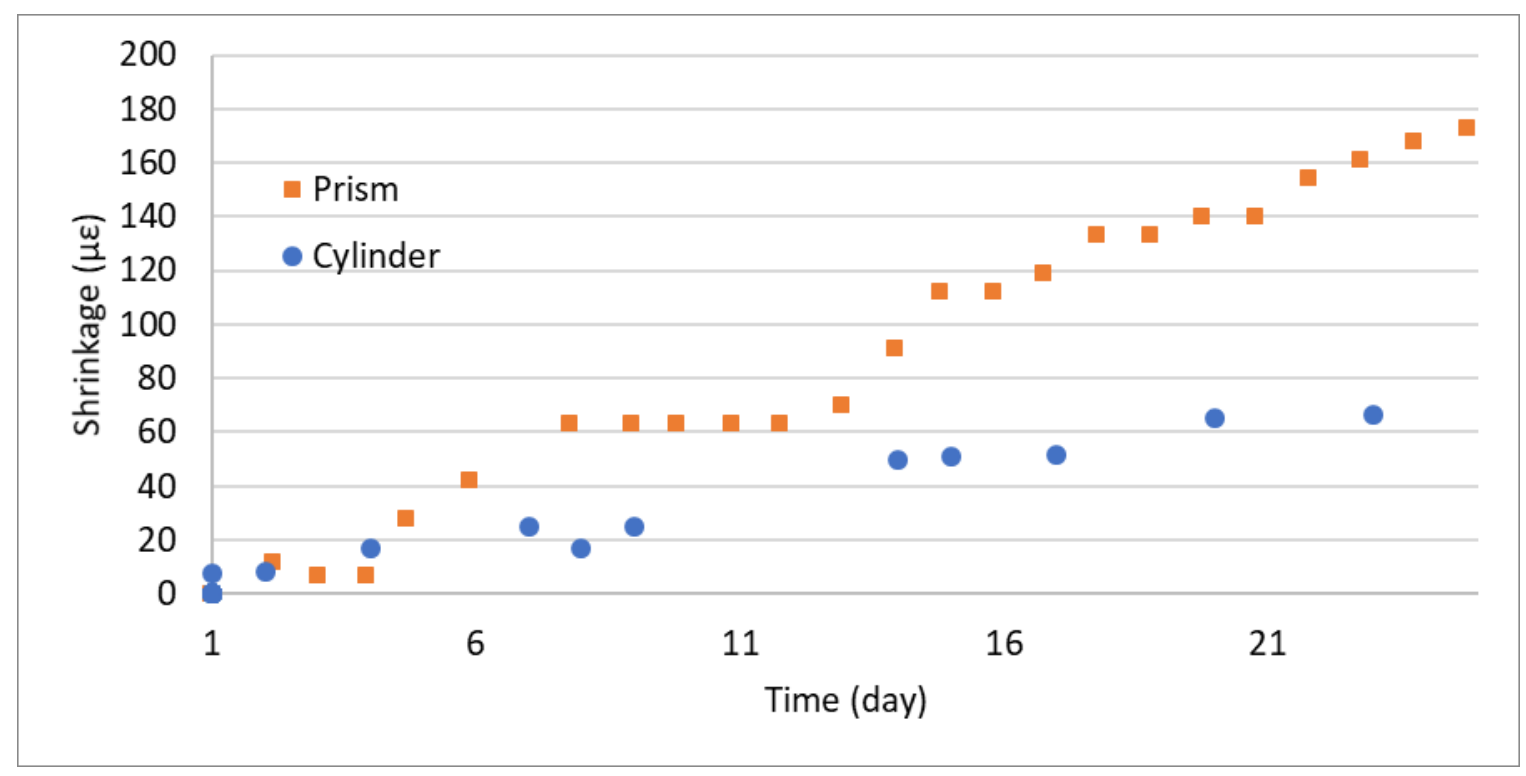

Figure 4-11: Comparison of 30\% fly ash 1 shrinkage results of 3 -in $(7.62-\mathrm{cm})$ by 3 -in (7.62cm) by 11.25-in $(28.58-\mathrm{cm})$ fully-wrapped prism and 6 -in $(15.24-\mathrm{cm})$ by 12 -in $(30.5-\mathrm{cm})$ cylinder. 


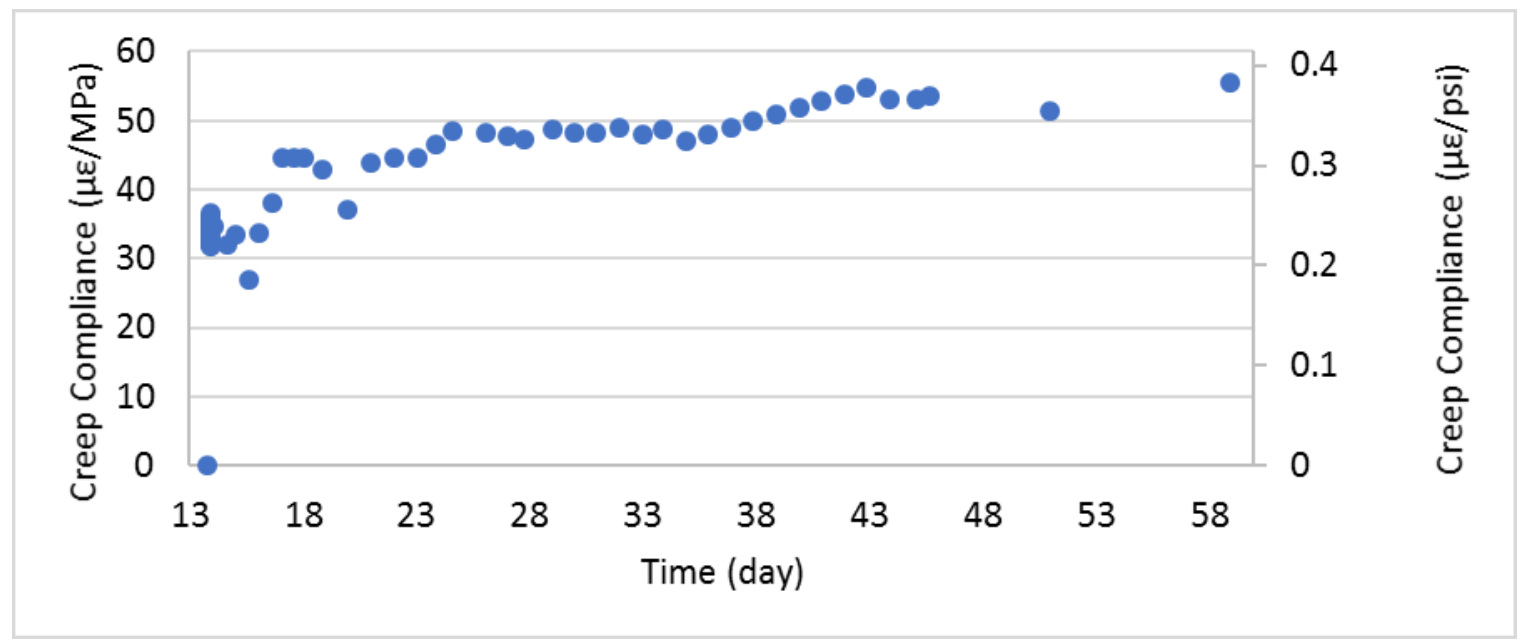

Figure 4-12: Compressive creep test result of 50\% slag 1 with sealed shrinkage deducted.

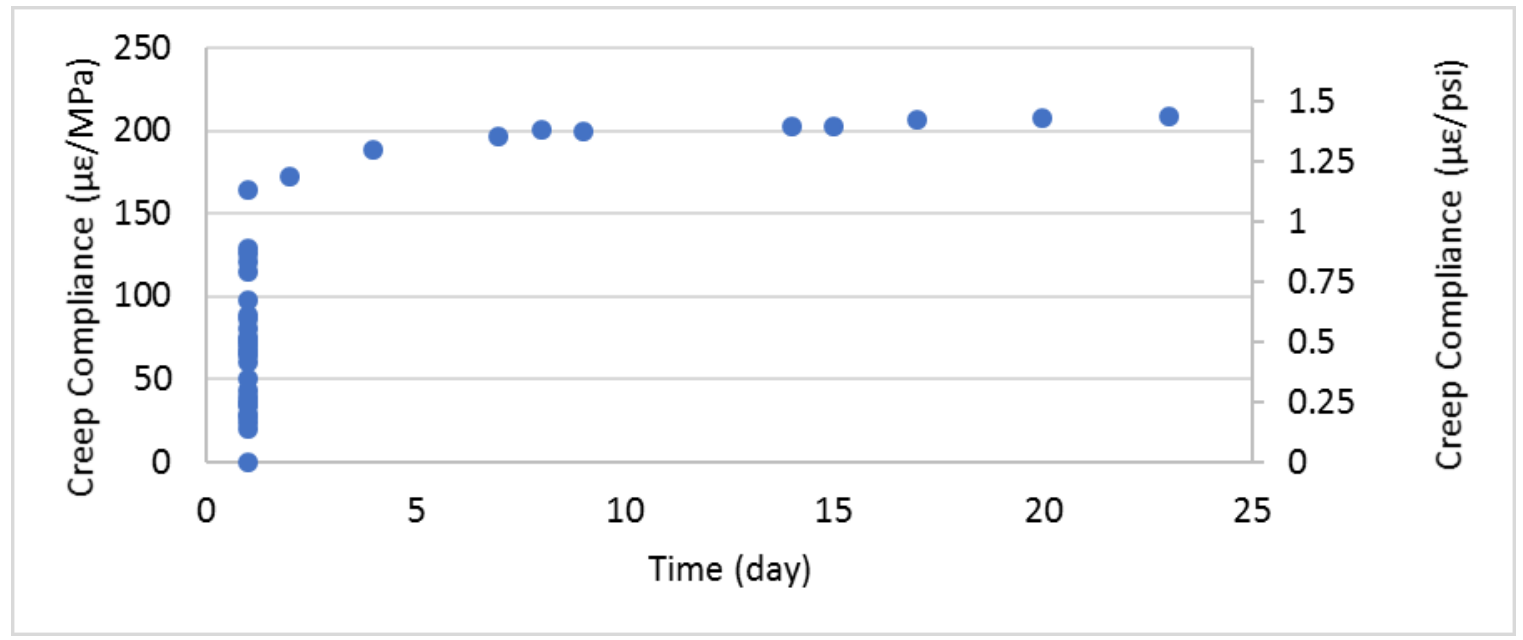

Figure 4-13: Compressive creep test result of $30 \%$ fly ash 1 with sealed shrinkage deducted. 


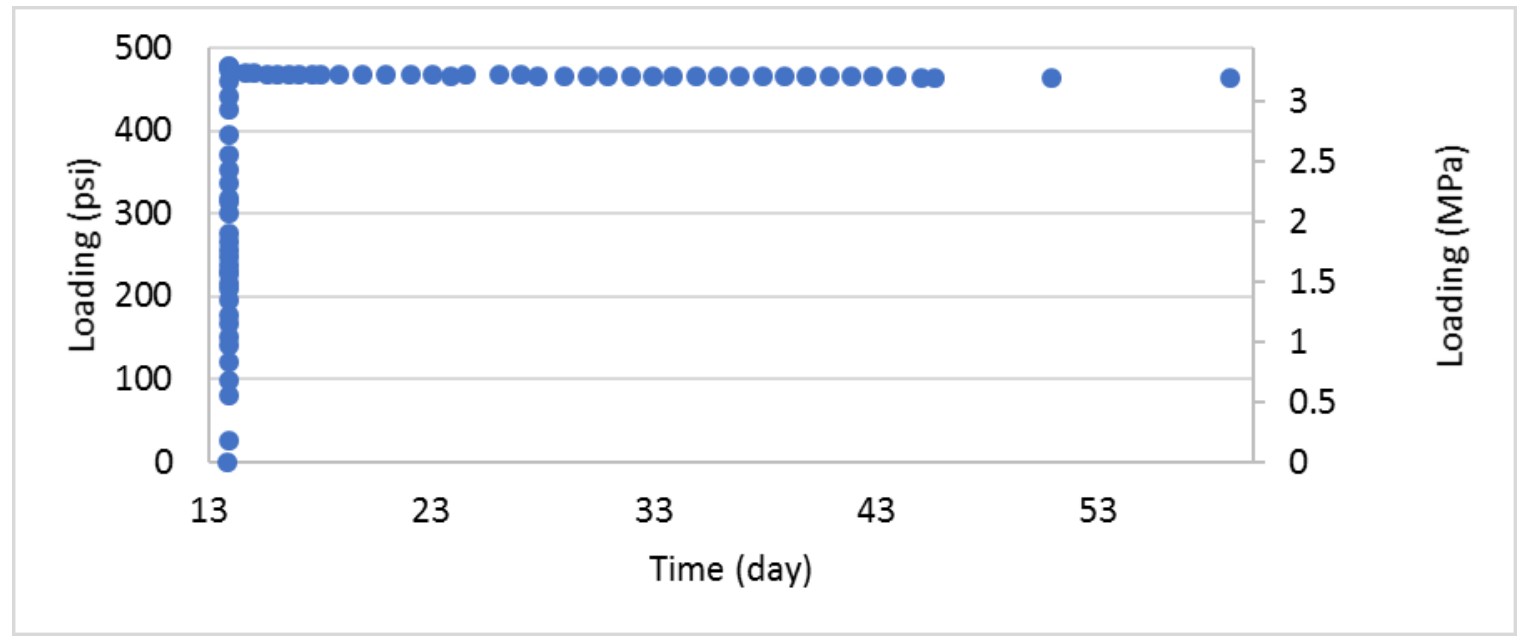

Figure 4-14: The compressive creep loading over time of 50\% slag 1.

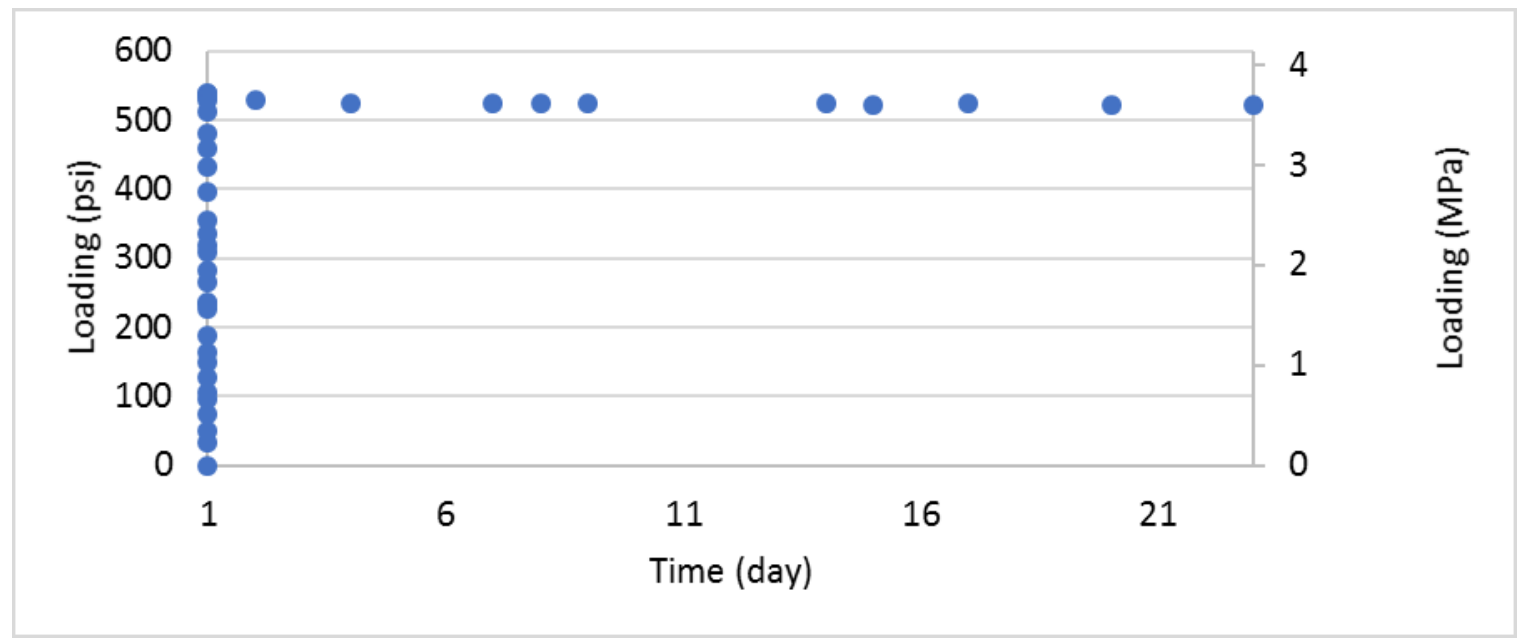

Figure 4-15: The compressive creep loading over time of $30 \%$ fly ash 1.

The prediction for shrinkage and compressive creep can be done with the following equations provided by Guide for Modeling and Calculating Shrinkage and Creep in Hardened Concrete (ACI Committee 209 2008), Model B3 (Bažant and Baweja 2000), CEB MC 90, CEB MC90-99, and GL2000 (Gardner and Lockman 2001). Regular concrete mixes and mixes with fly ash up to $30 \%$ replacement were used to calibrate the prediction models (ACI Committee 209 2008). The range of the parameters of each model are shown in Table 4-1 (ACI Committee 209 2008), showing the ACI 209R-92 model (ACI Committee 209 2008) has no limitations of 28 days 
concrete mean compressive cylinder strength $\left(\mathrm{f}_{\mathrm{cm} 28}\right)$, the aggregate-cement ratio by weight $(\mathrm{a} / \mathrm{c})$, the water-cement ratio by weight (w/c) and specimen material, the B3 model (Bažant and Baweja 2000) has no limitations of the steam curing time [tc (steam cured)], the CEB MC 90 and the CEB MC90-99 models (fib Committee 1999) has no limitations of the aggregate-cement ratio by weight $(\mathrm{a} / \mathrm{c})$, the cement content by weight $(\mathrm{c})$, the water-cement ratio by weight $(\mathrm{w} / \mathrm{c})$, the steam curing time [tc (steam cured)] and specimen material, the GL2000 model (Gardner and Lockman 2001) has no limitations of the aggregate-cement ratio by weight $(\mathrm{a} / \mathrm{c})$, the cement content by weight (c), the steam curing time [tc (steam cured)] and specimen material,

Table 4-1: Parameter ranges of each model (ACI Committee 209 2008).

\begin{tabular}{|c|c|c|c|c|c|}
\hline \multirow[b]{2}{*}{ Input variables } & \multicolumn{5}{|c|}{ Model } \\
\hline & ACI 209R-92 & Bažant-Baweja B3 & $\begin{array}{c}\text { CEB } \\
\text { MC90 }\end{array}$ & \begin{tabular}{|c|} 
CEB \\
MC90-99 \\
\end{tabular} & GL2000 \\
\hline $\mathbf{f}_{\mathrm{cm} 28,}, \mathrm{MPa}(\mathrm{psi})$ & - & $\begin{array}{c}17 \text { to } 70 \\
(2500 \text { to } 10,000)\end{array}$ & $\begin{array}{c}20 \text { to } 90 \\
(2900 \text { to } \\
13,000)\end{array}$ & $\begin{array}{c}15 \text { to } 120 \\
(2175 \text { to } \\
17,400)\end{array}$ & $\begin{array}{c}16 \text { to } 82 \\
(2320 \text { to } \\
11,900)\end{array}$ \\
\hline $\mathbf{a} / \mathbf{c}$ & - & 2.5 to 13.5 & - & - & - \\
\hline $\begin{array}{c}\mathrm{c}, \\
\mathrm{kg} / \mathrm{m}^{3}\left(\mathbf{l b} . / \mathrm{yd}^{3}\right)\end{array}$ & $\begin{array}{c}279 \text { to } 446 \\
\text { (470 to } 752)\end{array}$ & $\begin{array}{c}160 \text { to } 720 \\
(270 \text { to } 1215)\end{array}$ & - & - & - \\
\hline $\mathbf{w} / \mathbf{c}$ & - & 0.35 to 0.85 & - & - & 0.4 to 0.6 \\
\hline Rh, \% & 40 to 100 & 40 to 100 & 40 to 100 & 40 to 100 & 20 to 100 \\
\hline $\begin{array}{l}\text { Type of cement, } \\
\text { European (U.S.) }\end{array}$ & $\begin{array}{l}\mathrm{R} \text { or } \mathrm{RS} \\
\text { (I or III) }\end{array}$ & $\begin{array}{l}\text { R, SL, RS } \\
(\mathrm{I}, \mathrm{II}, \mathrm{III})\end{array}$ & $\begin{array}{l}\text { R, SL, RS } \\
\text { (I, II, III) }\end{array}$ & $\begin{array}{l}\text { R, SL, RS } \\
\text { (I, II, III) }\end{array}$ & $\begin{array}{l}\text { R, SL, RS } \\
\text { (I, II, III) }\end{array}$ \\
\hline$t_{c}($ moist cured $)$ & $\geq 1$ day & $\geq 1$ day & $<14$ days & $<14$ days & $\geq 1$ day \\
\hline$t_{c}($ steam cured) & 1 to 3 days & - & - & - & - \\
\hline $\mathbf{t}_{\mathbf{0}}$ & $\geq 7$ days & $t_{o} \geq t_{c}$ & $>1$ day & $>1$ day & $t_{o} \geq t_{c} \geq 1$ day \\
\hline $\begin{array}{l}\text { Other required } \\
\text { parameters }\end{array}$ & $\begin{array}{c}\mathrm{s}, \psi, \alpha, \text { mix proportions, } \\
\text { and } \mathrm{V} / \mathrm{S} \text { or } \mathrm{d}\end{array}$ & $\begin{array}{c}\mathrm{E}_{\mathrm{cm} 28,} \text {, shape, } \mathrm{V} / \mathrm{S} \text { or } \\
\mathrm{d}_{\text {effective cross-section }}\end{array}$ & $\mathrm{V} / \mathrm{S}$ & $\mathrm{V} / \mathrm{S}$ & $\begin{array}{l}\mathrm{V} / \mathrm{S}, \mathrm{f}_{\mathrm{cmto}} \\
\mathrm{E}_{\mathrm{cm} 28}, \mathrm{E}_{\mathrm{cmto}}\end{array}$ \\
\hline Specimen material & - & $\begin{array}{l}\text { Portland cement } \\
\text { concrete }\end{array}$ & - & - & - \\
\hline
\end{tabular}

where $\mathrm{f}_{\mathrm{cm} 28}$ is the 28 days concrete mean compressive cylinder strength, a/c is the aggregatecement ratio by weight, $\mathrm{c}$ is the content of cement by weight, w/c is the water-cement ratio by weight, $\mathrm{Rh}$ is the ambient relative humidity, $\mathrm{t}_{\mathrm{c}}$ is the curing time, $\mathrm{t}_{\mathrm{o}}$ is the loading time, $\mathrm{s}$ is the 
slump, $\psi$ is the fine aggregate percentage, $\alpha$ is the air content, $\mathrm{V} / \mathrm{S}$ is the volume-surface ratio, $\mathrm{d}$ is the average thickness, $\mathrm{E}_{\mathrm{cm} 28}$ is the 28 days concrete mean modulus of elasticity, $\mathrm{d}_{\mathrm{effective}}$ cross-section is the average thickness of the effective cross-section, $\mathrm{f}_{\mathrm{cm} t o}$ is the loading time concrete mean compressive strength and $\mathrm{E}_{\mathrm{cmto}}$ is the loading time concrete mean modulus of elasticity (2008). In this study w/cem ratio were used in the calculation process of $50 \%$ slag 1 and $30 \%$ fly ash 1 shrinkage and compressive creep predictions instead of w/c ratio mentioned in the ACI 209.2R-08 (2008). Input values used in the calculation process of 50\% slag 1 and $30 \%$ fly ash 1 shrinkage and compressive creep predictions is shown in Table 4-2.

Table 4-2: Input values used in the calculation process of 50\% slag 1 and $30 \%$ fly ash 1 shrinkage and compressive creep predictions

\begin{tabular}{|c|c|c|c|c|}
\hline \multirow[b]{2}{*}{ Input values } & \multicolumn{2}{|c|}{$50 \%$ slag 1} & \multicolumn{2}{|c|}{$30 \%$ fly ash 1} \\
\hline & Shrinkage & Compressive creep & Shrinkage & Compressive creep \\
\hline$f_{c}^{\prime}$ (specified 28-day strength) & \multicolumn{2}{|c|}{$5252.1 \mathrm{psi}(36.212 \mathrm{MPa})$} & \multicolumn{2}{|c|}{$3644.6 \mathrm{psi}(25.129 \mathrm{MPa})$} \\
\hline h\% (relative humidity) & 0.4 & 1 & 0.5781 & 1 \\
\hline T (temperature) & $\begin{array}{c}71.27^{\circ} \mathrm{F} \\
\left(21.817^{\circ} \mathrm{C}\right) \\
\end{array}$ & $\begin{array}{l}71.78^{\circ} \mathrm{F} \\
\left(22.1^{\circ} \mathrm{C}\right)\end{array}$ & $\begin{array}{c}73.12^{\circ} \mathrm{F} \\
\left(22.84^{\circ} \mathrm{C}\right) \\
\end{array}$ & $\begin{array}{c}72^{\circ} \mathrm{F} \\
\left(22.22^{\circ} \mathrm{C}\right) \\
\end{array}$ \\
\hline V/S (volume-surface ratio) & $\begin{array}{c}0.657-\text { in } \\
(16.7-\mathrm{mm})\end{array}$ & $\begin{array}{c}1.2 \text {-in } \\
(30.5-\mathrm{mm})\end{array}$ & $\begin{array}{c}0.657-\text { in } \\
(16.7-\mathrm{mm})\end{array}$ & $\begin{array}{c}1.2 \text {-in } \\
(30.5-\mathrm{mm})\end{array}$ \\
\hline$t_{c}$ (curing time) & 1 day & 7 days & & 1 day \\
\hline$t_{0}$ (loading time) & 1 day & 13.82 days & & 1 day \\
\hline Maximum aggregate size & \multicolumn{4}{|c|}{ 1-in $(25.4-\mathrm{mm})$} \\
\hline \begin{tabular}{|c|} 
cem (cementitious material \\
content by weight)
\end{tabular} & \multicolumn{4}{|c|}{$508 \mathrm{lb} . / \mathrm{yd}^{3}\left(301.384 \mathrm{~kg} / \mathrm{m}^{3}\right)$} \\
\hline $\begin{array}{c}\text { w/cem (water-cementitious } \\
\text { material ratio by weight) }\end{array}$ & \multicolumn{2}{|r|}{0.468} & \multicolumn{2}{|c|}{0.466} \\
\hline $\begin{array}{c}\text { a/cem (aggregate- } \\
\text { cementitious material ratio } \\
\text { by weight) }\end{array}$ & \multicolumn{2}{|r|}{6.219} & \multicolumn{2}{|c|}{6.181} \\
\hline $\begin{array}{l}\Psi \text { (fine aggregate } \\
\text { percentage) }\end{array}$ & \multicolumn{2}{|r|}{43.2} & \multicolumn{2}{|r|}{43.3} \\
\hline$\alpha \%$ (air content) & & 5.2 & & 6 \\
\hline s (slump) & \multicolumn{4}{|c|}{ 6.5-in $(165.1-\mathrm{mm})$} \\
\hline$\gamma_{c}$ (unit weight of concrete) & \multicolumn{2}{|c|}{3900.7 lb. $/ \mathrm{yd}^{3}\left(2314.19 \mathrm{~kg} / \mathrm{m}^{3}\right)$} & \multicolumn{2}{|c|}{$3881.5 \mathrm{lb} . / \mathrm{yd}^{3}\left(2302.8 \mathrm{~kg} / \mathrm{m}^{3}\right)$} \\
\hline
\end{tabular}




\subsection{Calculations}

The following models are used to predict the shrinkage and compressive creep:

\subsubsection{ACI 209R-92 model}

ACI Committee 209 (2008) stated that their model for predicting shrinkage and creep included standard conditions, and correction factors were provided to estimate the ultimate values for other conditions.

\subsubsection{Shrinkage}

The $\varepsilon_{s h}\left(t, t_{c}\right)$ is the shrinkage strain might be calculated by Equation 4-1,

$$
\varepsilon_{s h}\left(t, t_{c}\right)=\frac{\left(t-t_{c}\right)^{\alpha}}{f+\left(t-t_{c}\right)^{\alpha}} \varepsilon_{s h u}
$$

where $t$ is the concrete age (days), $t_{c}$ is curing time (days), $\varepsilon_{\text {shu }}$ is the ultimate shrinkage strain might be calculated by Equation 4-3, and in Equation 4-1, through substituting $\alpha=1.0$, along with $f$ where $V / S$ is the volume-surface ratio in inches or millimeters as given by Equation 4-2, the shape and size effect might be utterly assumed to be on the time-ratio,

$$
\begin{aligned}
& f=26.0 e^{[0.36(V / S)]}(\mathrm{in}), f=26.0 e^{\left[1.42 \times 10^{-2}(\mathrm{~V} / \mathrm{S})\right]}(\mathrm{mm}), \\
& \varepsilon_{s h u}=780 \gamma_{s h} \times 10^{-6} \geq 150 \times 10^{-6}(\text { in. } / \text { in. })(\text { state of continuous drying }), \\
& \gamma_{s h}=\gamma_{s h, t c} \gamma_{s h, R H} \gamma_{s h, v s} \gamma_{s h, s} \gamma_{s h, \Psi} \gamma_{s h, c} \gamma_{s h, \alpha} \leq 0.2,
\end{aligned}
$$

where $\gamma_{s h}$ calculated by Equation 4-4 is the cumulative outcome of the applicable adjustment components, $\gamma_{s h, t c}$ calculated by Equation 4-5 is the preliminary moist curing coefficient, $\gamma_{s h, R H}$ calculated by Equation 4-6 is the ambient relative humidity coefficient, $\gamma_{s h, v s}$ calculated by 
Equation 4-7 is the coefficient to reflect the member dimensions effect in terms of $V / S, \gamma_{s h, s}$ calculated by Equation 4-8 is the factor of the slump, $\gamma_{s h, \Psi}$ calculated by Equation 4-9 is the factor of fine aggregate, $\gamma_{s h, c}$ calculated by Equation 4-10 is the factor of the content of cement, $\gamma_{s h, \alpha}$ calculated by Equation 4-11 is the factor of the content of air,

$$
\gamma_{s h, t c}=1.202-0.2337 \log \left(t_{c}\right), R^{2}=0.9987
$$

$$
\gamma_{s h, R H}=\left\{\begin{array}{c}
1.4-1.02 h, 0.4 \leq h<0.8 \\
3-3 h, 0.8 \leq h \leq 1
\end{array}\right.
$$

where $h$ is the relative humidity in percentage,

$$
\begin{aligned}
& \gamma_{s h, v s}=1.2 e^{[-0.12(V / S)]}, \\
& \gamma_{s h, s}=0.89+0.041 s
\end{aligned}
$$

where $s$ is the slump (in.),

$$
\gamma_{s h, \Psi}=\left\{\begin{array}{l}
0.3+0.014 \Psi, \Psi<50 \% \\
0.9+0.002 \Psi, \Psi \geq 50 \%
\end{array}\right.
$$

where $\Psi$ is the fine/total aggregate weight ratio,

$$
\gamma_{s h, c}=0.75+0.00036 c
$$

where $c$ is the content of cement $\left(l b / y d^{3}\right)$,

$$
\gamma_{s h, \alpha}=0.95+0.008 \alpha \geq 1,
$$

where $\alpha$ is the content of air (\%). 


\subsubsection{Creep Compliance}

The $J\left(t, t_{0}\right)$ is the compliance function was calculated by Equation 4-12,

$$
J\left(t, t_{0}\right)=\frac{1+\phi\left(t, t_{0}\right)}{E_{c m t o}}
$$

where $E_{c m t o}$ calculated by Equation 4-13 is the loading time modulus of elasticity (psi), $\phi\left(t, t_{0}\right)$ calculated by Equation 4-15 is the loading time creep/elastic strain coefficient of creep,

$$
E_{c m t o}=33 \gamma_{c}^{1.5} \sqrt{f_{c m t o}}
$$

where $\gamma_{c}$ is the concrete unit weight $\left(l b / f t^{3}\right), f_{c m t o}$ calculated by Equation 4-14 is the loading time mean compressive strength of concrete (psi),

$$
f_{c m t o}=\left(\frac{t}{a+b t}\right) f_{c m 28}
$$

where $f_{c m 28}$ is the 28 days mean compressive strength of concrete, $t$ is the concrete age, $a$ and $b$ are recommended as 4 and 0.85 in the standard, respectively,

$$
\phi\left(t, t_{0}\right)=\frac{\left(t-t_{0}\right)^{\Psi}}{d+\left(t-t_{0}\right)^{\Psi}} \phi_{u}
$$

where $\phi_{u}$ calculated by Equation 4-16 is the coefficient of ultimate creep, $d$ and $\Psi$ are recommended as $f$ and 1 in standard, respectively,

$$
\phi_{u}=2.35 \gamma_{c}
$$

where $\gamma_{c}$ calculated by Equation 4-17 is the applicable improvement factors' cumulative outcome,

$$
\gamma_{c}=\gamma_{c, t o} \gamma_{c, R H} \gamma_{c, v s} \gamma_{c, s} \gamma_{c, \Psi} \gamma_{c, \alpha}
$$

where $\gamma_{c, t o}$ calculated by Equation 4-18 is the creep loading time factor, $\gamma_{c, R H}$ calculated by Equation 4-19 is the factor of the relative humidity of ambient, $\gamma_{c, v s}$ calculated by Equation 4-20 
is the coefficient to reflect the member dimensions effect in terms of $V / S, \gamma_{c, s}$ calculated by Equation 4-21 is the factor of the slump, $\gamma_{c, \Psi}$ calculated by Equation 4-22 is the factor of fine aggregate, $\gamma_{c, \alpha}$ calculated by Equation 4-23 is the factor of the content of air.

$$
\begin{aligned}
& \gamma_{c, t o}=1.25 t_{o}^{-1.118} \\
& \gamma_{c, R H}=1.27-0.67 \mathrm{~h} \\
& \gamma_{c, v s}=\frac{2}{3}\left[1+1.13 e^{(-0.54\{V / S\})}\right] \\
& \gamma_{c, s}=0.82+0.067 s \\
& \gamma_{c, \Psi}=0.88+0.0024 \Psi \\
& \gamma_{c, \alpha}=0.46+0.09 \alpha \geq 1
\end{aligned}
$$

\subsubsection{Bažant-Baweja B3 model}

Bažant and Baweja (2000) stated that the B3 model is calibrated by a data bank, including test data obtained in many laboratories. 


\subsubsection{Shrinkage}

From Equation 4-24, the cross-section mean shrinkage strain $\varepsilon_{s h}\left(t, t_{c}\right)$ might be calculated,

$$
\varepsilon_{s h}\left(t, t_{c}\right)=-\varepsilon_{s h \infty} k_{h} S\left(t-t_{c}\right)
$$

where $\varepsilon_{\text {shœ }}$ calculated by Equation 4-25 is the ultimate shrinkage strain, $k_{h}$ calculated by Equation 4-26 is the factor of the dependence of humidity, and $S\left(t-t_{c}\right)$ calculated by Equation 4-27 is the curve of time,

$$
\varepsilon_{s h \infty}=-\varepsilon_{s \infty} \frac{E_{c m 607}}{E_{c m\left(t_{c}+\tau_{s h}\right)}}
$$

where $\varepsilon_{s \infty}$ calculated by Equation $4-28$ is a constant, and $\frac{E_{c m 607}}{E_{c m\left(t_{c}+\tau_{s h}\right)}}$ ultimate shrinkage time dependence interpretation factor,

$$
\begin{aligned}
& k_{h}=1-h^{3} \\
& S\left(t-t_{c}\right)=\tanh \sqrt{\frac{\left(t-t_{c}\right)}{\tau_{s h}}}
\end{aligned}
$$

where $\tau_{s h}$ calculated by Equation 4-30 is the half-time shrinkage (days),

$$
\varepsilon_{s \infty}=-\alpha_{1} \alpha_{2}\left(0.02565 w^{2.1} f_{c m 28}^{-0.28}+270\right) \times 10^{-6}
$$

where $w$ is the content of water $\left(l b / y d^{3}\right), \alpha_{1}$ and $\alpha_{2}$ are recommended by the standard as 0.85 and 1.2 , respectively,

$$
E_{c m t}=E_{c m 28}\left(\frac{t}{4+0.85 t}\right)^{0.5}
$$




$$
\tau_{s h}=190.8 t_{c}^{-0.08} f_{c m 28}^{-0.25}\left(2 k_{s}[V / S]\right)^{2}
$$

where $k_{s}$ is the factor of shape-correction of the cross-section is recommended by the standard as 1.25 for this study.

\subsubsection{Creep Compliances}

The function of median compliance $J\left(t, t_{O}\right)$ might be calculated from Equation 4-31,

$$
J\left(t, t_{o}\right)=q_{1}+C_{o}\left(t, t_{o}\right)
$$

where $q_{1}$ calculated by Equation $4-32$ is the unit stress caused immediate strain, $C_{O}\left(t, t_{O}\right)$ calculated by Equation 4-34 is the basic creep function of compliance,

$$
q_{1}=0.6 / E_{c m 28}
$$

where,

$$
\begin{aligned}
& E_{c m 28}=57,000 \sqrt{f_{c m 28}} \\
& C_{o}\left(t, t_{o}\right)=q_{2} Q\left(t, t_{o}\right)+q_{3} \ln \left[1+\left(t-t_{o}\right)^{n}\right]+q_{4} \ln \left(t / t_{o}\right),
\end{aligned}
$$

where $q_{2} Q\left(t, t_{O}\right)$ calculated by multiplying Equations 4-35 and 4-36 is the term for aging viscoelastic compliance, $q_{3}$ calculated by Equation 4-40 is the parameter of nonaging viscoelastic compliance, and $q_{4}$ calculated by Equation 4-41 is the term for aging flow compliance and $n$ is recommended by the standard as 0.1 ,

$$
q_{2}=86.814 \times 10^{-6} c^{0.5} f_{c m 28}{ }^{-0.9}
$$


$Q\left(t, t_{o}\right)=Q_{f}\left(t_{o}\right)\left\{1+\left[\frac{Q_{f}\left(t_{o}\right)}{Z\left(t, t_{o}\right)}\right]^{r\left(t_{o}\right)}\right\}^{-1 / r\left(t_{o}\right)}$

where,

$$
\begin{aligned}
& Q_{f}\left(t_{o}\right)=\left[0.086\left(t_{o}\right)^{2 / 9}+1.21\left(t_{o}\right)^{4 / 9}\right]^{-1} \\
& Z\left(t, t_{o}\right)=t_{o}^{-m} \ln \left[1+\left(t-t_{o}\right)^{n}\right] \\
& r\left(t_{o}\right)=1.7\left(t_{o}\right)^{0.12}+8 \\
& q_{3}=0.29(w / c)^{4} q_{2} \\
& q_{4}=0.14 \times 10^{-6}(a / c)^{-0.7}
\end{aligned}
$$

where $a / c$ is the aggregate/cement in weight.

\subsubsection{CEB MC90-99 model}

The CEB MC90 model (1993) for creep and shrinkage predicts a hyperbolic change with time, and it also takes mixture proportion and environmental conditions into consideration when applying an ultimate value. The CEB MC90-99 model (1999) was intended to predict shrinkage and creep for normal and high-strength concrete, and it calculates autogenous and drying shrinkage.

\subsubsection{Shrinkage (CEB MC90)}

The $\varepsilon_{s h}\left(t, t_{c}\right)$ was calculated by Equation 4-42 is the concrete total shrinkage strains, 


$$
\varepsilon_{s h}\left(t, t_{c}\right)=\varepsilon_{c s o} \beta_{s}\left(t-t_{c}\right),
$$

where $\varepsilon_{c s o}$ calculated by Equation 4-43 is the coefficient of estimated shrinkage, $\beta_{s}\left(t-t_{c}\right)$ calculated by Equation 4-46 is the shrinkage progress coefficient,

$$
\varepsilon_{c s o}=\varepsilon_{s}\left(f_{c m 28}\right) \beta_{R H}(h),
$$

$$
\varepsilon_{s}\left(f_{c m 28}\right)=\left[160+10 \beta_{s c}\left(9-f_{c m 28} / f_{c m o}\right)\right] \times 10^{-6},
$$

where $f_{c m o}$ (psi) and $\beta_{s c}$ are recommended in the standard as 1450 and 5, respectively,

$$
\beta_{R H}(h)=-1.55\left[1-\left(\frac{h}{h_{o}}\right)^{3}\right],
$$

where $h_{o}$ is recommended in the standard as 1 ,

$$
\beta_{s}\left(t-t_{c}\right)=\left\{\frac{\left(t-t_{c}\right) / t_{1}}{350\left[(V / S) /(V / S)_{o}\right]^{2}+\left(t-t_{c}\right) / t_{1}}\right\}^{0.5},
$$

where $t_{1}$ (days) and $(V / S)_{o}$ (in.) are recommended by the standard as 1 and 2, respectively.

\subsubsection{Shrinkage (CEB MC90-99)}

The $\varepsilon_{s h}\left(t, t_{c}\right)$ was calculated by Equation $4-47$ is the concrete total shrinkage,

$$
\varepsilon_{s h}\left(t, t_{c}\right)=\varepsilon_{c a s}(t)+\varepsilon_{c d s}\left(t, t_{c}\right)
$$

where $\varepsilon_{c a s}(t)$ calculated by Equation 4-48 is the autogenous shrinkage and $\varepsilon_{c d s}\left(t, t_{c}\right)$ calculated by Equation $4-51$ is the drying shrinkage, 


$$
\varepsilon_{c a s}(t)=\varepsilon_{c a s o}\left(f_{c m 28}\right) \beta_{a s}(t),
$$

where $\varepsilon_{\text {caso }}\left(f_{c m 28}\right)$ calculated by Equation 4-49 is the coefficient of estimated autogenous shrinkage and $\beta_{a s}(t)$ calculated by Equation 4-50 is the autogenous shrinkage time progress function,

$$
\varepsilon_{c a s o}\left(f_{c m 28}\right)=-\alpha_{a s}\left(\frac{f_{c m 28} / f_{c m o}}{6+f_{c m 28} / f_{c m o}}\right)^{2.5} \times 10^{-6}
$$

where $\alpha_{a s}$ is recommended by the standard as 700 for this study,

$$
\begin{aligned}
& \beta_{a s}(t)=1-\exp \left[-0.2\left(\frac{t}{t_{1}}\right)^{0.5}\right], \\
& \varepsilon_{c d s}\left(t, t_{c}\right)=\varepsilon_{c d s o}\left(f_{c m 28}\right) \beta_{R H}(h) \beta_{d s}\left(t-t_{c}\right),
\end{aligned}
$$

where $\varepsilon_{c d s o}\left(f_{c m 28}\right)$ calculated by Equation 4-52 is the coefficient of estimated drying shrinkage, $\beta_{R H}(h)$ calculated by Equation 4-53 is the drying shrinkage relative humidity effect coefficient, and $\beta_{d s}\left(t-t_{c}\right)$ calculated by Equation 4-46 is the drying shrinkage time progress function,

$$
\varepsilon_{c d s o}\left(f_{c m 28}\right)=\left[\left(220+110 \alpha_{d s 1}\right) \exp \left(-\alpha_{d s 2} f_{c m 28} / f_{c m o}\right)\right] \times 10^{-6},
$$

where $\alpha_{d s 1}$ and $\alpha_{d s 2}$ recommended by the standard as 4 and 0.12 , respectively,

$$
\beta_{R H}(h)=\left\{\begin{array}{cr}
-1.55\left[1-\left(\frac{h}{h_{o}}\right)^{3}\right], 0.4 \leq h<0.99 \beta_{s 1} \\
0.25, & h \geq 0.99 \beta_{s 1}
\end{array}\right.
$$

where $h_{o}$ is recommended by the standard as $1, \beta_{s 1}$ calculated by Equation $4-54$ is the highperformance self-desiccation coefficient. 


$$
\beta_{s 1}=\left(\frac{3.5 f_{c m o}}{f_{c m 28}}\right)^{0.1} \leq 1
$$

\subsubsection{Creep Compliance}

The $J\left(t, t_{o}\right)$ was calculated by Equation 4-55 is the total stress-dependent strain by unit stress,

$$
J\left(t, t_{o}\right)=\frac{1}{E_{c m 28}}\left[\eta\left(t_{o}\right)+\Phi_{28}\left(t, t_{o}\right)\right]=\frac{1}{E_{c m t o}}+\frac{\Phi_{28}\left(t, t_{o}\right)}{E_{c m 28}}
$$

where $\Phi_{28}\left(t, t_{o}\right)$ calculated by Equation 4-57 is the coefficient of 28-day creep exempt from dimension, $\eta\left(t_{o}\right)$ calculated by Equation 4-56 is the 28 days concrete mean modulus of elasticity,

$$
\begin{aligned}
& \eta\left(t_{o}\right)=\frac{E_{c m 28}}{E_{c m t o}}, \\
& \Phi_{28}\left(t, t_{o}\right)=\Phi_{o} \beta_{c}\left(t-t_{o}\right),
\end{aligned}
$$

where $\Phi_{o}$ calculated by Equation 4-58 is the estimated creep coefficient and $\beta_{c}\left(t-t_{o}\right)$ calculated by Equation 4-64 is the creep progress coefficient,

$$
\Phi_{o}=\Phi_{R H}(h) \beta\left(f_{c m 28}\right) \beta\left(t_{o}\right),
$$

where,

$$
\begin{aligned}
& \Phi_{R H}(h)=\left[1+\frac{1-h / h_{o}}{\sqrt[3]{0.1\left\{(V / S) /(V / S)_{o}\right\}}} \alpha_{1}\right] \alpha_{2}, \\
& \beta\left(f_{c m 28}\right)=\frac{5.3}{\sqrt{f_{c m 28} / f_{c m o}}}
\end{aligned}
$$


$\beta\left(t_{o}\right)=\frac{1}{0.1+\left(t_{o} / t_{1}\right)^{0.2}}$

$\alpha_{1}=\left(\frac{3.5 f_{c m o}}{f_{c m 28}}\right)^{0.7}$

$\alpha_{2}=\left(\frac{3.5 f_{c m o}}{f_{c m 28}}\right)^{0.2}$

$\beta_{c}\left(t-t_{o}\right)=\left[\frac{\left(t-t_{o}\right) / t_{1}}{\beta_{h}+\left(t-t_{o}\right) / t_{1}}\right]^{0.3}$,

where,

$$
\beta_{h}=150\left[1+\left(1.2 h / h_{o}\right)^{18}\right](V / S) /(V / S)_{o}+250 \alpha_{3} \leq 1500 \alpha_{3}
$$

where,

$$
\alpha_{3}=\left(\frac{3.5 f_{c m o}}{f_{c m 28}}\right)^{0.5}
$$

If the elasticity modulus at an age other than 28 days $E_{c m t}$ needed, it might be calculated by Equation 4-67,

$$
E_{c m t}=E_{c m 28} \exp \left[\frac{s}{2}\left(1-\sqrt{\frac{28}{t / t_{1}}}\right)\right]
$$

where $s$ is recommended by the standard as 0.25 for this study,

$$
E_{c m 28}=3,118,310 \alpha_{E}^{3} \sqrt[3]{\frac{f_{c m 28}}{f_{c m o}}}
$$

where $\alpha_{E}$ is recommended by the standard as 0.9 for limestone aggregates, 
$f_{c m 28}=f_{c}^{\prime}+1160$,

where $f_{c}^{\prime}$ is the characteristic compressive cylinder strength (psi).

\subsubsection{GL2000 model}

The GL2000 model (2011) proposes a design-office procedure for predicting normal strength concrete's shrinkage and creep.

\subsubsection{Shrinkage}

The $f_{c m 28}$ was calculated by Equation $4-70$ is the 28 days concrete mean compressive strength,

$$
f_{c m 28}=1.1 f_{c}^{\prime}+700,
$$

where $f_{c}^{\prime}$ is the characteristic compressive strength. $E_{c m t}$ calculated by Equation $4-71$ is the modulus of elasticity,

$$
E_{c m t}=500,000+52,000 \sqrt{f_{c m t}},
$$

where $f_{c m t}$ calculated by Equation 4-72 is the strength development with time,

$$
f_{c m t}=\beta_{e}{ }^{2} f_{c m 28},
$$

where $\beta_{e}$ calculated by Equation 4-73 relates strength development to cement type,

$$
\beta_{e}=\exp \left[\frac{s}{2}\left(1-\sqrt{\frac{28}{t}}\right)\right],
$$

where $s$ is recommended by the standard as 0.4 for this study. $\varepsilon_{s h}\left(t, t_{c}\right)$ calculated by Equation 4-74 is the shrinkage strain, 


$$
\varepsilon_{s h}\left(t, t_{c}\right)=\varepsilon_{s h u} \beta(h) \beta\left(t-t_{c}\right),
$$

where $\varepsilon_{s h u}$ calculated by Equation 4-75 is the ultimate shrinkage strain, $\beta(h)$ calculated by Equation 4-76 is a correction term for the effect of humidity, $\beta\left(t-t_{c}\right)$ calculated by Equation 4-77 is a correction term for the drying time effect,

$$
\varepsilon_{\text {shu }}=900 k\left(\frac{4350}{f_{c m 28}}\right)^{0.5} \times 10^{-6}
$$

where $k$ is recommended by the standard as 0.75 for this study.

$$
\begin{aligned}
& \beta(h)=\left(1-1.18 h^{4}\right) \\
& \beta\left(t-t_{c}\right)=\sqrt{\frac{\left(t-t_{c}\right)}{\left(t-t_{c}\right)+77(V / S)^{2}}}
\end{aligned}
$$

\subsubsection{Creep Compliance:}

$$
J\left(t, t_{o}\right)=\frac{1}{E_{c m t o}}+\frac{\Phi_{28}\left(t, t_{o}\right)}{E_{c m 28}},
$$

where,

$$
\begin{aligned}
& \Phi_{28}\left(t, t_{o}\right)=\Phi\left(t_{c}\right)\left[2 \frac{\left(t-t_{o}\right)^{0.3}}{\left(t-t_{o}\right)^{0.3}+14}+\left(\frac{7}{t_{o}}\right)^{0.5}\left(\frac{\left(t-t_{o}\right)}{\left(t-t_{o}\right)+7}\right)^{0.5}+2.5(1-\right. \\
& \left.\left.1.086 h^{2}\right)\left(\frac{\left(t-t_{o}\right)}{\left(t-t_{o}\right)+77(V / S)^{2}}\right)^{0.5}\right] .
\end{aligned}
$$

The numeric examples in ACI 209 (ACI Committee 209 2008) shown in Figure 4-16 and Figure 4-17 were built in Excel, shown in Figure 4-18 and Figure 4-19. Then, 50\% slag 1,30\% fly ash 1 mix design, and specimen inputs were inserted to calculate predictions of the test results. 
Comparisons of predictions and test results are illustrated in Figure 4-23, Figure 4-24, Figure 4-25, and Figure 4-26, respectively.

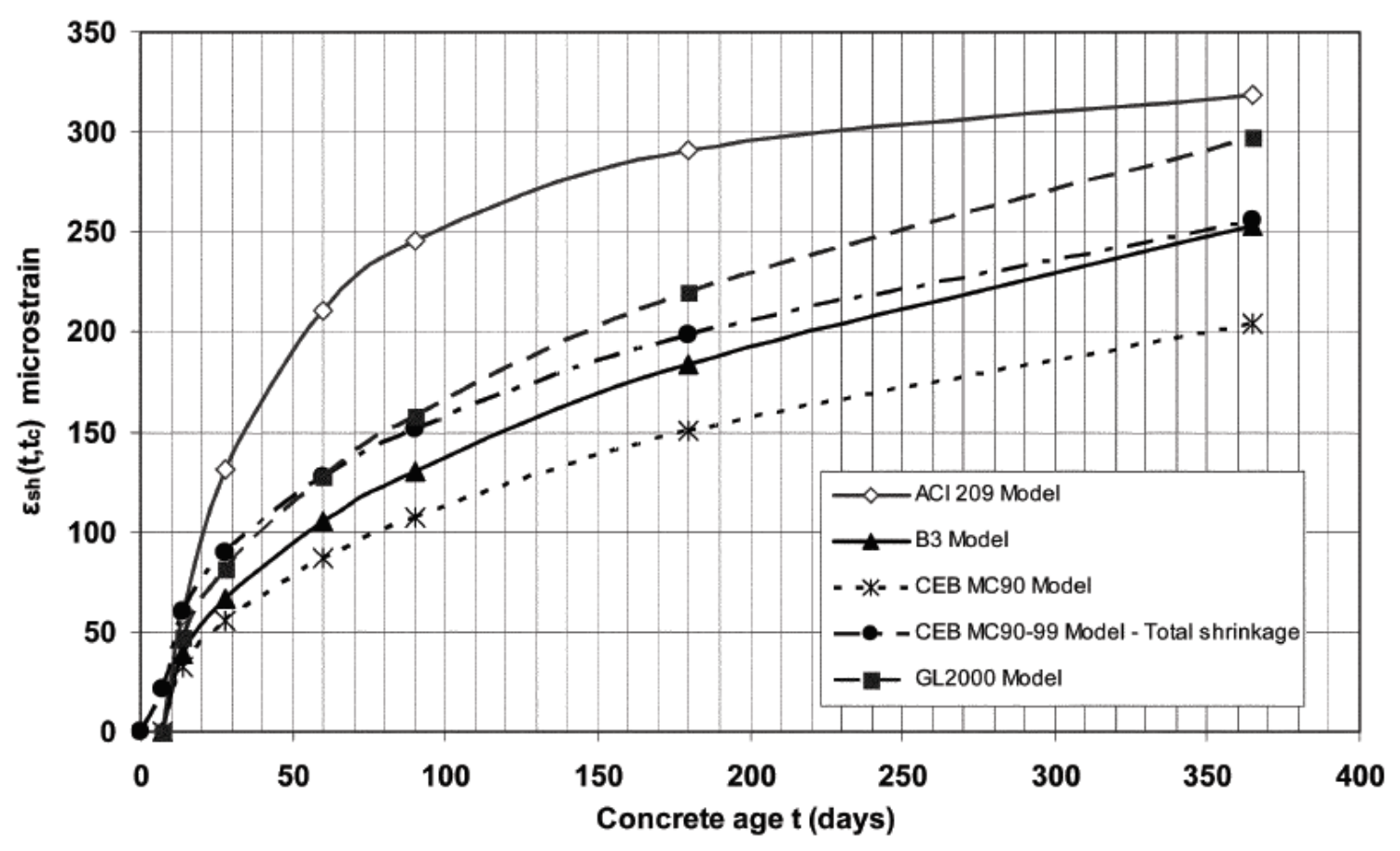

Figure 4-16: Authorized reprint of shrinkage strain predictions of numeric examples from ACI 209 (ACI Committee 209 2008). 


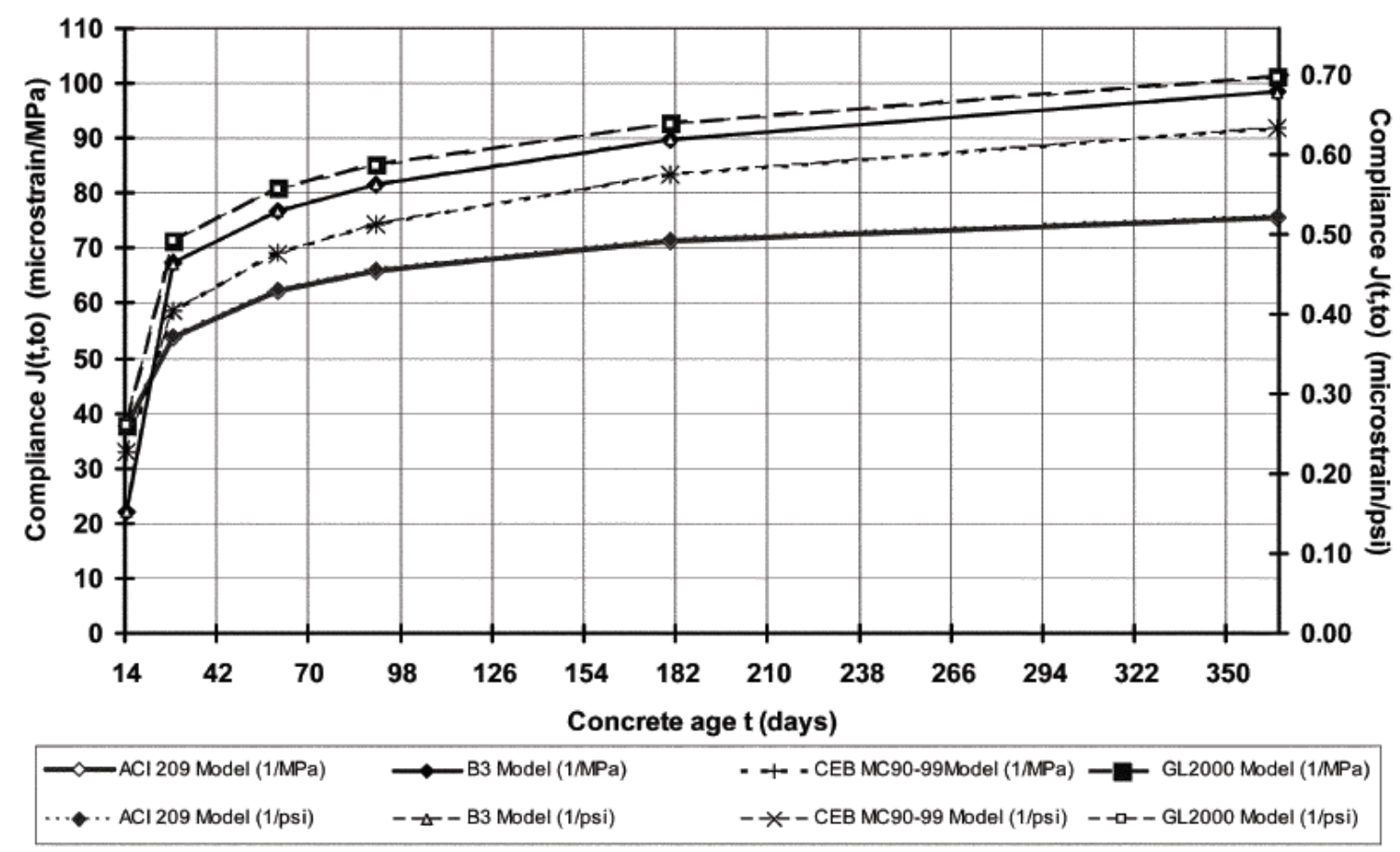

Figure 4-17: Authorized reprint of compliance predictions of numeric examples from ACI 209 (ACI Committee 209 2008).

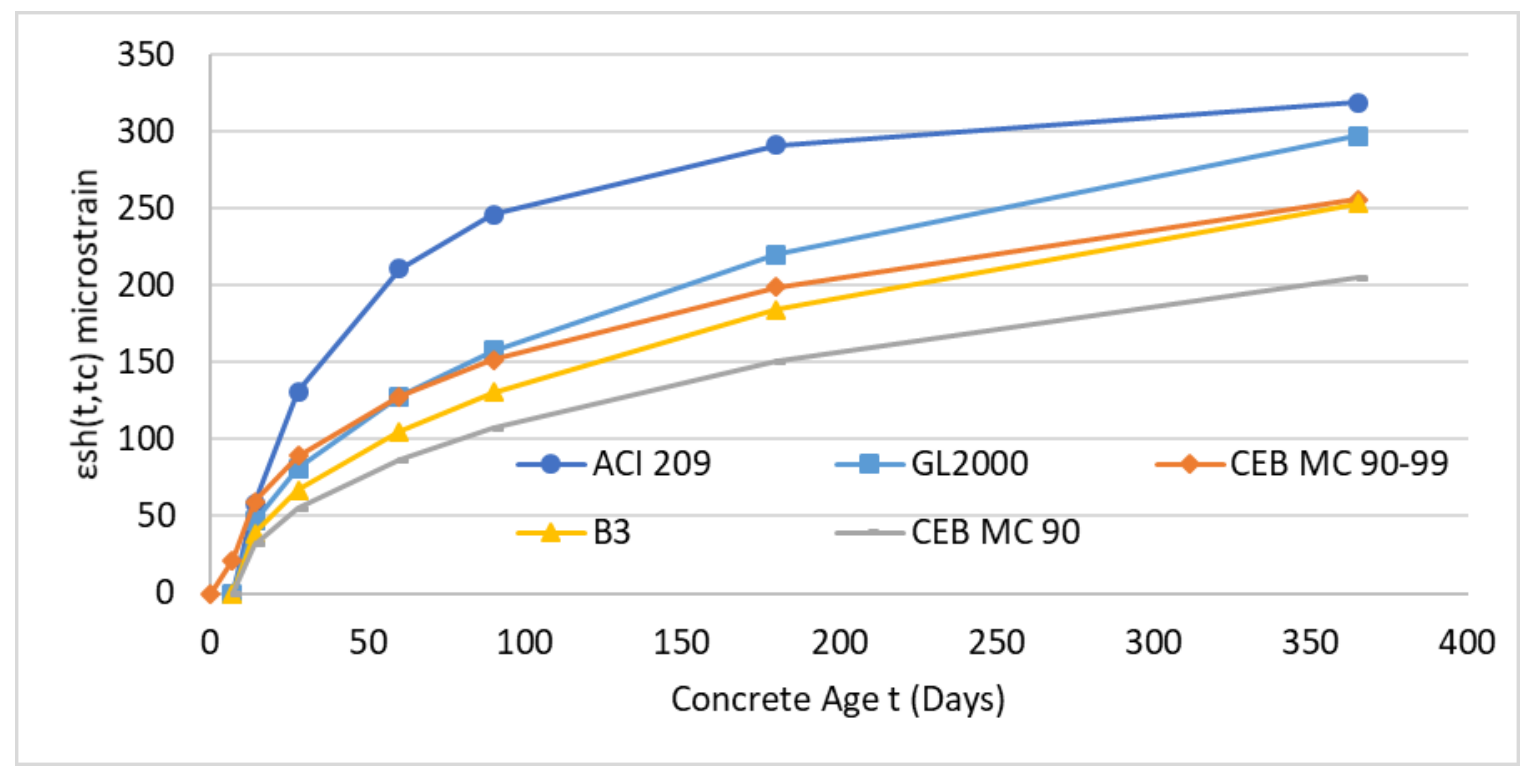

Figure 4-18: Shrinkage strain predictions of numeric examples of ACI 209 document (ACI Committee 209 2008) were built in the Excel. 


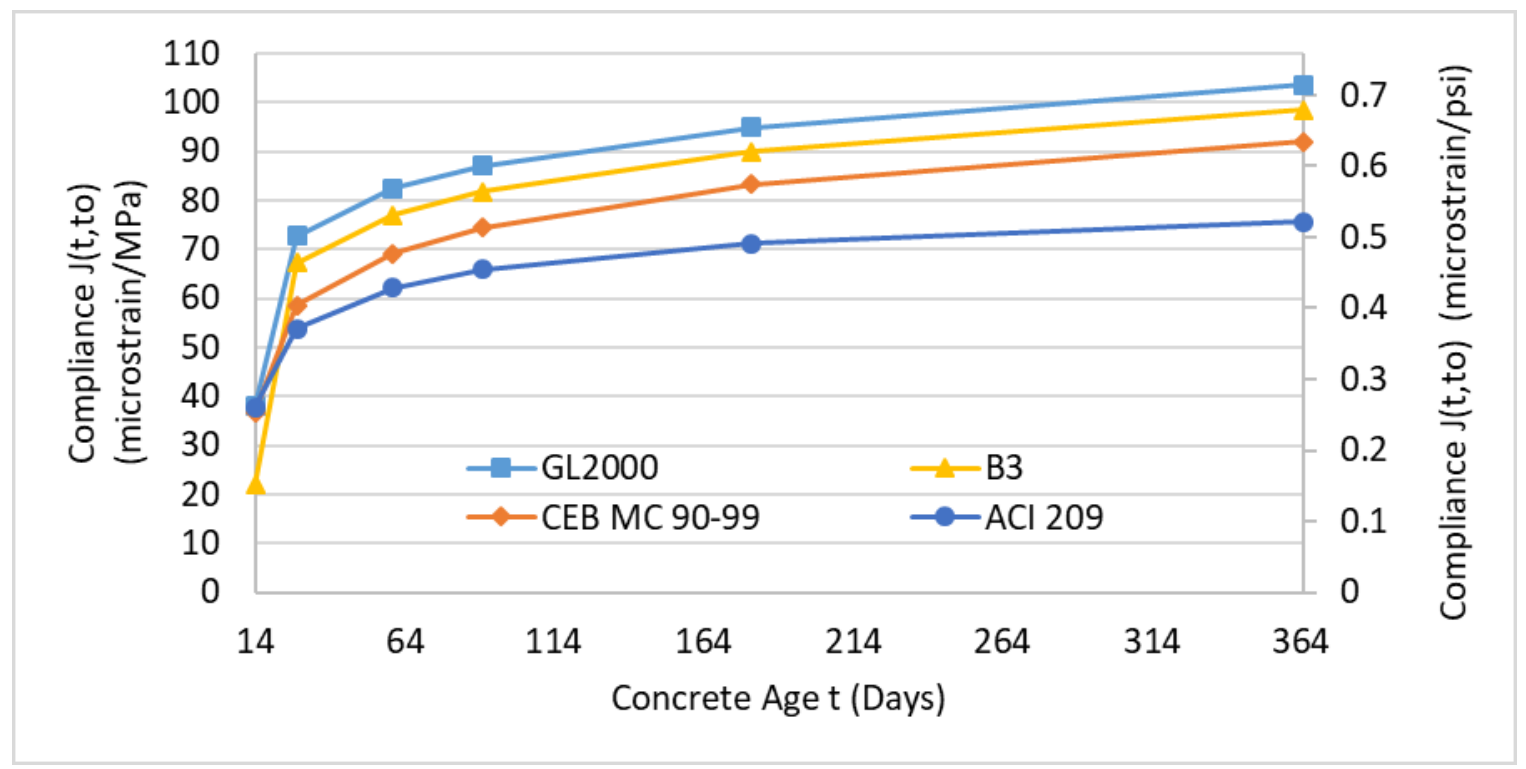

Figure 4-19: Compliance predictions of numeric examples of ACI 209 document (ACI Committee 209 2008) were built in the Excel.

To check the validity of the models, they first compared to an OPC mix design, which was cast in the WVDOH RP312 research project. The OPC mix design properties and input parameters are shown in Table 4-3. Comparisons of the predictions, and the test results of the OPC mix are shown in Figure 4-20 and Figure 4-21, respectively. Comparison of the shrinkage test results of $50 \%$ slag 1, 30\% fly ash 1 and the OPC mixes are shown in Figure 4-22.

Table 4-3: The OPC mix design properties and input parameters.

\begin{tabular}{|c|c|c|c|c|c|}
\hline \multirow{3}{*}{$\frac{\text { Materials }}{\text { c }}$} & \multicolumn{5}{|c|}{ OPC } \\
\hline & \multirow{2}{*}{$\begin{array}{c}\left.\text { (lb./yd }{ }^{\mathbf{3}}\right) \\
564\end{array}$} & \multirow{2}{*}{$\begin{array}{c}\mathbf{( k g / \mathbf { m } ^ { \mathbf { 3 } } )} \\
335\end{array}$} & \multicolumn{3}{|c|}{ Input parameters } \\
\hline & & & \multirow{2}{*}{$\mathbf{f}_{\mathbf{c}^{\prime}}$} & \multirow{2}{*}{3987 (psi) } & \multirow{2}{*}{$27(\mathrm{MPa})$} \\
\hline $\mathbf{w}$ & 282 & 167 & & & \\
\hline $\mathbf{a} / \mathbf{c}$ & \multicolumn{2}{|c|}{5.418} & \multirow{2}{*}{ h } & \multirow{2}{*}{\multicolumn{2}{|c|}{0.5}} \\
\hline$\psi$ & \multicolumn{2}{|c|}{41.9} & & & \\
\hline Measured w/c & \multicolumn{2}{|c|}{0.5} & \multirow{2}{*}{$\mathbf{s}$} & \multirow{2}{*}{5 (in) } & \multirow{2}{*}{$127(\mathrm{~mm})$} \\
\hline$\gamma_{c}$ & 3895.6 & 2311.2 & & & \\
\hline
\end{tabular}




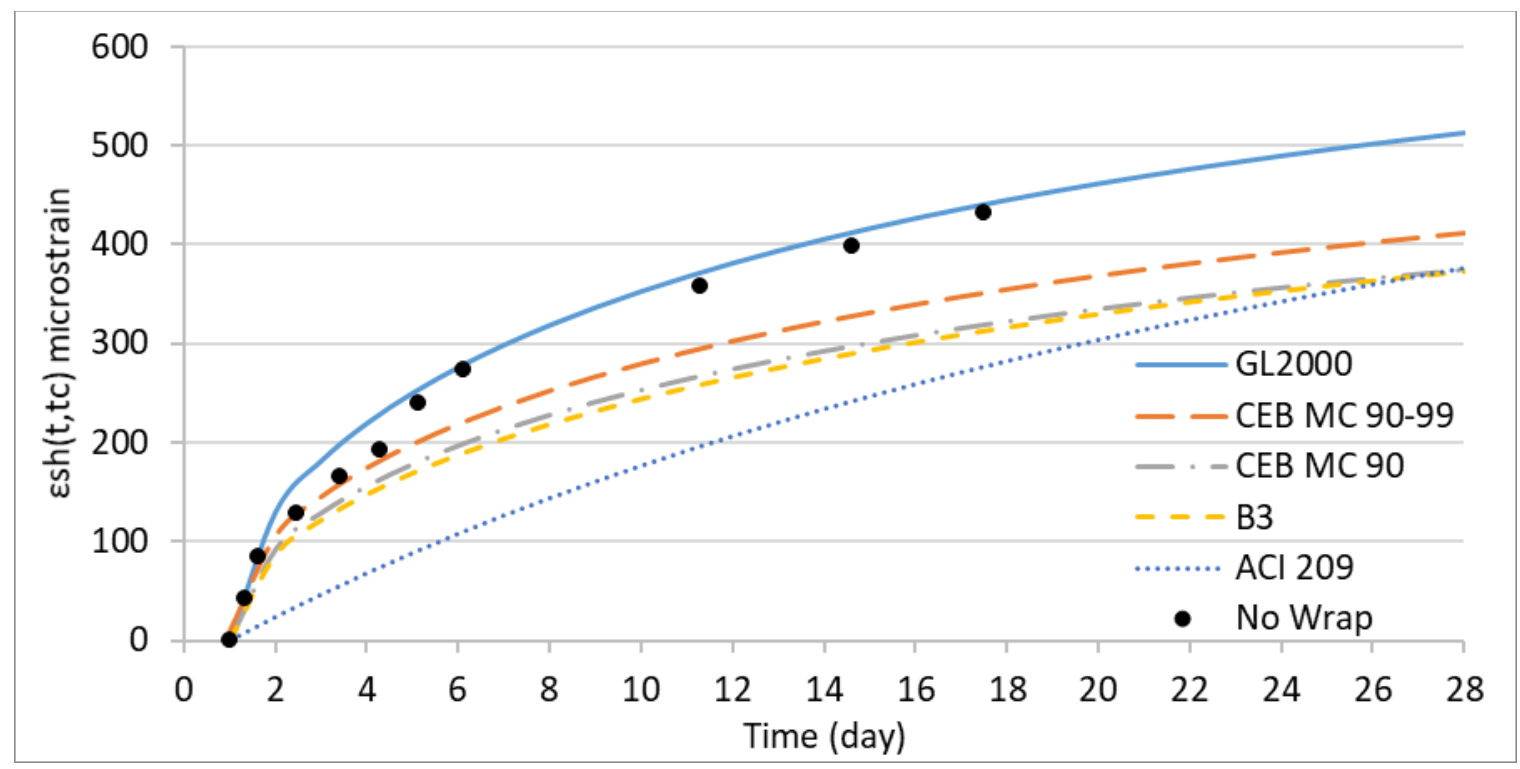

Figure 4-20: Comparison of the OPC shrinkage test results and predictions.

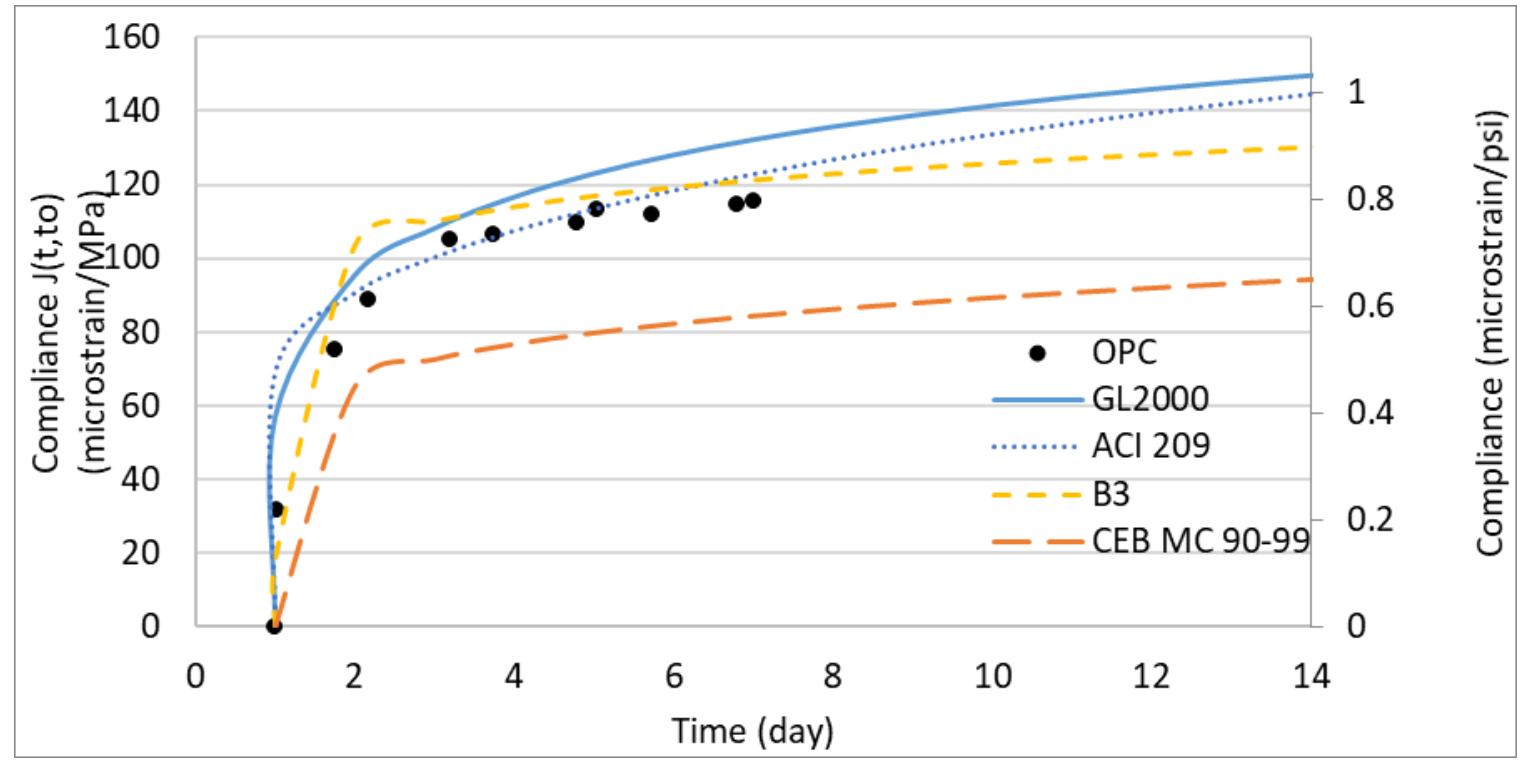

Figure 4-21: Comparison of the OPC compressive creep test results and predictions. 


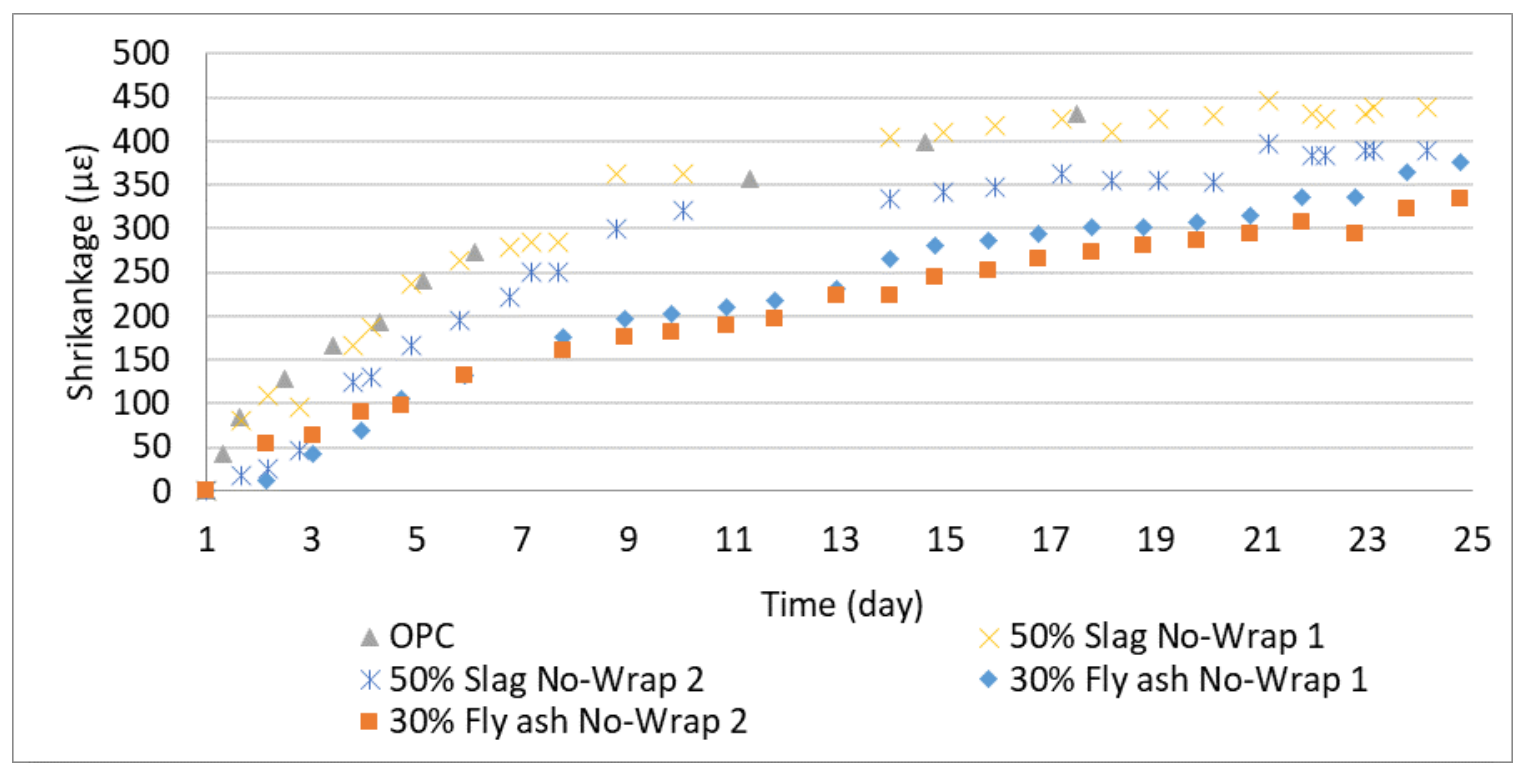

Figure 4-22: Comparison of the shrinkage test results of 50\% slag $1,30 \%$ fly ash 1 and the OPC mixes.

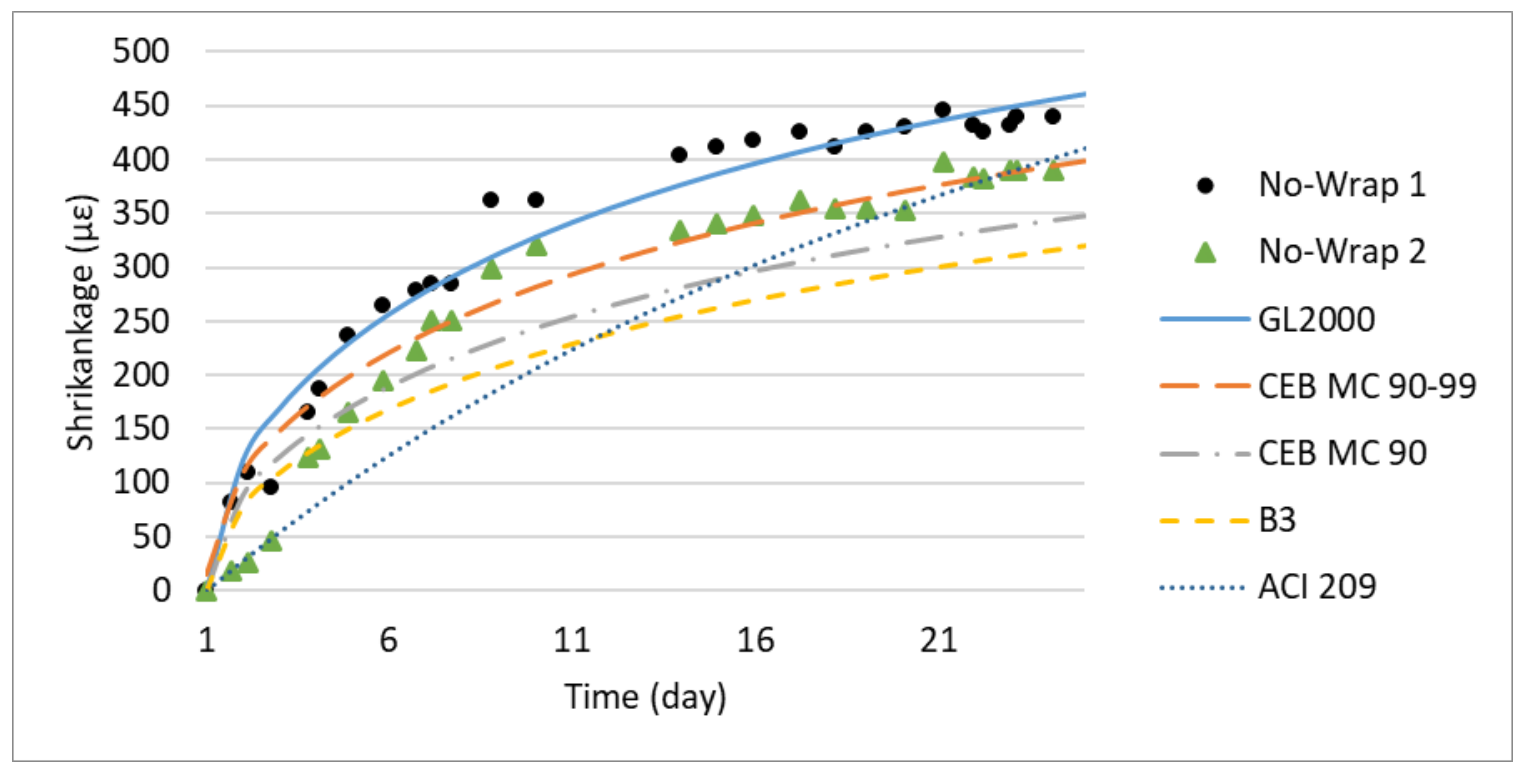

Figure 4-23: Comparison of 50\% slag 1 shrinkage test results and predictions. 


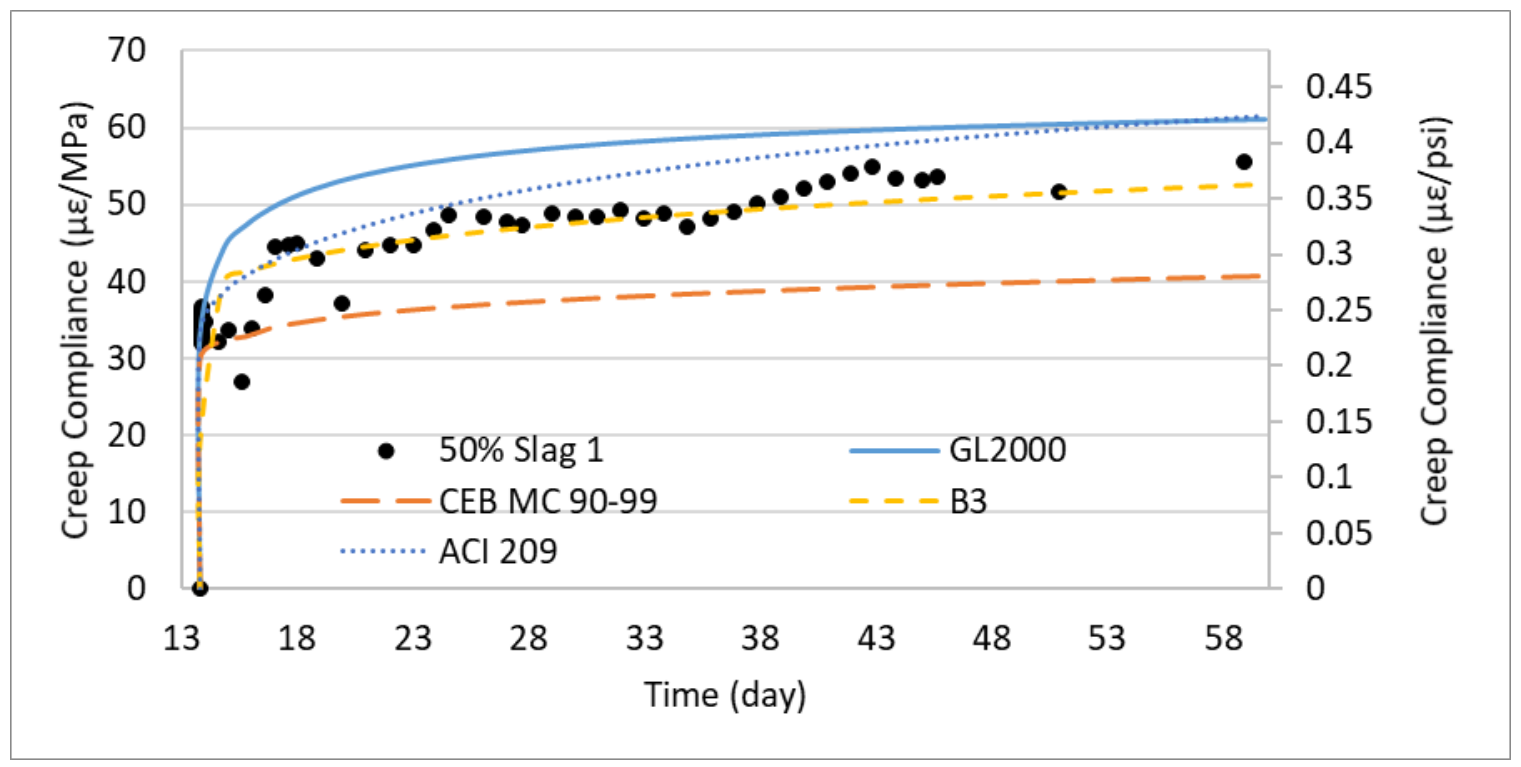

Figure 4-24: Comparison of 50\% slag 1 compressive creep test result and predictions.

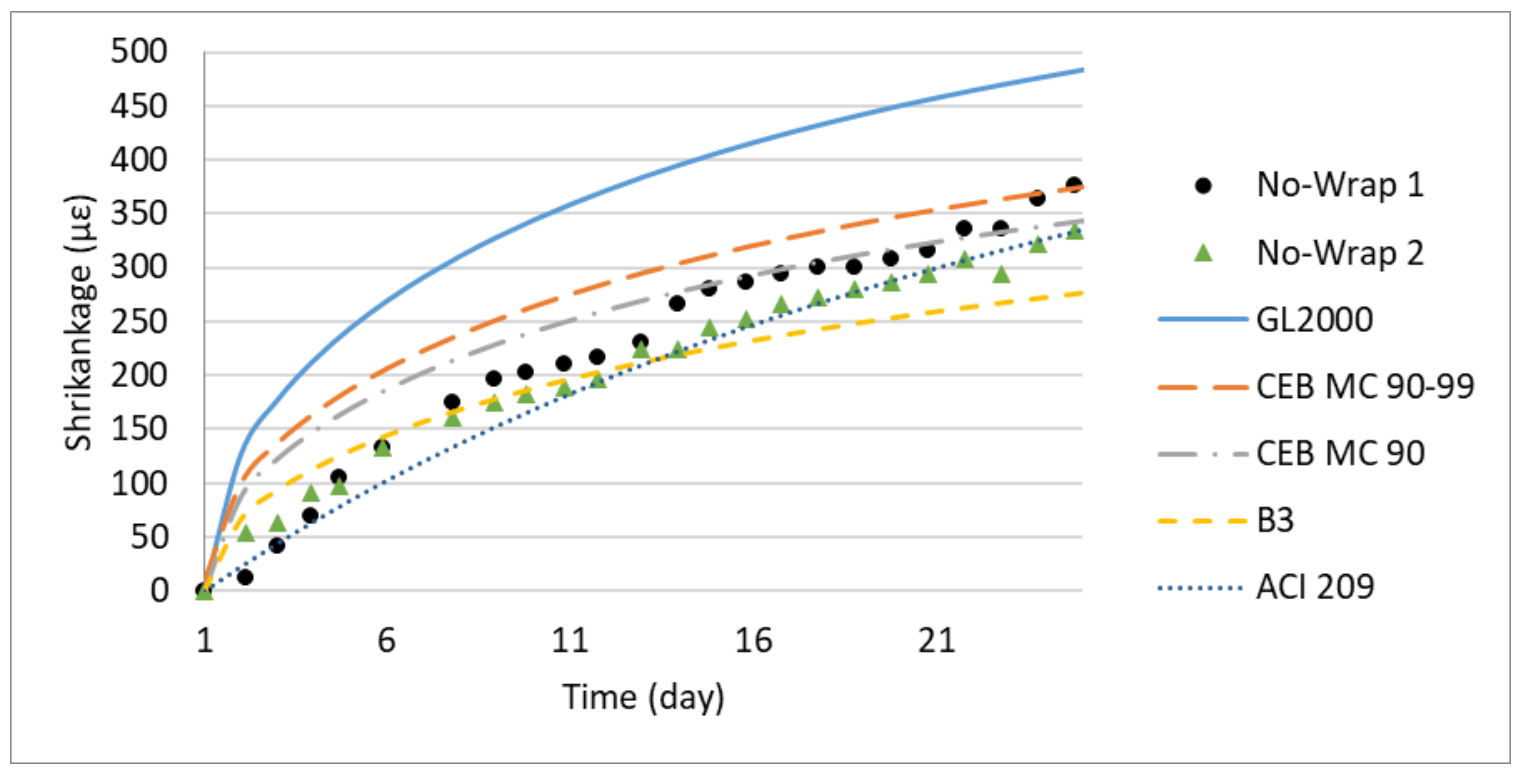

Figure 4-25: Comparison of 30\% fly ash 1 shrinkage test results and predictions. 


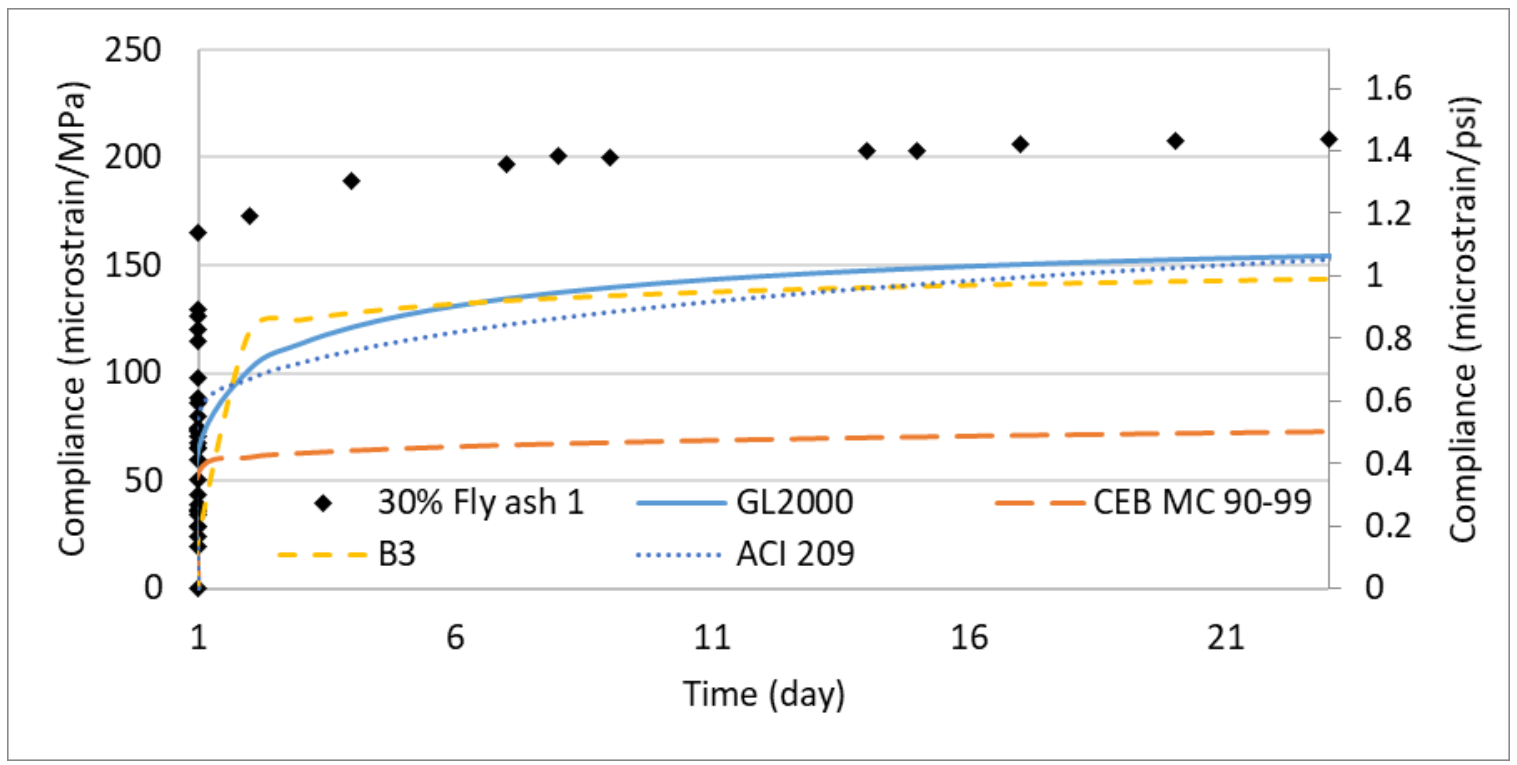

Figure 4-26: Comparison of 30\% fly ash 1 compressive creep test result and predictions.

\subsection{Conclusions}

$50 \%$ slag 1 shrinkage test results appeared to fall within the range of the predictions of GL2000 and CEB MC 90-99 models. 50\% slag 1 compressive creep test results appeared to fall within the range of the predictions of the $\mathrm{B} 3$ model.

$30 \%$ fly ash 1 shrinkage test results appeared to fall within the range of predictions of the ACI 209 method; however, compressive creep test results failed to appear to fall within the range of any prediction, possibly due to first-day loading.

The OPC shrinkage test results appeared to fall within the range of predictions of the GL2000 model. The OPC shrinkage test results appeared to compare closely with 50\% slag nowrap 1's. The OPC compressive creep test results appeared to fall within the range of predictions of the B3 model. 


\section{Chapter 5 : Measurement of Adiabatic Temperature Rise}

\subsection{Experimental Setups}

The first design of the semi-adiabatic device from inside consists of a 10 -in by 10 -in (25.4cm by $25.4-\mathrm{cm}$ ) cylindrical specimen cast inside and covered by a plastic bag, an insulated plastic cooler jug, and six layers of 1-in $(2.54-\mathrm{cm})$ thick extruded polystyrene (XPS) insulation. The gap between the insulated plastic cooler jug and the XPS insulation board was filled with thermal fiberglass insulation wool. The device was separated from the ground by 2 -in by 4 -in $(5.08$-cm by 10.16-cm) woods placed horizontally with another layer of 1 -in $(2.54-\mathrm{cm})$ thick XPS insulation to prevent heat loss to the ground. The plastic bag was sealed with duct tape. The casting was made with a K-type thermocouple inserted at the center of the specimen. Temperature time histories were recorded with an Omega RDXL4SD 4-Channel datalogger thermometer connecting which had an accuracy of $\pm\left(0.4 \%+1{ }^{\circ} \mathrm{F}\right)\left[ \pm\left(0.4 \%+0.5^{\circ} \mathrm{C}\right)\right]$. The ambient temperature was measured with another K-type thermocouple connected to the digital thermometer. The temperatures of the two locations mentioned above were recorded for 7-days. The center and ambient temperatures were recorded at intervals of 5-minutes. The Omega RDXL4SD 4-Channel datalogger thermometer is shown in Figure 5-1. The device with the lid opened is shown in Figure 5-2. 


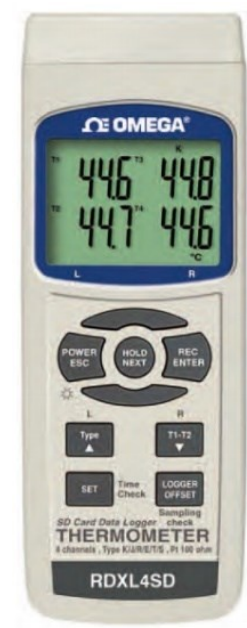

Figure 5-1: Omega RDXL4SD 4-channel datalogger thermometer.

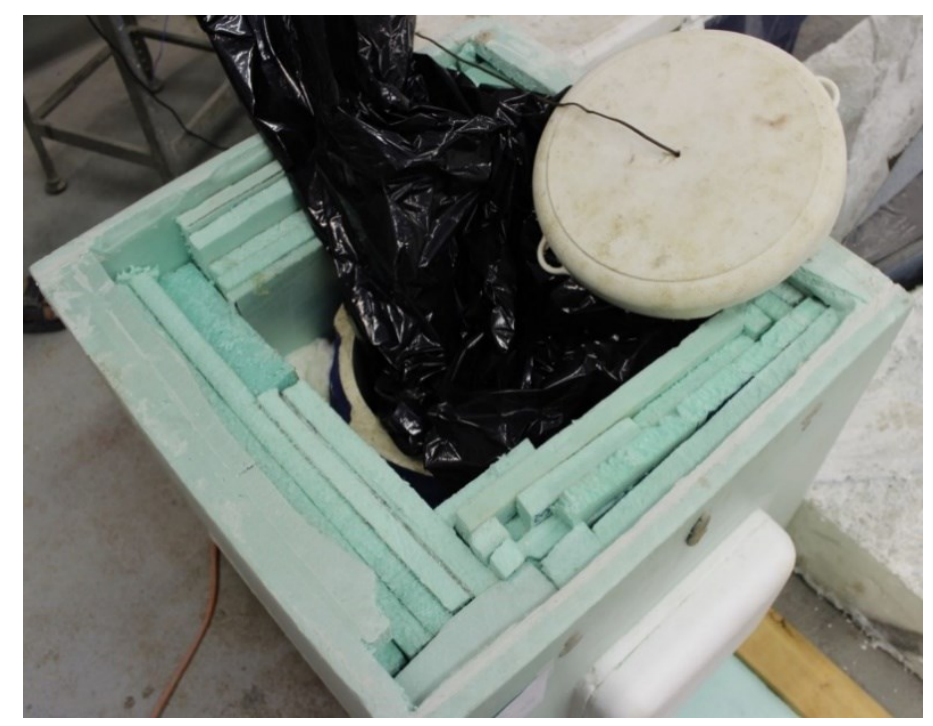

Figure 5-2: The first design of the semi-adiabatic device.

The second design of the semi-adiabatic device consists of a 20 -in $(50.8-\mathrm{cm})$ cube concrete specimen cast inside and covered by a double plastic wrap, three layers of 2 -in $(5.08-\mathrm{cm})$ thick extruded polystyrene (XPS) insulation, and 0.688-in $(1.748-\mathrm{cm})$ thick plywood. The selected XPS insulation was Type-IV in the ASTM C578 classification. There were also 2-in by 4-in (5.08-cm by $10.16-\mathrm{cm}$ ) wooden belt supporting the system from the sides at the middle of the plywood cover. The device was separated from the ground with three 2 -in by 4 -in $(5.08-\mathrm{cm}$ by $10.16-\mathrm{cm})$ 
placed under the system vertically and with 2 -in $(5.08-\mathrm{cm})$ thick XPS insulation in between to prevent heat loss to the ground. The plastic wraps were sealed with duct tape. The casting was made with three K-type thermocouples fixed at three locations: (1) center of specimen, (2) center of a side face, and (3) a top corner using metal frames and zip ties. XPS insulation was put together with construction adhesive to maintain stability and to have no air gaps between layers. Temperature time histories were recorded with an Omega RDXL4SD 4-Channel datalogger thermometer. The ambient temperature was measured with another K-type thermocouple connected to the digital thermometer. The temperatures of the four locations mentioned above were recorded for 14-days. The inside of the device and the schematic drawing from a vertical viewpoint is shown in Figure 5-3 and Figure 5-4, respectively.
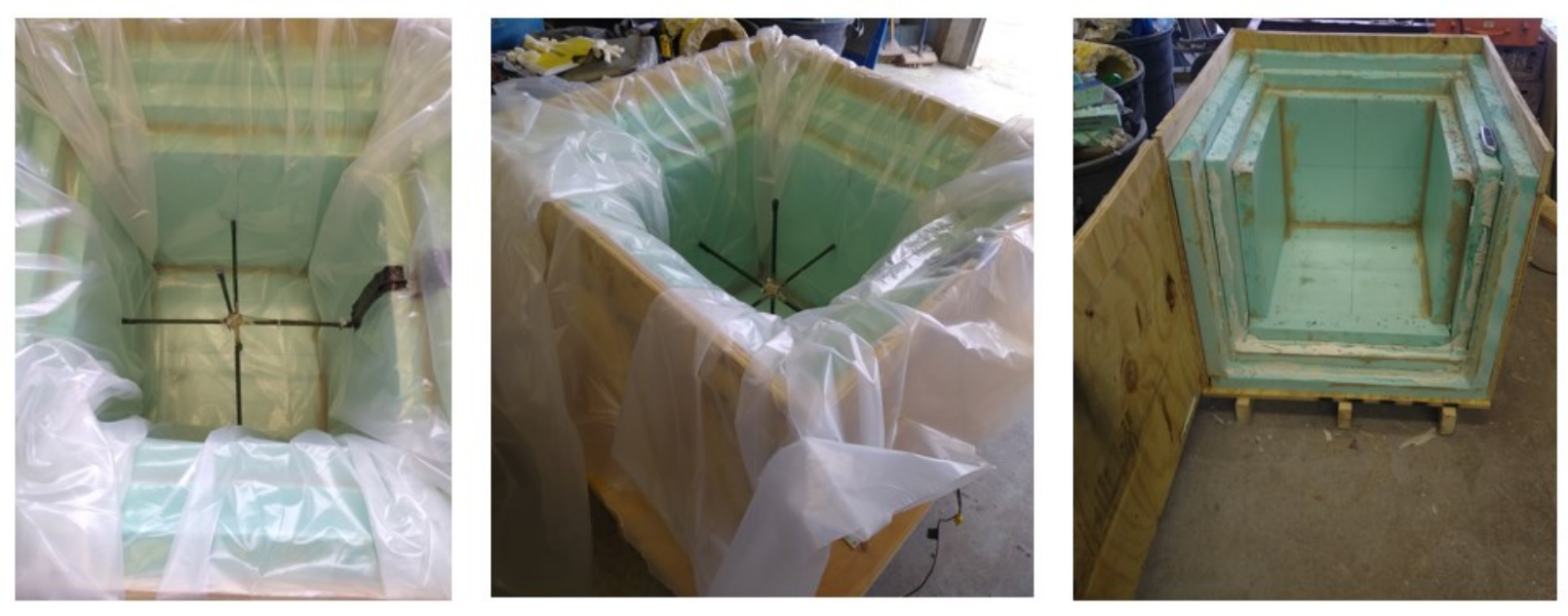

Figure 5-3: The second semi-adiabatic device with the lid opened in the first two pictures and one side opened in the right picture. 


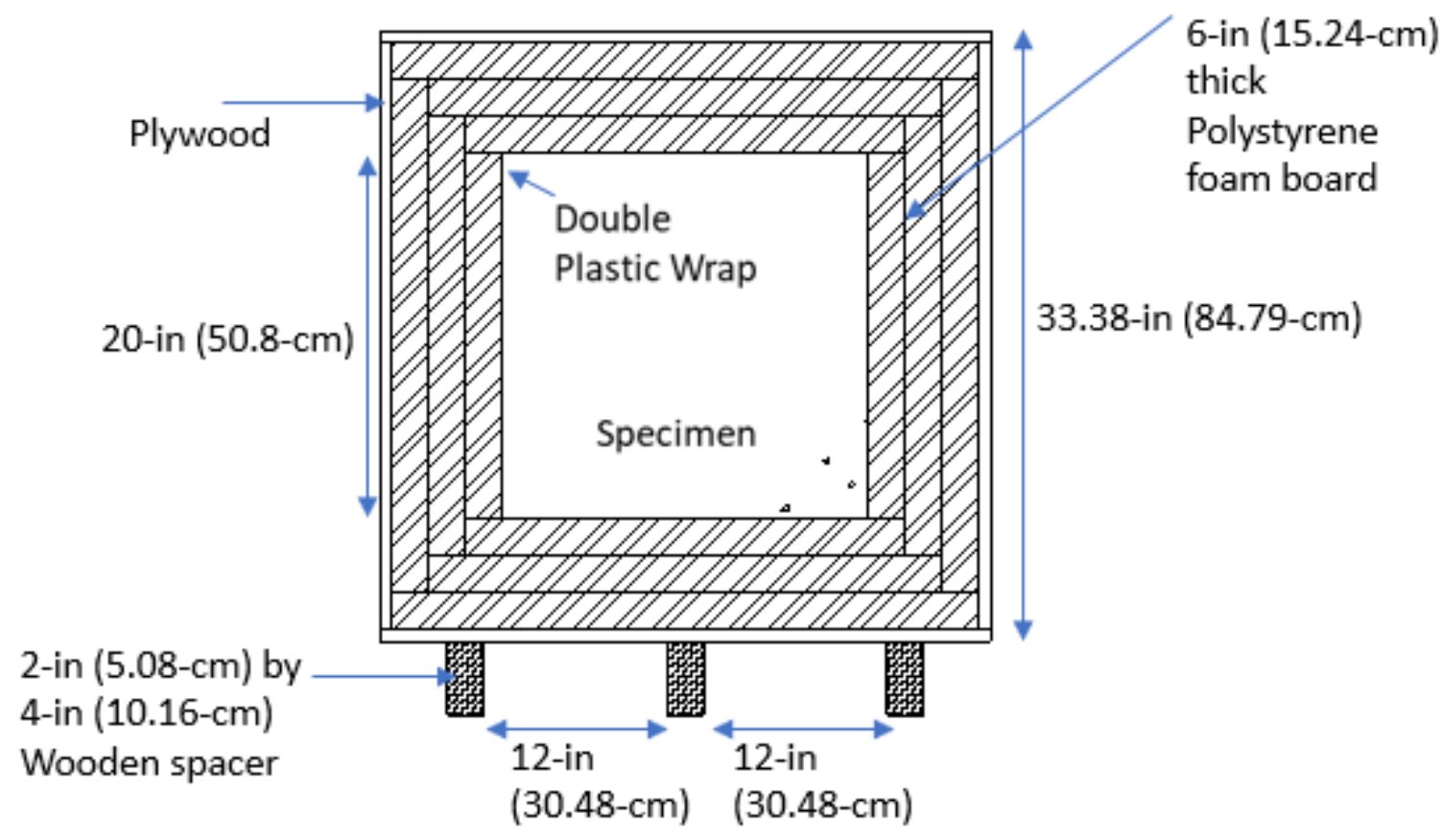

Figure 5-4: Insulated mold for 20 -in $(50.8-\mathrm{cm})$ cube specimen.

\subsection{Calculations}

The analysis of the results from semi-adiabatic tests can be done with the following equations provided by $\mathrm{Ng}$ et al. (P. L. $\mathrm{Ng} 2008$ ). $T_{V}-T_{P}$ calculated by Equation $5-1$ is the difference between volumetric mean and placing temperatures,

$$
T_{V}-T_{P}=T_{G}-\frac{H_{L}}{V \rho c}
$$

where $V$ is the specimen volume, $T_{G}$ calculated by Equation 5-2 is the adiabatic temperature rise, $H_{L}$ calculated by Equation 5-4 with integrating Equation 5-3 and substituting it in Equation 5-1 is the heat loss, $\rho$ is the mass density, and $c$ is the specific heat capacity.

$$
T_{G}=\left(T_{V}-T_{P}\right)+\frac{H_{L}}{V \rho c}
$$

$\partial \mathrm{H}_{\mathrm{L}}$ calculated by Equation 5-3 is the heat loss rate determined by applying Fourier Law (Holman 2010), 


$$
\frac{\partial H_{L}}{\partial t}=k\left(T_{S}-T_{A}\right)
$$

where $k$ is the overall thermal conductivity of the insulating materials, $T_{S}$ is the surface mean temperature of the specimen, $T_{A}$ is the ambient temperature, and $t$ is the time passed after the casting.

$$
H_{L}=k \int_{0}^{t}\left(T_{S}-T_{A}\right) d t
$$

$T_{G}$ can be Equation 5-5 by substituting Equation 5-4 into Equation 5-2 and denominating $\frac{k}{V \rho c}$ into $\lambda$,

$$
T_{G}=\left(T_{V}-T_{P}\right)+\lambda \int_{0}^{t}\left(T_{S}-T_{A}\right) d t, \lambda=\frac{k}{V \rho c},
$$

where $\lambda$ calculated by Equation $5-6$ is the heat loss characteristic $(1 / \mathrm{sec})$ because after very longtime, heat generation stops, and adiabatic temperature rise becomes stable so $\frac{\partial T_{G}}{\partial t}$ considered zero.

$$
\frac{\partial T_{G}}{\partial t}=\frac{\partial T_{V}}{\partial t}+\lambda\left(T_{S}-T_{A}\right), \quad \lambda=\frac{\frac{\partial T_{V}}{\partial t}}{\left(T_{S}-T_{A}\right)}
$$

Volumetric mean temperature and surface temperature $\left(T_{S}\right)$ calculated by Equation 5-7,

$$
T_{V}=\frac{1}{V} \int_{V} T(x, y, z) d V, T_{S}=\frac{1}{A} \int_{A} T(x, y, z) d A,
$$

where $A$ is the concrete surface area, $(x, y, z)$ is the spatial coordinates. After integrating Equation 5-5, $T_{G}$ becomes Equation 5-8, 


$$
T_{G}=\left(T_{V}-T_{P}\right)+\lambda\left(\sum_{i=1}^{n}\left(T_{S}-T_{A}\right)_{i} \Delta t_{i}\right),
$$

where, $\Delta \mathrm{t}_{i}$ is the time interval at time step $i$, and $n$ is the number of time steps. The temperaturetime histories of the 10-in $(25.4-\mathrm{cm})$ cylinder specimen cast from 50\% slag 1 are shown in Figure $5-5$.

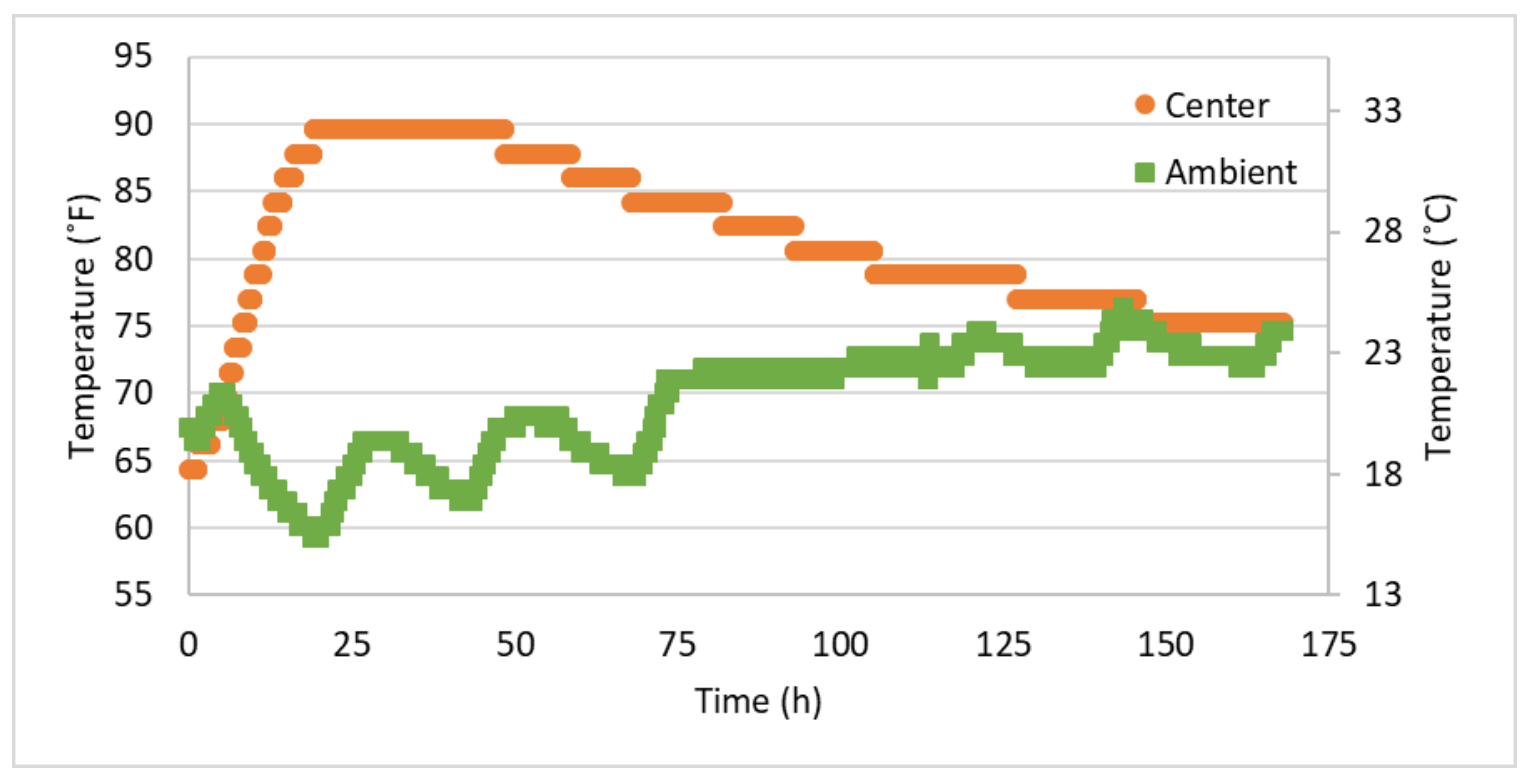

Figure 5-5: Temperature-time history of 10-in (25.4-cm) cylinder specimen cast from 50\% slag 1.

The casting of $30 \%$ fly ash 2 in the second design of the semi-adiabatic device was made with three thermocouples inserted at locations center of specimen, the center of a side face, and a top corner to see if there are much difference or not. Test results show that the maximum difference happens between specimen center and corner, and the value was $3.8^{\circ} \mathrm{F}\left(6.84{ }^{\circ} \mathrm{C}\right)$. Hence, it was a neglectable value; only the center (1-point) was used to calculate the heat loss compensation. Temperature-time histories of the 20 -in $(50.8-\mathrm{cm})$ cube specimen cast from $30 \%$ fly ash 2 are shown in Figure 5-6. 


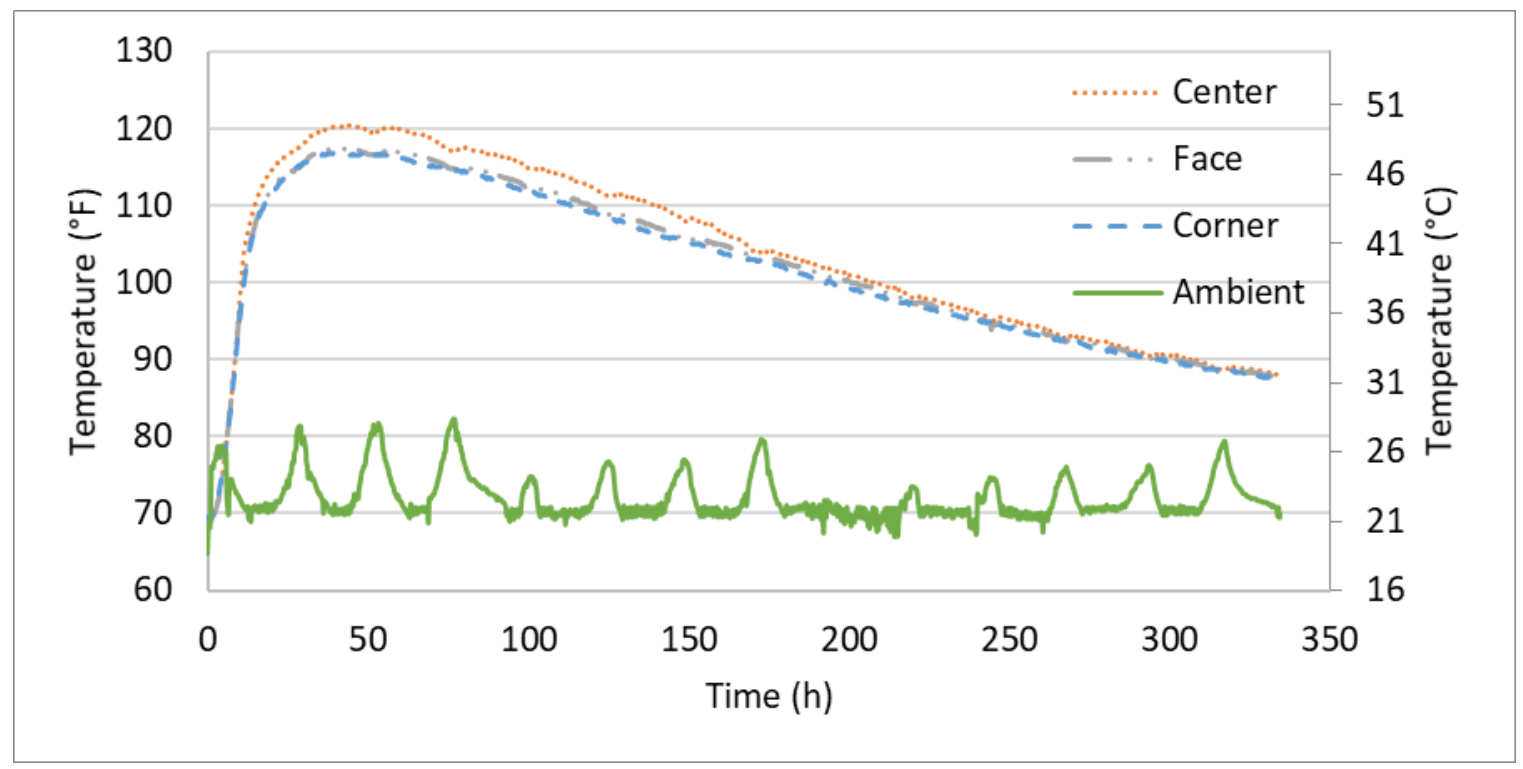

Figure 5-6: Temperature-time history of 20 -in $(50.8-\mathrm{cm})$ cube specimen cast from $30 \%$ fly ash 2.

The adiabatic temperature rise of concrete mixes was also measured using an adiabatic calorimeter. The adiabatic calorimeter (Lin and Chen 2015) was developed by using the concept described by (Gibbon, Ballim, and Grieve 1997), which limits the heat exchange between the concrete and the environment to determine the ATR of the specimen. The ATR measurements obtained from the adiabatic calorimeter and heat loss compensations calculated from the semiadiabatic device are shown in Figure 5-7 and Figure 5-8. The average value of $\lambda$ calculated within the time period of 120 to 144 hours after casting in the calculation of 50\% slag 1 and $30 \%$ fly ash 2 heat loss compensation shown in Table 5-1. The heat loss characteristic can be calculated by Equation 5-9. The heat loss characteristic ranges and effecting values taken into consideration of both mixes shown in Table 5-2. As shown in Figure 5-7, the heat loss compensated ATR is much less than the ATR obtained from the calorimetry. Therefore, the first semi-adiabatic design using the 10-in (25.4-cm) cylindrical specimen is not acceptable. However, Figure 5-8 shows that both heat loss compensated ATR and the calorimetry compare well. Therefore, the second semiadiabatic calorimetry design can be an acceptable method to measure the ATR of a concrete mix. 
Table 5-1: Comparison of average $\lambda$ 's calculated with literature recommendation.

\begin{tabular}{|c|c|c|}
\hline Design No & Average $\lambda\left(\mathrm{hr}^{-1}\right)$ & Max $\lambda\left(\mathrm{hr}^{-1}\right)$ from Ng et al. (P. L. Ng 2008) \\
\hline $1^{\text {st }}$ & $\mathbf{0 . 0 1 2 4 8 1 7 1 1}$ & $>7.848 \times \mathbf{1 0}^{-3}$ \\
\hline $2^{\text {nd }}$ & $\mathbf{0 . 0 0 4 4 1 6 6 6 7}$ & $<7.848 \times 10^{-3}$ \\
\hline
\end{tabular}

$$
\lambda=\left(\frac{T_{V_{n+1}}-T_{V_{n}}}{t_{n+1}-t_{n}}\right) /\left(T_{V_{n}}-T_{A_{n}}\right)
$$

Table 5-2: The heat loss characteristic ranges and effecting values taken into consideration of both mixes.

\begin{tabular}{|c|c|c|c|c|c|c|c|c|c|c|c|c|}
\hline \multirow{2}{*}{$\begin{array}{c}\text { Design } \\
\text { No }\end{array}$} & $\operatorname{Max} \lambda$ & $\operatorname{Min} \lambda$ & \multicolumn{2}{|c|}{$T_{V_{\max }}$} & \multicolumn{2}{|c|}{$T_{V_{\min }}$} & \multicolumn{2}{|c|}{$T_{A_{\max }}$} & \multicolumn{2}{|c|}{$T_{A_{\text {min }}}$} & $t_{\max }$ & $t_{\min }$ \\
\hline & \multicolumn{2}{|c|}{$\left(h^{-1}\right)$} & $\left({ }^{\circ} \mathbf{F}\right)$ & $\left({ }^{\circ} \mathrm{C}\right)$ & $\left({ }^{\circ} \mathbf{F}\right)$ & $\left({ }^{\circ} \mathrm{C}\right)$ & $\left({ }^{\circ} \mathrm{F}\right)$ & $\left({ }^{\circ} \mathrm{C}\right)$ & $\left({ }^{\circ} \mathrm{F}\right)$ & $\left({ }^{\circ} \mathrm{C}\right)$ & \multicolumn{2}{|c|}{ (h) } \\
\hline $1^{\text {st }}$ & 3.607214 & 0 & 78.8 & 26 & 77 & 25 & 76.4 & 24.7 & 71.9 & 22.2 & 144 & 120 \\
\hline $2^{\text {nd }}$ & 0.042431 & -0.035517 & 108.9 & 42.7 & 101.8 & 38.8 & 79.7 & 26.5 & 67.4 & 19.7 & 193 & 145 \\
\hline
\end{tabular}

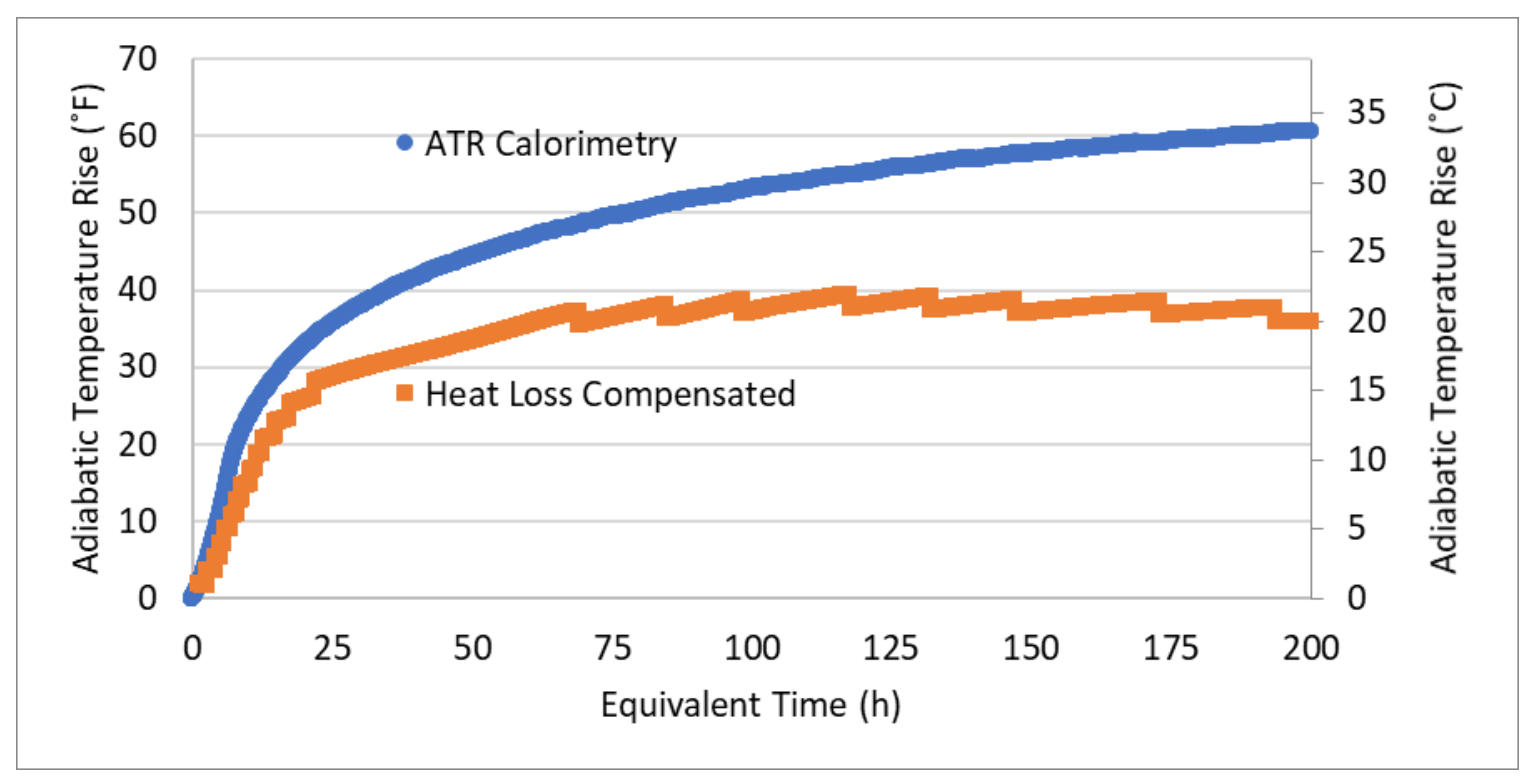

Figure 5-7: Comparison of the semi-adiabatic device and ATR calorimetry of 50\% slag 1. 


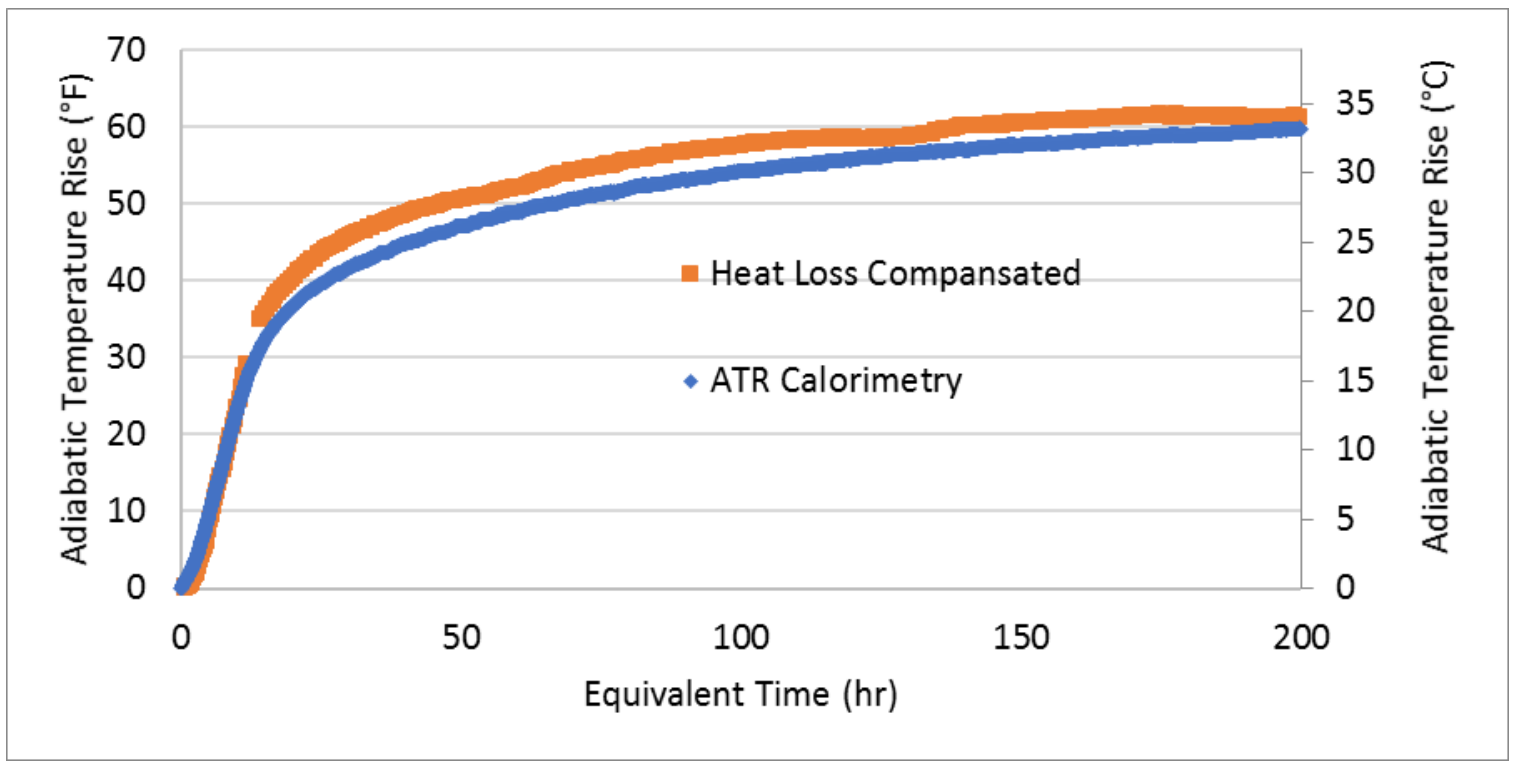

Figure 5-8: Comparison of the semi-adiabatic device and ATR calorimetry of $30 \%$ fly ash 2.

\subsection{Conclusions}

The second semi-adiabatic design compares better with the ATR calorimetry. The leading causes of the failure of the first semi-adiabatic design may be caused by the relatively small specimen size [10-in $(25.4-\mathrm{cm})$ diameter cylinder] and using fragmental XPS with significant air gaps. Its heat loss characteristic value failed to stay below the recommended value. However, the second semi-adiabatic design's heat loss characteristic value was below the recommended value, possibly due to the larger specimen size $[20$-in $(50.8-\mathrm{cm})$ cube] and more intact XPS leaving fewer air gaps. 


\section{Chapter 6 : Measurement of Thermal Conductivity}

\subsection{Thermal conductivity of concrete materials}

After 28 days of curing, those two 6-inch $(15.24-\mathrm{cm}$ diameter) by 12 -inch $(30.48-\mathrm{cm}$ height) cylinders that were used to measure the static elastic modulus were used to measure the thermal conductivity for either $50 \%$ slag or $30 \%$ fly ash mix. The cylinders were first drilled using a 3/8-in $(0.9525-\mathrm{cm})$ drill bit with a height of 6-in $(15.24-\mathrm{cm})$ with a hammer drill. Then, a thermocouple was placed in the hole and grouted by a cement paste mixture with a water-cement ratio of 0.5 . The specimens were cured for one day to ensure the hardness of the cement paste then used to measure the temperature decays. CRD-C 36-73 (US Army Corps of Engineers 1973) was adopted to measure the thermal conductivities. Each specimen was placed in a hot water bath with a heating unit to reach $180^{\circ} \mathrm{F}\left(82.2^{\circ} \mathrm{C}\right)$. Then, each specimen was placed on top of two pieces of plywood and submerged in a cold-water bath. The temperature of the water was kept constant throughout each experiment by circulating the water. The temperature of the water was measured using a thermocouple placed 2 -in $(5.08-\mathrm{cm})$ from the side of the specimen. The concrete and water temperatures were recorded at an interval of 5-seconds until the concrete temperature reached the water temperature. Each test was repeated two times. Then the time that the temperature difference dropped from $60{ }^{\circ} \mathrm{F}\left(33.33{ }^{\circ} \mathrm{C}\right)$ to $20^{\circ} \mathrm{F}\left(11.11^{\circ} \mathrm{C}\right)$ was used to calculate the thermal conductivities using the following equations,

$$
\alpha=\frac{M}{\left(t_{2}-t_{1}\right)}, \quad \alpha=\frac{K}{\rho C_{p}}
$$




$$
M=\frac{60 \operatorname{Ln}\left(\frac{T_{1}}{T_{2}}\right)}{\left(\frac{5.783}{r^{2}}+\frac{\pi^{2}}{l^{2}}\right)},
$$

where $\alpha$ is thermal diffusivity $\left(\mathrm{ft}^{2} / \mathrm{h}\right.$ or $\left.\mathrm{m}^{2} / \mathrm{h}\right), M\left(\mathrm{ft}^{2}\right.$ or $\left.\mathrm{m}^{2}\right)$ is a factor depending on the size and shape of the specimen, $t_{1}$ and $t_{2}$ are times at which the center of the specimen reaches the specified temperature differences (min), $T_{1}$ and $T_{2}$ are temperature differences $\left({ }^{\circ} \mathrm{F}\right.$ or $\left.{ }^{\circ} \mathrm{C}\right)$ at times $t_{1}$ and $t_{2}$, $r$ is the radius of cylinder ( $\mathrm{ft}$ or $\mathrm{m}$ ), $l$ is the length of cylinder ( $\mathrm{ft}$ or $\mathrm{m}$ ), $K$ is thermal conductivity $\left(B T U / h / f t /{ }^{\circ} \mathrm{F}\right.$ or $\left.W / \mathrm{m} / \mathrm{K}\right), \rho$ is weight density of the concrete $\left(l b / f t^{3}\right.$ or $\left.\mathrm{kg} / \mathrm{m}^{3}\right)$, and $C_{p}$ is specific heat capacity $\left(B T U /{ }^{\circ} \mathrm{F} / \mathrm{lb}\right.$ or $\left.\mathrm{J} / \mathrm{kg} / \mathrm{K}\right)$. Based on the dimension of the cylinder and the $T_{1}=60^{\circ} \mathrm{F}\left(33.33^{\circ} \mathrm{C}\right), T_{2}=20^{\circ} \mathrm{F}\left(11.11^{\circ} \mathrm{C}\right)$, the $\mathrm{M}$ factor can be calculated to be 0.643733198 $\left(\mathrm{ft}^{2}\right)\left[0.0598\left(\mathrm{~m}^{2}\right)\right]$. The specific heat was calculated using the following Equation 6-3 (Lin and Chen 2015; Van Breugel 1998),

$$
C_{p}=\frac{\left(740 \rho_{c}+710 \rho_{s}+4184 \rho_{w}+840 \rho_{a}\right)}{\rho}
$$

where $\rho_{c}, \rho_{s}, \rho_{w}$, and $\rho_{a}$ are the weight densities $\left(\mathrm{kg} / \mathrm{m}^{3}\right)$ of the cement, sand, water, and aggregate in the mix design, respectively. Two 50\% slag 1 cylinder's temperature decays of center locations and ambient water are shown in Figure 6-1 and Figure 6-2. The comparison of the temperature differences between these two $50 \%$ slag 1 cylinders was shown in Figure 6-3, and they compare well. Two $30 \%$ fly ash 2 cylinders' temperature decays of center locations and water temperature were shown in Figure 6-4 and Figure 6-5. The comparison of the temperature differences between two 30\% fly ash 2 cylinders was shown in Figure 6-6, and they show slight differences. The density and specific heat are shown in Table 6-1. The calculated thermal conductivities are shown in Table 6-2. 


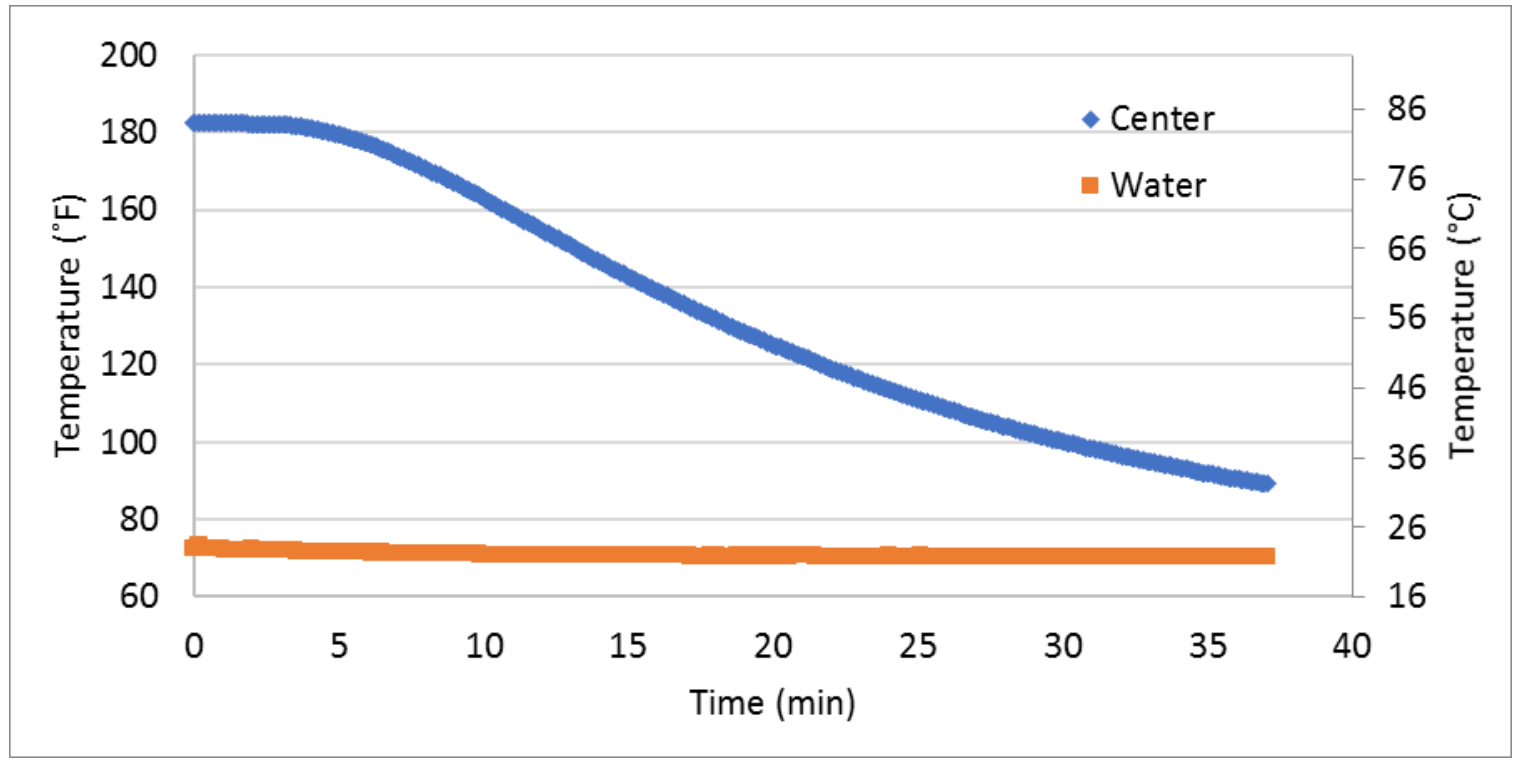

Figure 6-1: 50\% slag 1 cylinder 1 temperature decay of center location and water temperature.

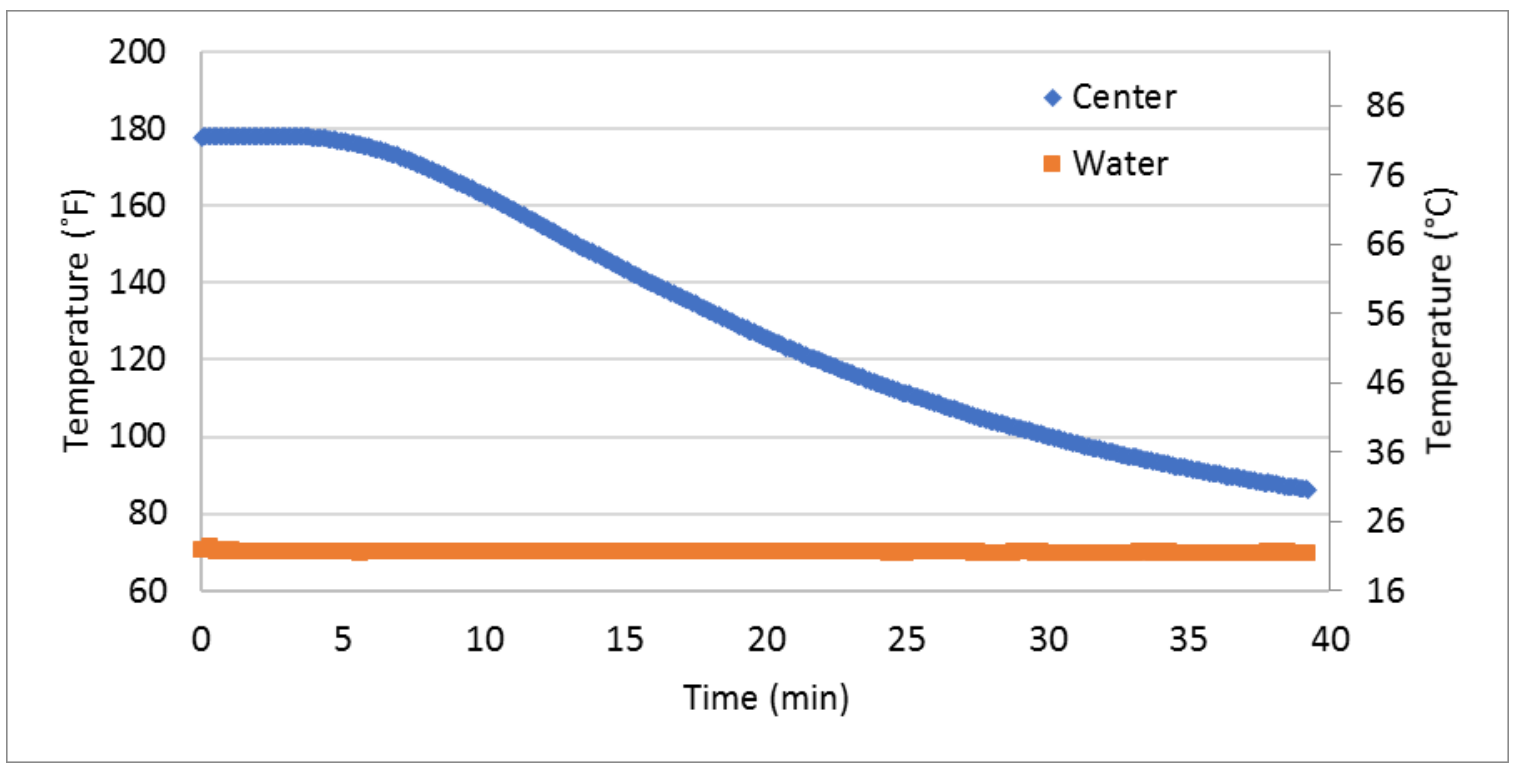

Figure 6-2: 50\% slag 1 cylinder 2 temperature decay of center location and water temperature. 


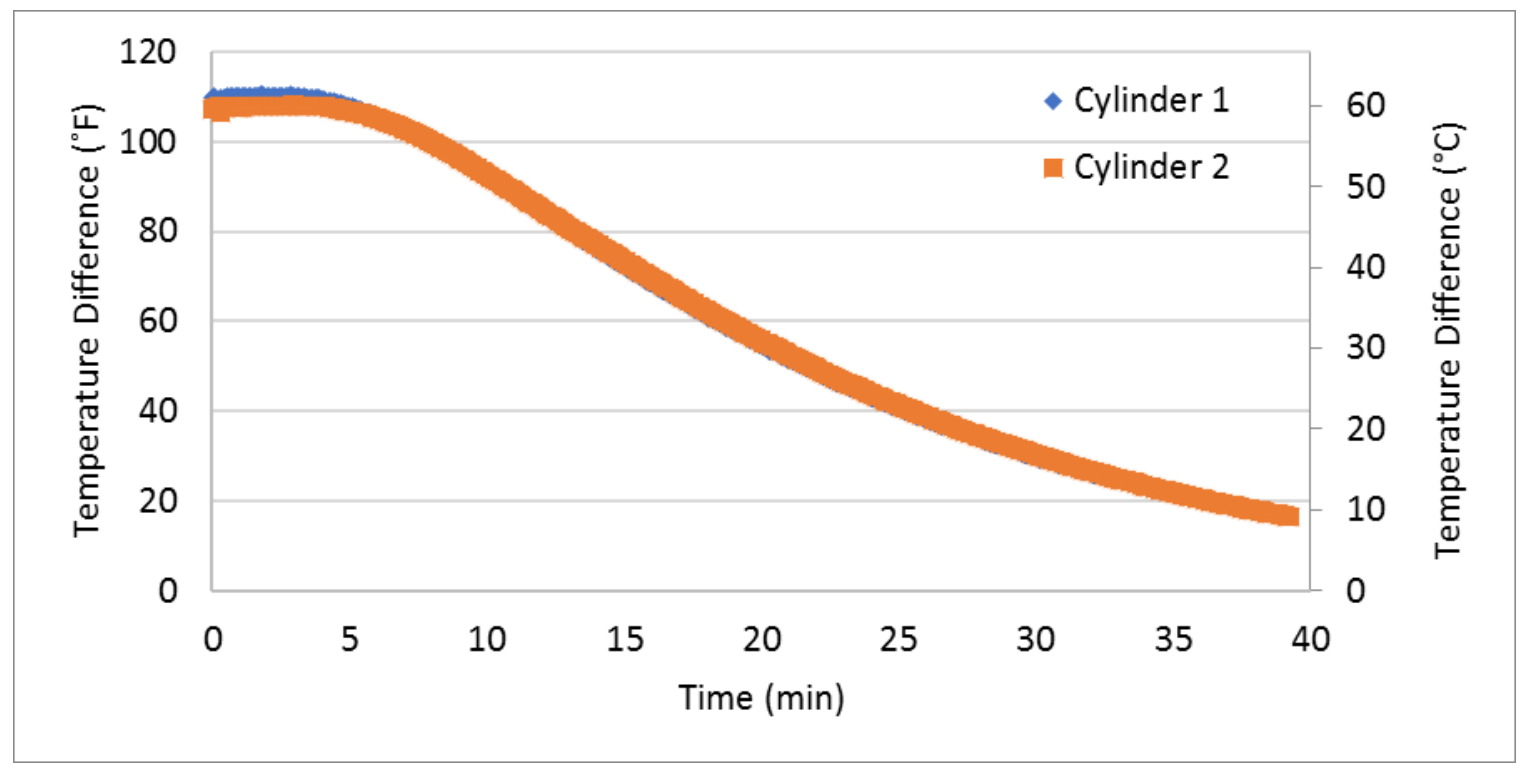

Figure 6-3: Comparison of the temperature differences between two 50\% slag 1 cylinders.

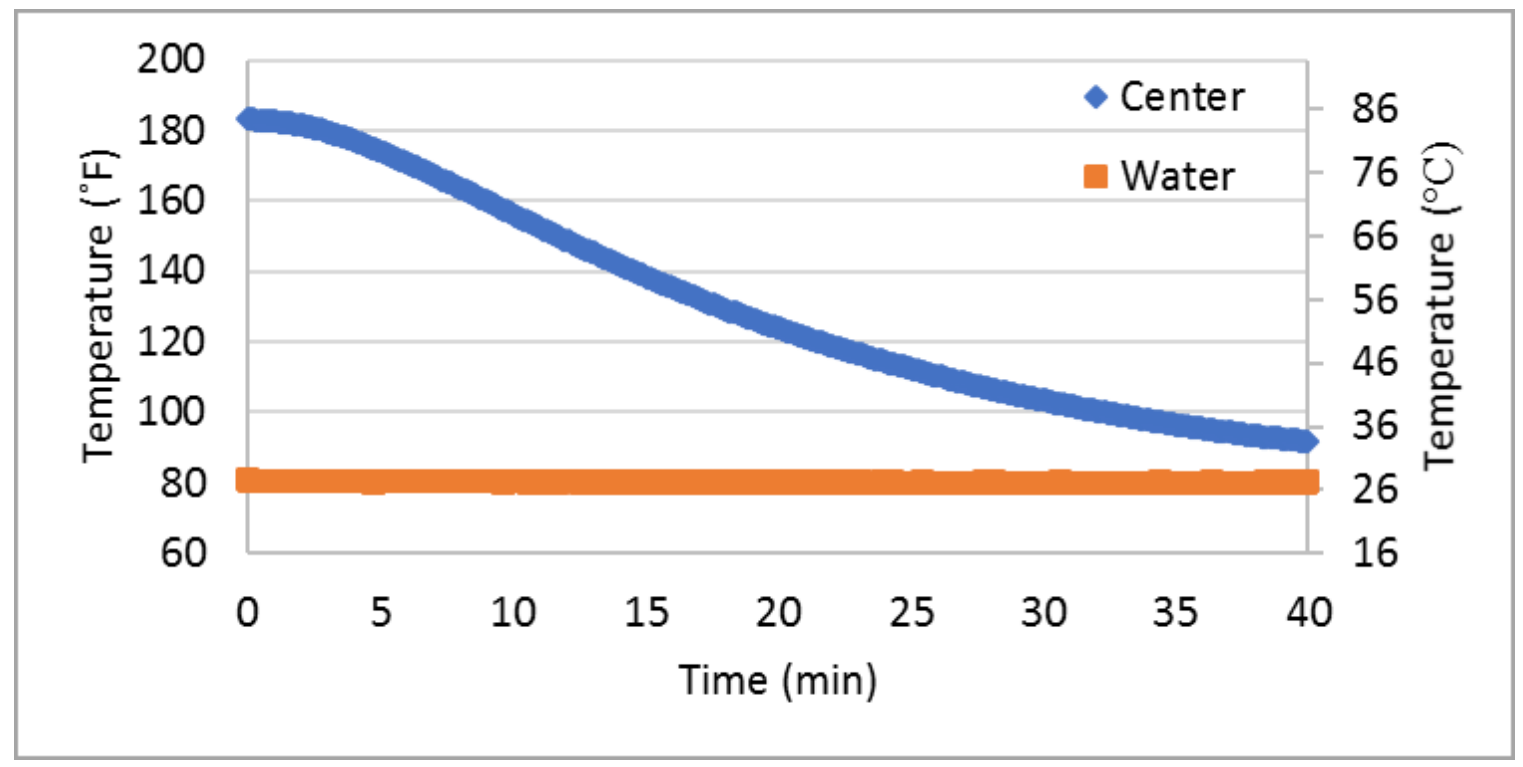

Figure 6-4: 30\% fly ash 2 cylinder 1 temperature decay of center location and ambient water. 


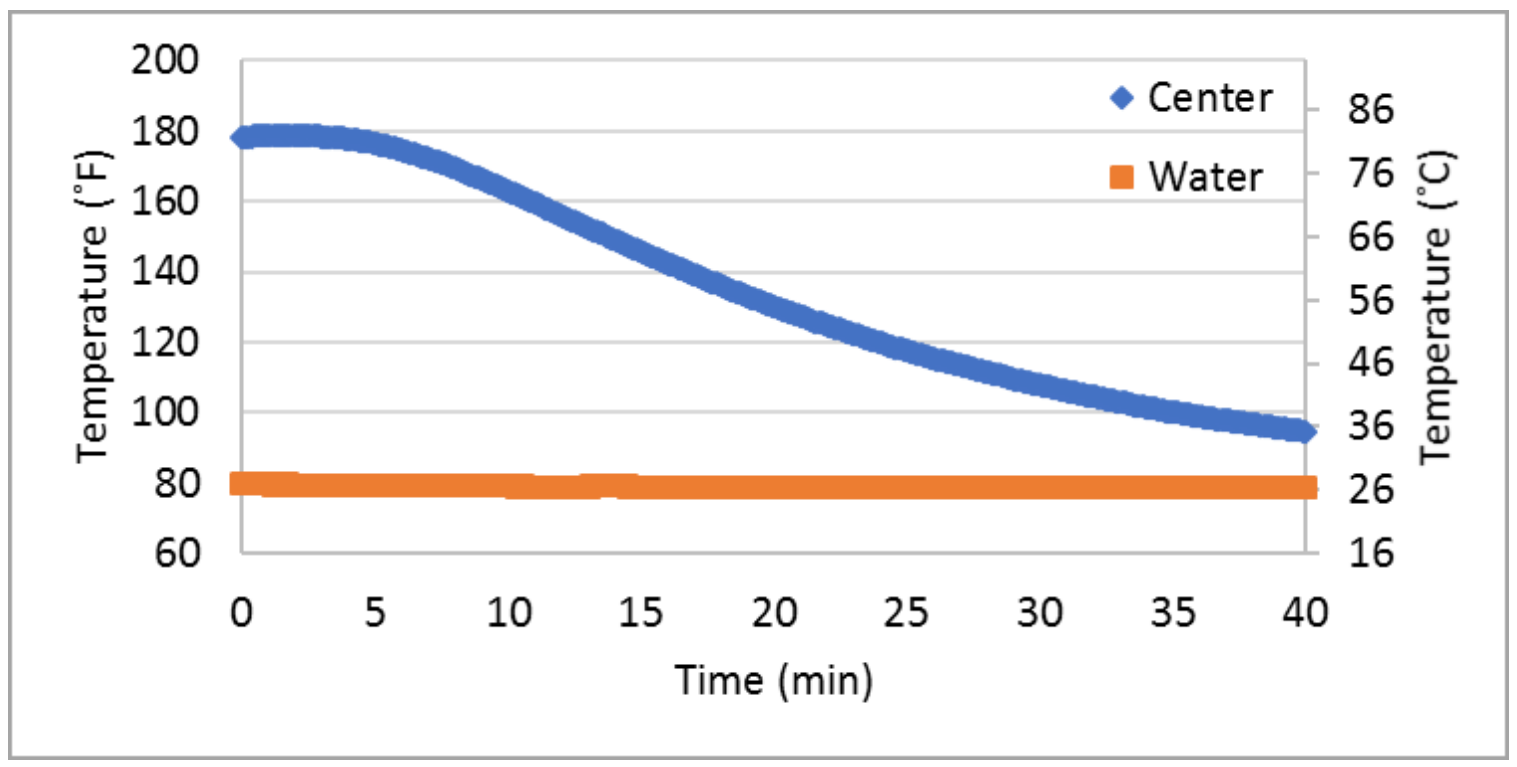

Figure 6-5: 30\% fly ash 2 cylinder 2 temperature decay of center location and ambient water.

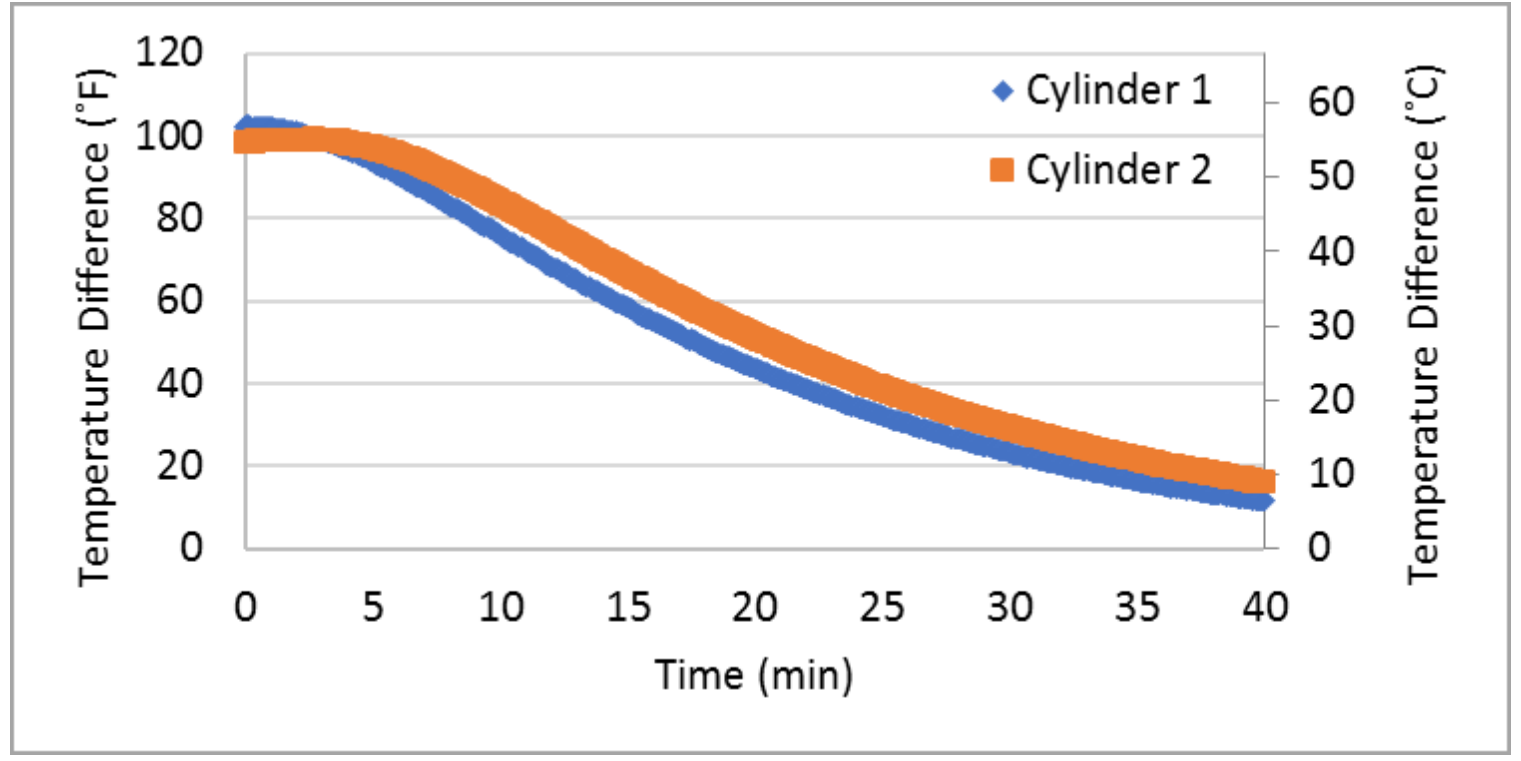

Figure 6-6: Comparison of the temperature differences between two $30 \%$ fly ash 2 cylinders. 
Table 6-1: Density and specific heat of 50\% slag 1 and $30 \%$ fly ash 2 cylinders.

\begin{tabular}{|c|c|c|c|c|}
\hline \multirow{2}{*}{ Batch } & \multicolumn{2}{|c|}{$\boldsymbol{\rho}$} & \multicolumn{2}{c|}{$\boldsymbol{C}_{\boldsymbol{p}}$} \\
\cline { 2 - 5 } & $\left(\boldsymbol{l b} / \boldsymbol{f t}^{\mathbf{3}}\right)$ & $\left(\boldsymbol{k g} / \boldsymbol{m}^{\mathbf{3}}\right)$ & $\left(\boldsymbol{B T U} /{ }^{\circ} \mathrm{F} / \boldsymbol{l b}\right)$ & $(\boldsymbol{J} / \boldsymbol{k g} / \boldsymbol{K})$ \\
\hline $\mathbf{5 0 \%}$ slag 1 & 144.2 & 2309.9 & 0.23492 & 983.56 \\
\hline 30\% fly ash 2 & 144.5 & 2314.7 & 0.23868 & 999.31 \\
\hline
\end{tabular}

Table 6-2: Thermal conductivities of 50\% slag 1 and $30 \%$ fly ash 2 cylinders.

\begin{tabular}{|c|c|c|c|c|c|c|c|}
\hline \multirow[b]{3}{*}{ Batch } & \multicolumn{3}{|c|}{ Cylinder 1} & \multicolumn{4}{|c|}{ Cylinder 2} \\
\hline & $\alpha$ & \multicolumn{2}{|l|}{$K$} & \multirow{2}{*}{\multicolumn{2}{|c|}{\begin{tabular}{|c|}
$\alpha$ \\
$\left(f t^{2} / h\right)\left(m^{2} / h\right)$
\end{tabular}}} & \multicolumn{2}{|l|}{$K$} \\
\hline & $\left(f t^{2} / h\right)\left(m^{2} / h\right)$ & $\left(\boldsymbol{B T U} / \boldsymbol{h} / \boldsymbol{f t} /{ }^{\circ} \mathrm{F}\right)$ & $(W / m / K)$ & & & $\left(B T \boldsymbol{U} / \boldsymbol{h} / \boldsymbol{f t} /{ }^{\circ} \mathrm{F}\right)$ & $(W / \boldsymbol{m} / \boldsymbol{K})$ \\
\hline $50 \%$ slag 1 & 0.036150 .003358 & 1.23 & 2.13 & 0.03643 & 0.00338 & 1.24 & 2.14 \\
\hline $30 \%$ fly ash 2 & \begin{tabular}{|l|l|}
0.03622 & 0.003364 \\
\end{tabular} & 1.26 & 2.18 & 0.03346 & 0.00311 & 1.16 & 2.01 \\
\hline
\end{tabular}

\subsection{Thermal conductivity of reinforced concrete}

Six 6-in (15.24-cm diameter) by 12-in (30.48-cm height) cylinders were prepared. The specimens were prepared using plain mortar, 4.24\% steel rebars-mortar volumetric ratio (plain mortar plus six steel rebars), and 7.78\% steel rebars-mortar volumetric ratio (plain mortar plus eleven steel rebars). The steel rebars were 18 -in $(45.72-\mathrm{cm}$ long) and \#4 [0.5-in (1.27-cm diameter)]. The area of \#4 steel rebar cross-section was calculated as $0.2-\mathrm{in}^{2}\left(1.29-\mathrm{cm}^{2}\right)$. The crosssection areas of six and eleven steel rebars were calculated as $1.2-\mathrm{in}^{2}\left(7.74-\mathrm{cm}^{2}\right)$ and 2.2-in ${ }^{2}(14.19-$ $\mathrm{cm}^{2}$ ), respectively. The cross-section area of the mortar specimen was calculated as $28.27-\mathrm{in}^{2}$ $\left(182.39-\mathrm{cm}^{2}\right)$. The volumetric steel reinforcement-mortar ratios of the specimens containing six and eleven steel rebars were calculated by dividing the steel rebar cross-section areas with specimen cross-section areas resulting in $4.24 \%$ and $7.78 \%$, respectively. The mortar mix design 
is shown in Table 6-3. The locations of the steel rebars are shown in Figure 6-7. The unmolded specimens are shown in Figure 6-8.

Table 6-3: Mortar mix design.

\begin{tabular}{|c|c|c|}
\hline \multirow{2}{*}{ Material } & \multicolumn{2}{|c|}{ Weight density } \\
\cline { 2 - 3 } & $\left(\mathbf{l b} \cdot \mathbf{y d}^{\mathbf{3}} \mathbf{)}\right.$ & $\mathbf{( k g / \mathbf { m } ^ { \mathbf { 3 } } )}$ \\
\hline Cement & 879.5 & 521.8 \\
\hline Sand & 2550.6 & 1513.2 \\
\hline Water & 432.8 & 256.8 \\
\hline
\end{tabular}

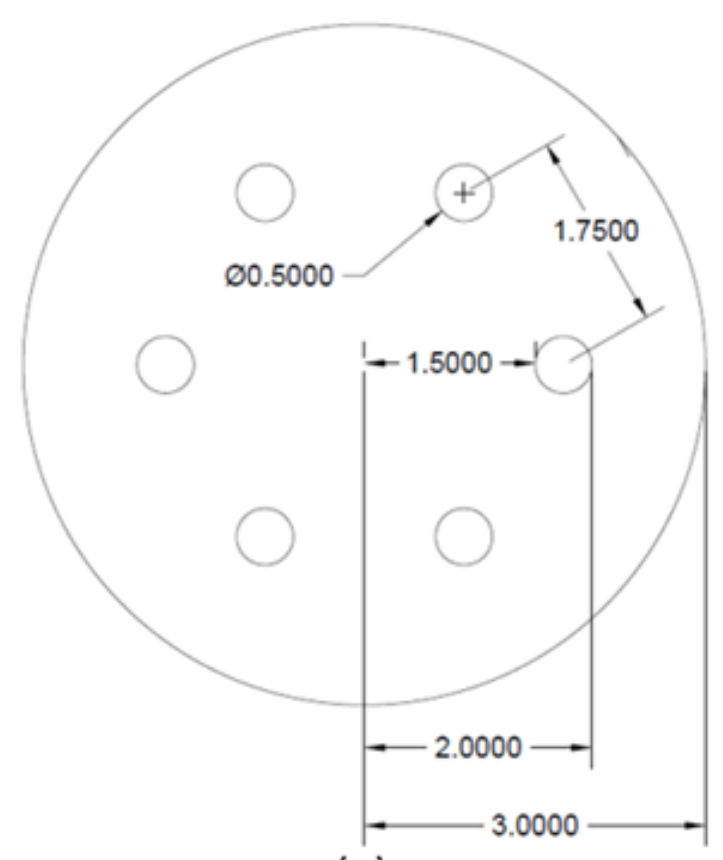

(a)

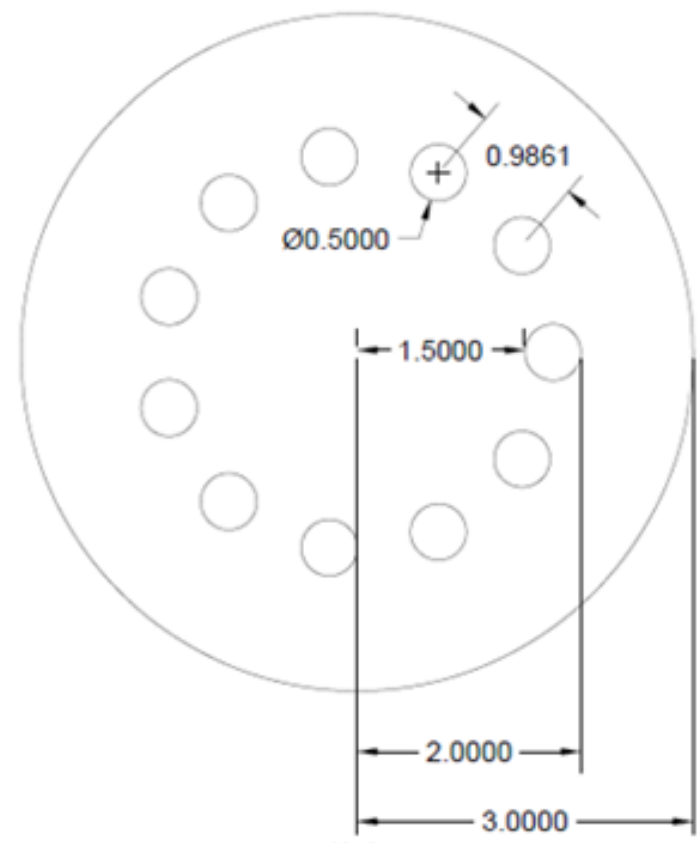

(b)

Figure 6-7: Specimens layout of (a) 4.24\% reinforcement ratio (mortar +6 steel rebars) (b) $\mathbf{7 . 7 8 \%}$ reinforcement ratio (mortar +11 steel rebars) (dimensions are in inch). 

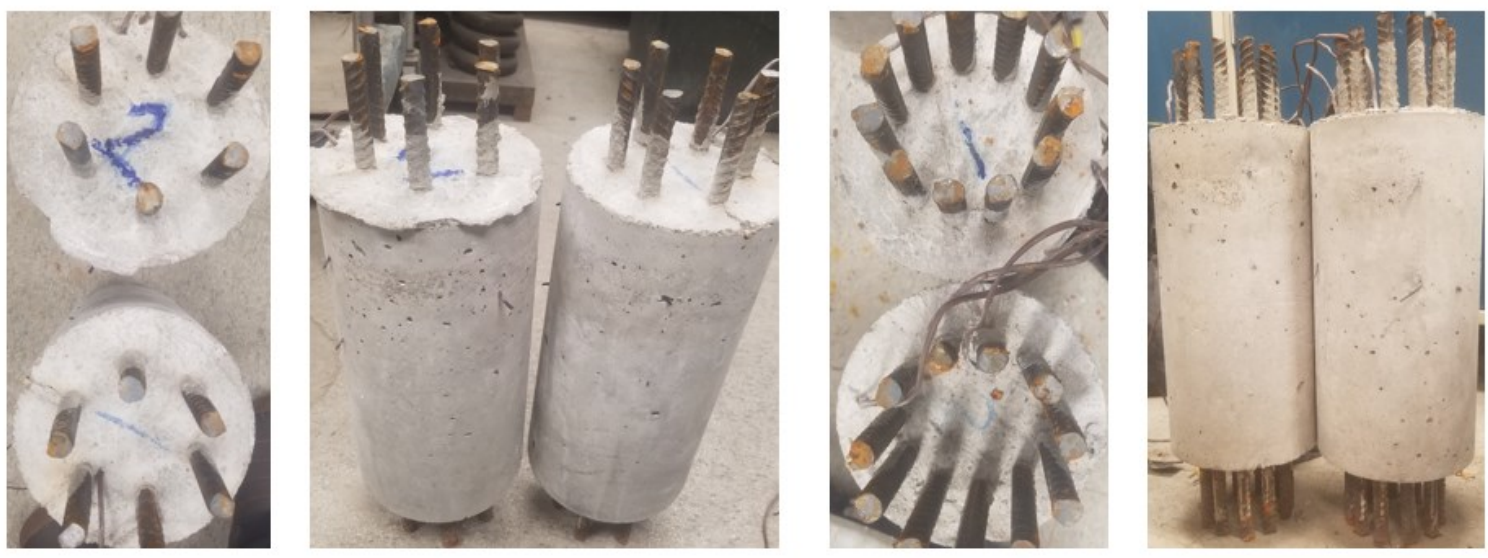

Figure 6-8: 4.24\% reinforcement ratio (mortar +6 steel rebars) and $7.78 \%$ reinforcement ratio (mortar +11 steel rebars).

Three K-type thermocouples were inserted in each cylinder. They were located at the center, 1.75-in $(4.445-\mathrm{cm})$ from the center, and 2.75-in $(6.985-\mathrm{cm})$ from the center. All the thermocouples were in the middle of the cylinders and fixed with multiple zip ties. The locations of the thermocouples are shown in Figure 6-9. In order to maintain the location and the spacing of the rebars, two pieces of plywood with holes at the locations of the steel rebar were placed on the top and the bottom of the plastic mold. The specimens were cured for 14-days with a curing temperature of $109{ }^{\circ} \mathrm{F}\left(42.7778{ }^{\circ} \mathrm{C}\right)$, which is more than 28 -days of curing at a reference temperature of $73.4^{\circ} \mathrm{F}\left(23^{\circ} \mathrm{C}\right)$. 

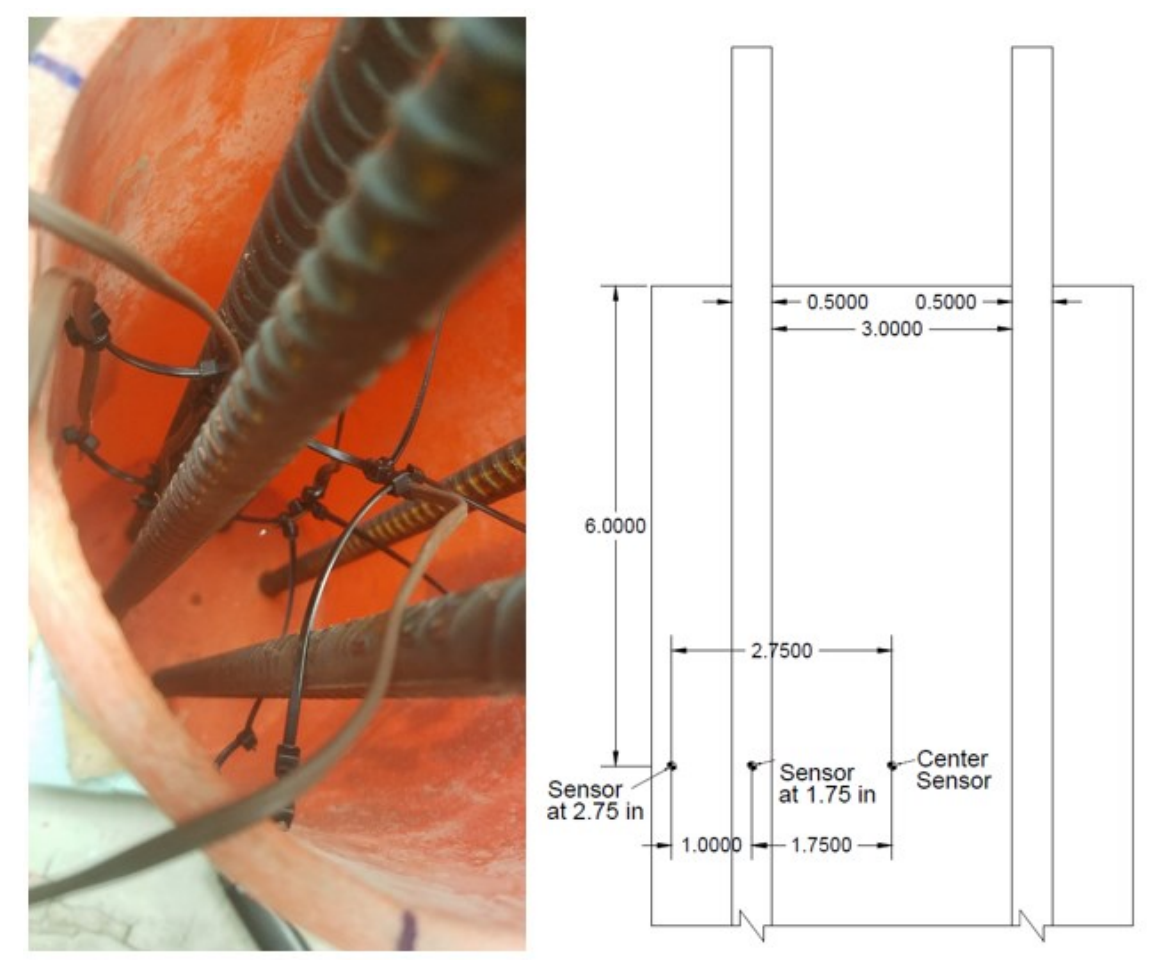

Figure 6-9: Location of thermocouples (dimensions are in inch).

\subsection{Analysis of Results}

Based on dimensions of the cylinder and assuming $T_{1}$ and $T_{2}$ are $60^{\circ} \mathrm{F}\left(33.33^{\circ} \mathrm{C}\right)$ and 20 ${ }^{\circ} \mathrm{F}\left(11.11^{\circ} \mathrm{C}\right), M$ in Equation $6-2$ can be calculated to be $0.64373 \mathrm{ft}^{2}\left(0.0598 \mathrm{~m}^{2}\right)$. The specific heat of mortar can be calculated using Equation 6-4 (Lin and Chen 2015; Van Breugel 1998).

$$
C_{p-\text { mortar }}=\frac{\left(740 \rho_{c}+710 \rho_{s}+4184 \rho_{w}\right)}{\rho_{M}}
$$

Therefore, the effective thermal conductivities can be obtained and are shown in Table 6-4. As shown in Table 6-4, the effective thermal conductivities of the cylinders with the steel reinforcement increased by $16.9 \%$ and $22.3 \%$. 
Finite element analysis (FEA) software (ABAQUS) was used to simulate the thermal behavior of the cylinders. For the cylinders with the steel rebar, the reinforcements were bonded with the mortar using a tie constraint (i.e., perfect bond). Hexahedral linear elements (DC3D8) with a size of 0.06-in (1.524-mm) were used for both the mortar and steel rebar. The FEA temperature distributions in the middle of the cylinders at 10 minutes are shown in Figure 6-10. The temperature-time histories were exported and compared with the experimental results in Figure 6-11. The convection boundary condition had a film coefficient (convection coefficient) of $800 \mathrm{BTU} / \mathrm{h} / \mathrm{ft} \mathrm{t}^{2} /{ }^{\circ} \mathrm{F}\left(4500 \mathrm{~W} / \mathrm{m}^{2} / \mathrm{K}\right)$ and was assumed to model the effect of the circulating water. As shown in Figure 6-10, the FEA results compare well with the experimental temperature measurement at different locations. The largest variation occurs with the sensors closest to the surface. The initial temperature and the water temperature were input individually for each case. Since the experimental initial temperature of the 1.75 -in $(4.445-\mathrm{cm})$ and 2.75 -in $(6.985-\mathrm{cm})$ thermocouples is not the same as the center temperature, due to the delay between taking the cylinders out of the hot water and submerging it in the cold-water bath, the FEA results were adjusted accordingly.

Table 6-4: Specific heat and thermal conductivity.

\begin{tabular}{|c|c|c|c|c|c|c|}
\hline \multirow[b]{2}{*}{ Material } & \multicolumn{2}{|c|}{ Mass density } & \multicolumn{2}{|c|}{ Specific heat } & \multicolumn{2}{|c|}{ Thermal conductivity } \\
\hline & $\left(\mathbf{l b} . / \mathbf{f t}^{3}\right)$ & $\left(\mathrm{kg} / \mathrm{m}^{3}\right)$ & (BTU/ $\left.{ }^{\circ} \mathrm{F} / \mathrm{lb}.\right)$ & $(\mathrm{J} / \mathrm{kg} / \mathrm{K})$ & $\left(\mathrm{BTU} / \mathrm{h} / \mathbf{f t} /{ }^{\circ} \mathrm{F}\right)$ & $(\mathbf{W} / \mathbf{m} / \mathbf{K})$ \\
\hline Steel & 493 & 7897.1 & 0.12 & 502.4 & 30.64 & 53 \\
\hline Mortar & 143 & 2291.8 & 0.264 & 1106 & 1.3 & 2.253 \\
\hline Mortar +6 reinforcements & 157.92 & 2529.7 & 0.245 & 1026 & 1.52 & 2.634 \\
\hline Mortar + 11 reinforcements & 170.3 & 2727.9 & 0.232 & 970 & 1.59 & 2.756 \\
\hline
\end{tabular}




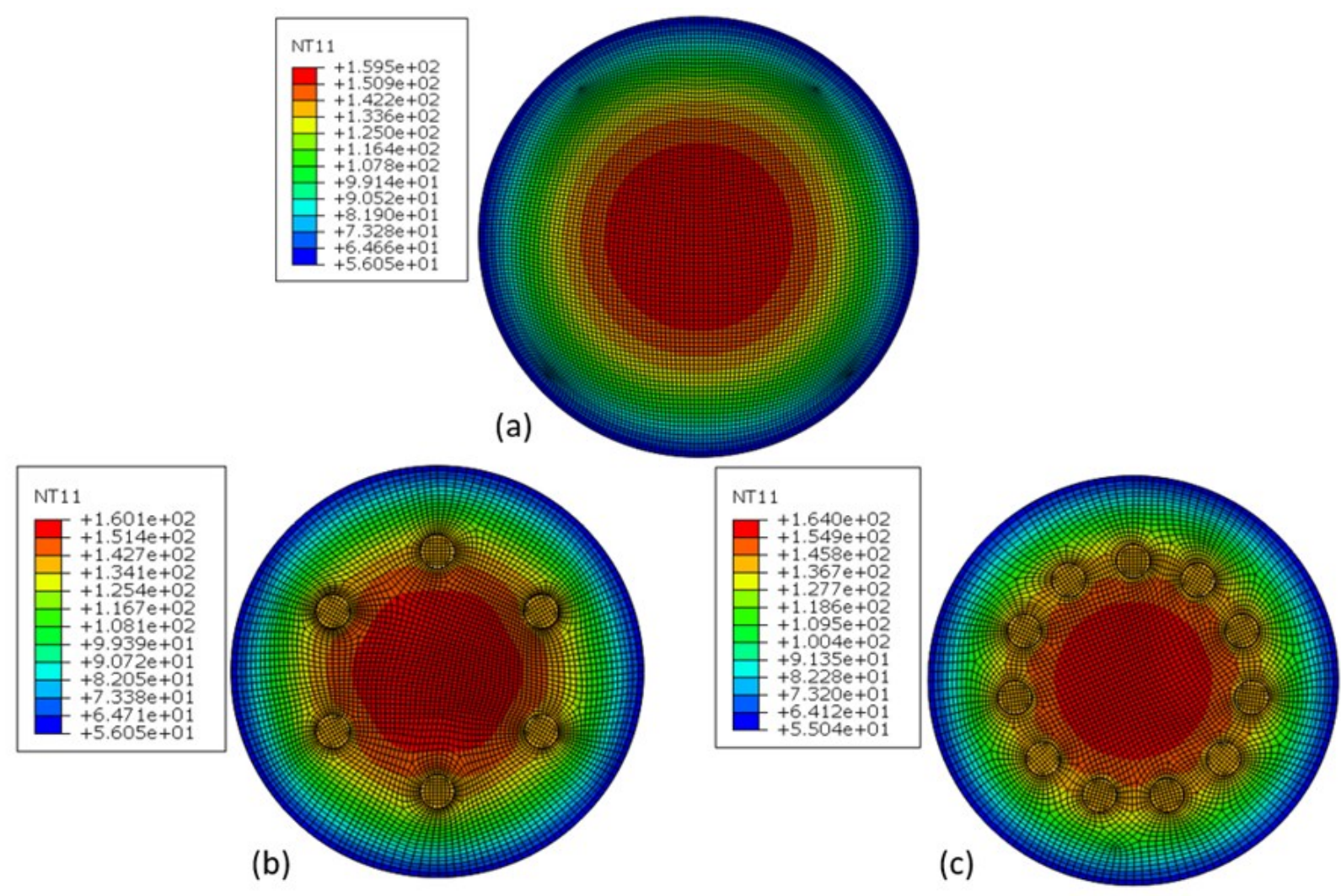

Figure 6-10: Temperature distribution at 10 min for (a) mortar (b) $4.24 \%$ reinforcement ratio (mortar +6 steel rebars) (c) $7.78 \%$ reinforcement ratio (mortar +11 steel rebars) (temperatures are in $\left.{ }^{\circ} \mathbf{F}\right)$. 


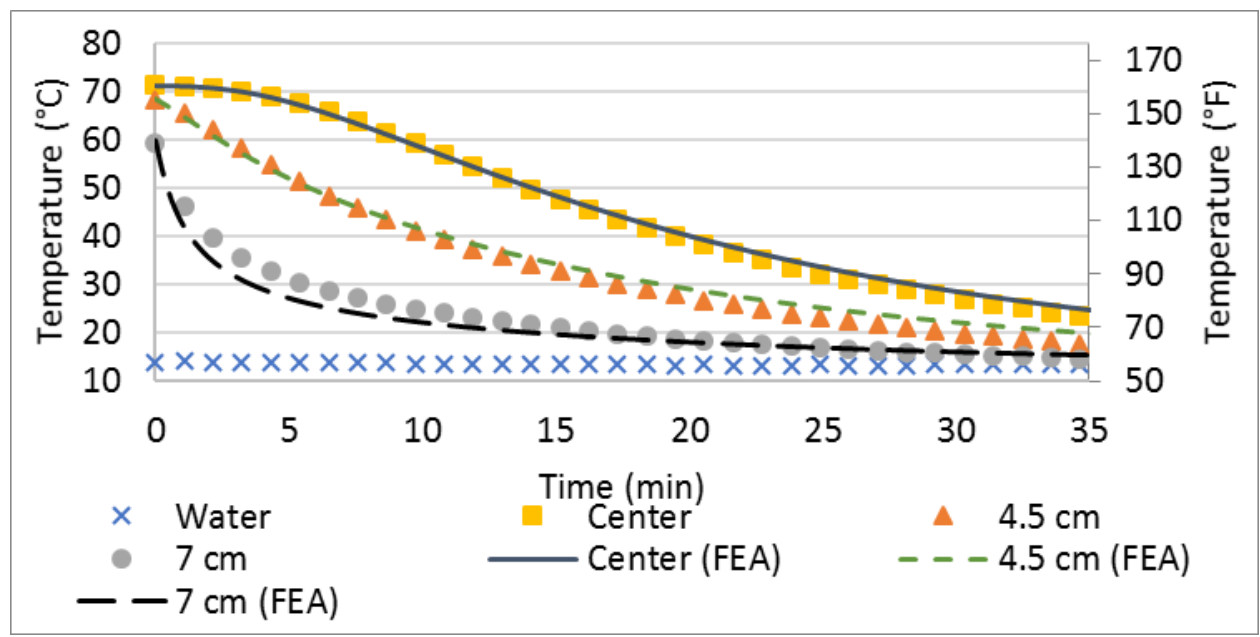

(a)

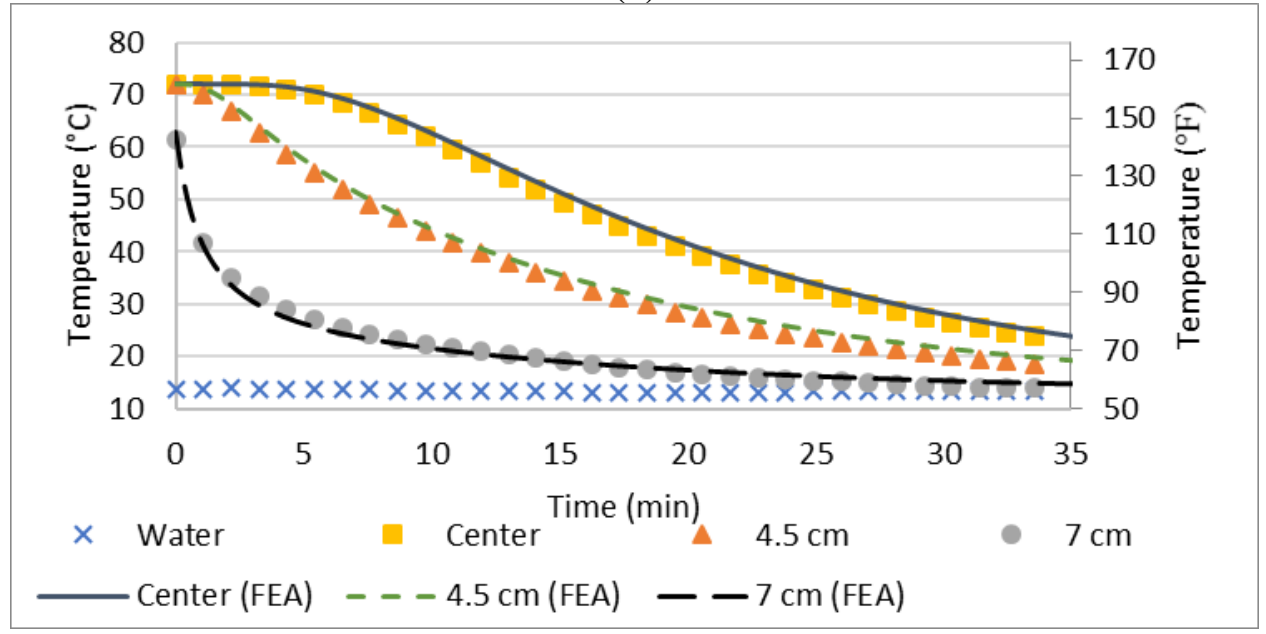

(b)

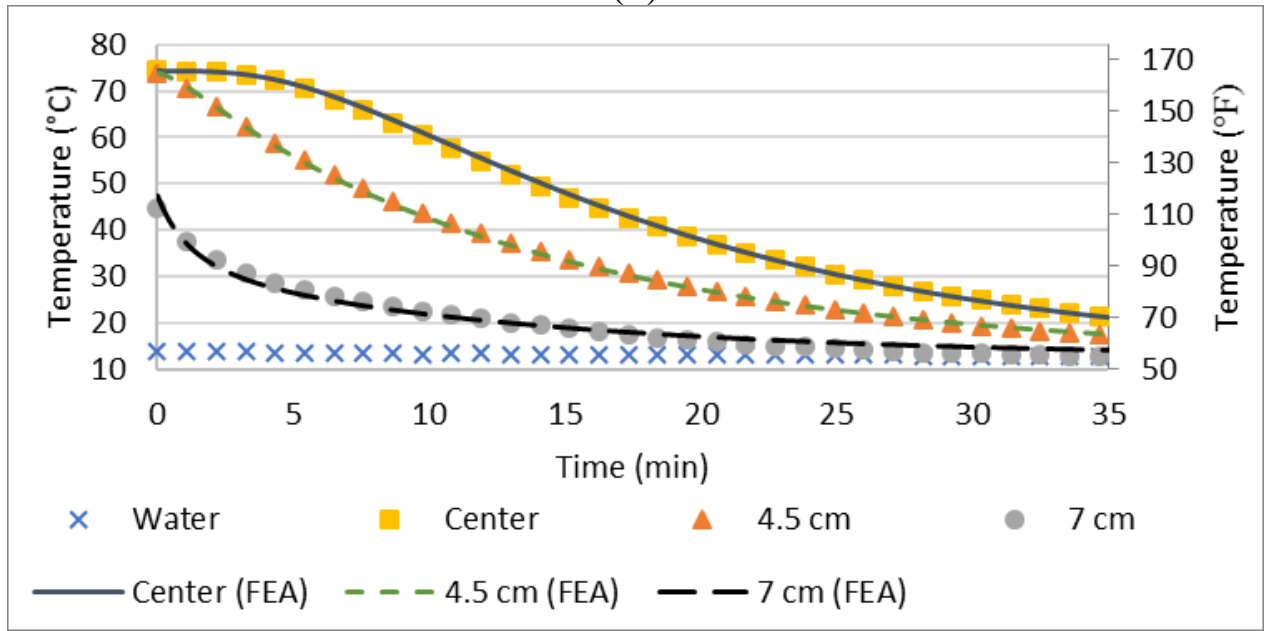

(c)

Figure 6-11: Temperature time history comparisons of experiment and FEA at different locations: (a) mortar (b) 4.24\% reinforcement ratio (mortar +6 steel rebars) (c) $7.78 \%$ reinforcement ratio (mortar +11 steel rebars). 


\subsection{Effective Thermal Conductivity}

Another set of FEA models was used to develop an effective thermal conductivity equation. The effective thermal conductivity could be used to simulate the complicated steel reinforcement. In these analyses, the temperature-time history of the cylinders with different reinforcement ratios was calculated using the material properties mentioned in Table 6-4. The temperature decays were obtained for cylinders with $2.12 \%, 3.54 \%, 4.95 \%, 6.37 \%$ and $7.78 \%$ reinforcement ratios $(3,5,7$, 9 and 11 steel rebars) using the same spacing [1-in $(2.54-\mathrm{cm})$ from the surface of the cylinder] for all the analyses. An initial temperature of $212^{\circ} \mathrm{F}\left(100{ }^{\circ} \mathrm{C}\right)$ and a water temperature of $68^{\circ} \mathrm{F}(20$ ${ }^{\circ} \mathrm{C}$ ) were chosen to calculate the effective thermal conductivities. The time period it took for the temperature difference between the center location of the cylinder and the water temperature to reach from $80{ }^{\circ} \mathrm{F}\left(44.44{ }^{\circ} \mathrm{C}\right)$ to $20^{\circ} \mathrm{F}\left(11.11^{\circ} \mathrm{C}\right)$ was used to calculate the effective thermal conductivities. An $M$ of $0.8123 \mathrm{ft}^{2}\left(0.0755 \mathrm{~m}^{2}\right)$ is calculated based on the mentioned temperature differences and the dimension of the cylinder using Equations 6-1 and 6-2. The linear relationships, of the natural logarithm of the temperature difference versus time shown in Figure 6-12 from FEA, indicate that the homogeneous solution in Equations 6-1 and 6-2 can still be a reasonable estimation in the calculation of the effective thermal conductivity with rebar. Using the FEA results, the normalized effective thermal conductivity $\left(\mathrm{K}_{\mathrm{eff}} / \mathrm{K}_{0}\right)$ versus the percentage of reinforcements (by volume) can be calculated, and the results are shown in Figure 6-12. The fitted trend line is shown in Equation 6-5. The value of $K_{0}$ was obtained to be $1.271 \mathrm{BTU} / \mathrm{h} / \mathrm{ft} /{ }^{\circ} \mathrm{F}$ $(2.198 \mathrm{~W} / \mathrm{m} / \mathrm{K})$ based on the temperature decay calculated by the FEA analysis which matches well with the measured value of $1.303 \mathrm{BTU} / \mathrm{h} / \mathrm{ft} /{ }^{\circ} \mathrm{F}(2.253 \mathrm{~W} / \mathrm{m} / \mathrm{K})$. Using the proposed Equation 6-5, the effective thermal conductivities of $4.24 \%$ reinforcement ratio (mortar with six steel rebars) and $7.78 \%$ reinforcement ratio (11 steel rebars) are 1.472 and $1.645 \mathrm{BTU} / \mathrm{h} / \mathrm{ft} /{ }^{\circ} \mathrm{F}$ 
$(2.546$ and $2.846 \mathrm{~W} / \mathrm{m} / \mathrm{K})$, respectively. The calculated values are $5.3 \%$ and $2.9 \%$ different than the experimental values calculated using Equations 6-1 and 6-2, as shown in Table 6-4. The comparison of the calculated thermal conductivities and the measured data is also displayed in Figure 6-12.

$$
\frac{K_{e f f}}{K_{0}}=0.0388(\text { reinforcement ratio }(\%))+1
$$

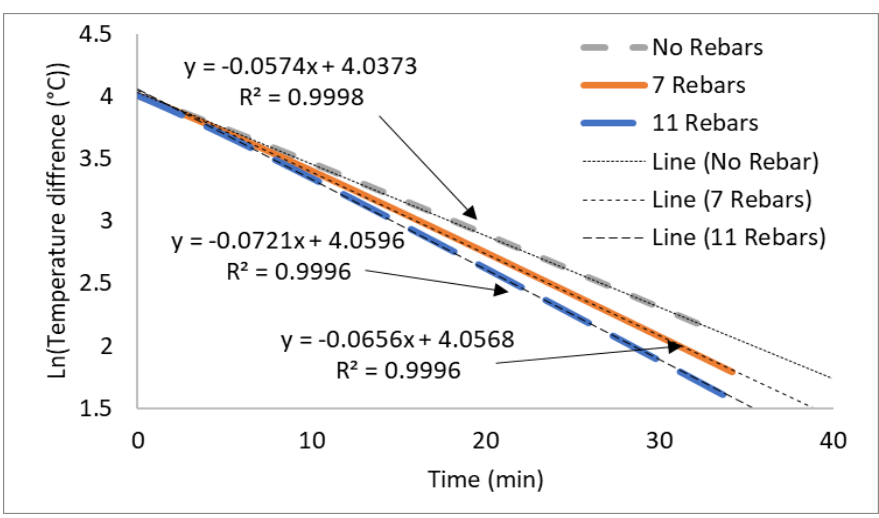

(a)

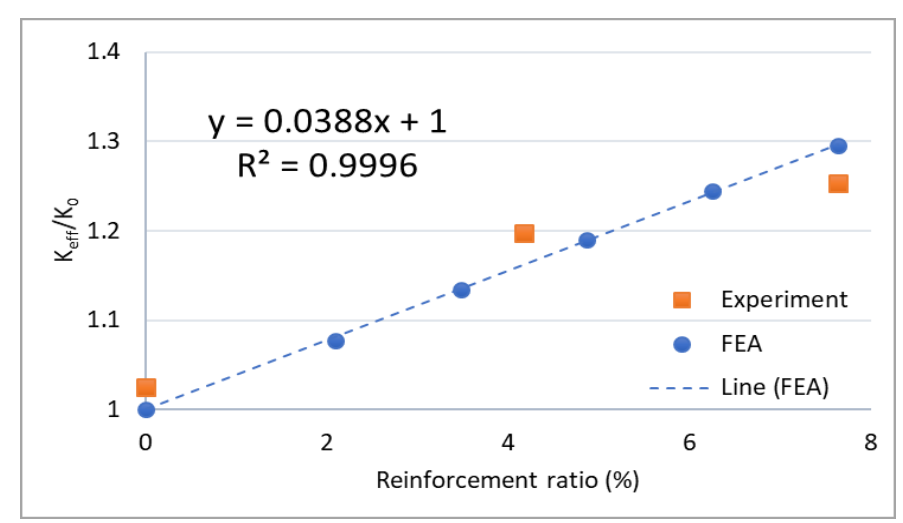

(b)

Figure 6-12: (a) Natural logarithm of temperature difference vs. time, (b) normalized effective thermal conductivity vs. volumetric reinforcement ratio.

\subsection{Conclusions}

In this study, the thermal conductivity of mortar cylinders with $4.24 \%$ and $7.78 \%$ reinforcement ratios (embedded with 6 and 11 steel rebars) was experimentally measured. CRDC 36-73 was used to calculate the thermal conductivities based on the temperature decay of the center. Besides the center temperature, two other locations, 1.75 -in $(4.445-\mathrm{cm})$ and 2.75 -in $(6.985-$ $\mathrm{cm}$ ) from the center were monitored. FEA was conducted and successfully predicted the experimental measurements. The experimental measurements showed a thermal conductivity increase of $22.9 \%$ and $26.5 \%$ with $4.24 \%$ and $7.78 \%$ reinforcement ratios (by embedding 6 and 11 
steel rebars in the cylinders). Then, the FEA was used to develop a linear effective thermal conductivity equation that can be used in the thermal analysis of reinforced concrete elements without complicated calculations or modeling.

\section{Chapter 7 : Conclusion and Future Study}

\subsection{Conclusion}

In this study, $50 \%$ slag 1 and $30 \%$ fly ash 1 replaced mix designs' shrinkage, and compressive creep test results were compared with the empirical models of ACI 209 (ACI Committee 209 2008), B3 (Bažant and Baweja 2000), CEB MC 90, CEB MC 90-99, and GL2000 (Gardner and Lockman 2001). 50\% slag 1 and 30\% fly ash 2 replaced mix designs' ATR were investigated, and semi-adiabatic calorimetry was designed. Steel reinforcements' effect on thermal conductivity was investigated, and a linear effective thermal conductivity equation was proposed.

$50 \%$ slag 1 shrinkage test results appeared to fall within the range of the predictions of GL2000 and CEB MC 90-99 models (Gardner and Lockman 2001). 50\% slag 1 compressive creep test results appeared to fall within the range of the predictions of the B3 model (Bažant and Baweja 2000). $30 \%$ fly ash 1 shrinkage test results appeared to fall within the range of predictions of the ACI 209 method (ACI Committee 209 2008); however, compressive creep test results of 30\% fly ash 1 failed to appear to fall within the range of any prediction, possibly due to first-day loading.

The second design of the semi-adiabatic calorimetry proved that heat loss compensation methods could be applicable. More intact XPS material and less air gap in the design were crucial to match ATR calorimetry results, as well as, increasing the specimen size played a significant role in the back-calculation accuracy. As it might be seen in Chapter 6, reinforcements increased thermal conductivity of concretes significantly, such as $22.9 \%$ and $26.5 \%$ for insertion of $4.24 \%$ 
reinforcement ratio (6 steel rebars) and 7.78\% reinforcement ratio (11 steel rebars), respectively, and the proposed equation might reduce the need for complicated experiments or modeling.

In this thesis, only two mix designs, $50 \%$ slag, and $30 \%$ fly ash was investigated to determine the applicability of Guide for Modeling and Calculating Shrinkage and Creep in Hardened Concrete (ACI Committee 209 2008), Model B3 (Bažant and Baweja 2000), CEB MC 90, CEB MC90-99, and GL2000 (Gardner and Lockman 2001) to predict drying shrinkage and compressive creep properties. Only a semi-adiabatic calorimetry result of 30\% fly ash 2 mix was converged to ATR calorimetry results with heat loss compensation calculations. Temperature [59.3 $\left.{ }^{\circ} \mathrm{F}\left(15.2{ }^{\circ} \mathrm{C}\right) \sim 82.4{ }^{\circ} \mathrm{F}\left(28^{\circ} \mathrm{C}\right)\right]$ and humidity $(43 \% \sim 66 \%)$ of the laboratory were the limitations of the study.

\subsection{Future Study}

The study was limited with only two different mix designs one for $50 \%$ slag and one for $30 \%$ fly ash replacement, and the comparison with their results to five shrinkage and four creep prediction models based on the ACI 209.2R-08 (2008). Investigating different slag or fly ash ratios in mix designs and comparing to those prediction methods in the future would be recommended. Slag and fly ash affecting ATR should be investigated with different mix designs; additionally, new semi-adiabatic designs using more quality insulation and smaller specimen size should be investigated. 


\section{REFERENCES}

ACI Committee. 2000. "Cement and Concrete Terminology." American Concrete Institute.

ACI Committee 209. 2008. "ACI 209.2R-08." American Concrete Institute.

ACI Committee. 2016. "Specifications for Structural Concrete." American Concrete Institute.

ACI Committee 207. 2005. "Guide to Mass Concrete," ACI 207.1R-05, 30.

ACI Committee 209. 92. "Prediction of Creep, Shrinkage, and Temperature Effects in Concrete Structures." American Concrete Institute.

ACI Committee 209. 2008. "Guide for Modeling and Calculating Shrinkage and Creep in Hardened Concrete." American Concrete Institute.

Agrawal, Alok, and Alok Satapathy. 2015. "Mathematical Model for Evaluating Effective Thermal Conductivity of Polymer Composites with Hybrid Fillers." International Journal of Thermal Sciences 89 (March): 203-9. https://doi.org/10.1016/j.ijthermalsci.2014.11.006.

American Association of State Highway and Transportation Officials, ed. 2010. AASHTO LRFD Bridge Design Specifications. Fifth edition. Washington, DC: American Association of State Highway and Transportation Officials.

American Coal Ash Association. 2003. "Fly Ash Facts for Highway Engineers." FHWA-IF-03019.

ASTM C09 Committee. 2010. "Test Method for Static Modulus of Elasticity and Poissons Ratio of Concrete in Compression." C469/C469M. ASTM International. https://doi.org/10.1520/C0469_C0469M-10.

ASTM C09 Committee. 2011. "Standard Test Method for Splitting Tensile Strength of Cylindrical Concrete Specimens." C496/C496M. ASTM International. https://doi.org/10.1520/C0496_C0496M-11.

ASTM Committee C09. 2018. "Standard Test Method for Compressive Strength of Cylindrical Concrete Specimens." ASTM International. https://doi.org/10.1520/C0039_C0039M-18.

ASTM Committee C09. 2019. "AASHTO M 302-19 Standard Specification for Slag Cement for Use in Concrete and Mortars (ASTM C 989/C989M-18a)." American Association of State Highway and Transportation Officials.

Bai, J, and S Wild. 2002. "Investigation of the Temperature Change and Heat Evolution of Mortar Incorporating PFA and Metakaolin.” Cement and Concrete Composites 24 (2): 201-9. https://doi.org/10.1016/S0958-9465(01)00042-7.

Bažant, Zdenek P, and Sandeep Baweja. 2000. "Creep and Shrinkage Prediction Model for Analysis and Design of Concrete Structures: Model B3," 77.

C09 Committee. 2015. "Standard Test Method for Creep of Concrete in Compression." ASTM C512/C512M. ASTM International. https://doi.org/10.1520/C0512_C0512M-15.

C09 Committee. 2019. "Specification for Coal Fly Ash and Raw or Calcined Natural Pozzolan for Use in Concrete." ASTM International. https://doi.org/10.1520/C0618-19.

Committee C09. 2017. "Standard Test Method for Length Change of Hardened Hydraulic-Cement Mortar and Concrete." ASTM C157/C157M. ASTM.

Concrete, FIB-International Federation for Structural. 1993. CEB-FIP Model Code 1990: Design Code. fib Fédération internationale du béton.

Davraz, Metin, Murat Koru, and Ali Ekrem Akdağ. 2015. "The Effect of Physical Properties on Thermal Conductivity of Lightweight Aggregate." World Multidisciplinary Earth Sciences 
Symposium, $\quad$ WMESS $2015 \quad 15 \quad$ (January): $85-92$.

https://doi.org/10.1016/j.proeps.2015.08.022.

FIB-International Federation for Structural Concrete. 1990. Evaluation of the Time Dependent Behavior of Concrete. FIB - International Federation for Structural Concrete.

Fib Committee. 1999. Structural Concrete, the Textbook on Behaviour, Design and Performance. Vol. 1. 3 vols. The International Federation for Structural Concrete (fib).

Fraternali, Fernando, Vincenzo Ciancia, Rosaria Chechile, Gianvittorio Rizzano, Luciano Feo, and Loredana Incarnato. 2011. "Experimental Study of the Thermo-Mechanical Properties of Recycled PET Fiber-Reinforced Concrete." Composite Structures 93 (9): 2368-74. https://doi.org/10.1016/j.compstruct.2011.03.025.

Gardner, N. J., and M. J. Lockman. 2001. "Design Provisions for Drying Shrinkage and Creep of Normal-Strength Concrete." Materials Journal 98 (2): 159-67. https://doi.org/10.14359/10199.

Gardner, N. J. 2011. "Comparison of Prediction Provisions for Drying Shrinkage and Creep of Normal Strength Concretes."

Gibbon, G., Y. Ballim, and G. Grieve. 1997. "A Low-Cost, Computer-Controlled Adiabatic Calorimeter for Determining the Heat of Hydration of Concrete." Journal of Testing and Evaluation 25 (no.2): 261-66.

He, Wenjun. 2013. "Creep and Shrinkage of High Performance Concrete, and Prediction of LongTerm Camber of Prestressed Bridge Girders." Master of Science, Ames: Iowa State University, Digital Repository. https://doi.org/10.31274/etd-180810-3293.

Holman, J.P. 2010. Heat Transfer. 10th ed. The McGraw-Hill Companies, Inc.

Huo, X.S., N. Al-Omaishi, and Maher Tadros. 2001. "Creep, Shrinkage, and Modulus of Elasticity of High-Performance Concrete.” ACI Materials Journal 98 (November): 440-49.

Kanbur, B. Burak, S. Ozgur Atayilmaz, Hakan Demir, Aliihsan Koca, and Zafer Gemici. 2013. "Investigating the Thermal Conductivity of Different Concrete and Reinforced Concrete Models with Numerical and Experimental Methods." Advances in Mechanical Engineering Applications.

Kar, Arkamitra. 2010. "Prediction of Shrinkage of Concrete Containing Supplementary Cementitious Materials Using Microscale Characterizations and Composite Modeling." MS, West Virginia University Libraries. https://doi.org/10.33915/etd.4614.

Kim, H.K., J.H. Jeon, and H.K. Lee. 2012. "Workability, and Mechanical, Acoustic and Thermal Properties of Lightweight Aggregate Concrete with a High Volume of Entrained Air." Construction and Building Materials 29 (April): 193-200. https://doi.org/10.1016/j.conbuildmat.2011.08.067.

Kim, Kook-Han, Sang-Eun Jeon, Jin-Keun Kim, and Sungchul Yang. 2003. "An Experimental Study on Thermal Conductivity of Concrete." Cement and Concrete Research 33 (3): 363 71. https://doi.org/10.1016/S0008-8846(02)00965-1.

Kosmatka, Steven H., Michelle L. Wilson, and Portland Cement Association. 2016. Design and Control of Concrete Mixtures.

L. Poole, Jonathan, Kyle Riding, Kevin Folliard, Maria C.G. Juenger, and Anton Schindler. 2007. Methods for Calculating Activation Energy for Portland Cement. Vol. 104.

LaBarca, Irene, Ryan Foley, and Steven Cramer. 2007. "Effects of Ground Granulated Blast Furnace Slag in Portland Cement Concrete (PCC)-Expanded Study," SPR \# 0092-05-01, , 89. 
Lin, Yun. 2015. "Thermal Stress Analysis for Early Age Mass Concrete Members." PhD, West Virginia University Libraries. https://doi.org/10.33915/etd.6090.

Lin, Yun, and Hung-Liang Chen. 2015. "Thermal Analysis and Adiabatic Calorimetry for EarlyAge Concrete Members." Journal of Thermal Analysis and Calorimetry 122 (2): 937-45. https://doi.org/10.1007/s10973-015-4843-2.

Mardmomen, Seyednavid, Hung-Liang Chen, and Guadalupe Leon. 2019. "Revised Method for Rapid Determination of On-Site Water-Cement Ratio Using Microwave Oven." Transportation Research Record Journal of the Transportation Research Board, June, 110. https://doi.org/10.1177/0361198119849408.

Morabito, P. 1998. Methods to Determine the Heat of Hydration of Concrete. 15 vols. UK: Springenschmid.

Noh, Hyung Gyun, Hie Chan Kang, Moo Hwan Kim, and Hyun Sun Park. 2018. "Estimation Model for Effective Thermal Conductivity of Reinforced Concrete Containing Multiple Round Rebars." International Journal of Concrete Structures and Materials 12 (1): 65. https://doi.org/10.1186/s40069-018-0291-2.

P. L. Ng, I. Y. T. Ng, and A. K. H. Kwan. 2008. "Heat Loss Compensation in Semi-Adiabatic Curing Test of Concrete." ACI Materials Journal 105 (1). https://doi.org/10.14359/19207.

RILEM TC 119-TCE. 1997. "TCE1: Adiabatic and Semi-Adiabatic Calorimetry to Determine the Temperature Increase in Concrete Due to Hydration Heat of the Cement." Materials and Structures 30 (8): 451-64. https://doi.org/10.1007/BF02524773.

US Army Corps of Engineers. 1973. "CRD-C36-73 Method of Test for Thermal Diffusivity of Concrete." CRD-C36-73.

U.S. Army Corps of Engineers. 1994. Arch Dam Design.

Van Breugel, K. 1998. "Prediction of Temperature Development in Hardening Concrete." Prevention of Thermal Cracking in Concrete at Early Ages 15: 51-75.

Yun, Tae Sup, Yeon Jong Jeong, Tong-Seok Han, and Kwang-Soo Youm. 2013. "Evaluation of Thermal Conductivity for Thermally Insulated Concretes." Energy and Buildings 61 (June): 125-32. https://doi.org/10.1016/j.enbuild.2013.01.043. 


\section{VITA}

Bekir Erdem Bas was born in Ankara, Turkey, on October 26, 1988. After graduating from Meram Anatolian high school in 2006, he continued his education at Yildiz Technical University and obtained a B.S. in Civil Engineering in the spring of 2014. He began graduate school at West Virginia University under the guidance of Dr. Roger Chen in the fall of 2017. 